\title{
Assessing antioxidant activity
}

Citation for published version (APA):

Arts, M. J. T. J. (2007). Assessing antioxidant activity. [Doctoral Thesis, Maastricht University]. Datawyse / Universitaire Pers Maastricht. https://doi.org/10.26481/dis.20070531ma

Document status and date:

Published: 01/01/2007

DOI:

10.26481/dis.20070531ma

Document Version:

Publisher's PDF, also known as Version of record

\section{Please check the document version of this publication:}

- A submitted manuscript is the version of the article upon submission and before peer-review. There can be important differences between the submitted version and the official published version of record.

People interested in the research are advised to contact the author for the final version of the publication, or visit the DOI to the publisher's website.

- The final author version and the galley proof are versions of the publication after peer review.

- The final published version features the final layout of the paper including the volume, issue and page numbers.

Link to publication

\footnotetext{
General rights rights.

- You may freely distribute the URL identifying the publication in the public portal. please follow below link for the End User Agreement:

www.umlib.nl/taverne-license

Take down policy

If you believe that this document breaches copyright please contact us at:

repository@maastrichtuniversity.nl

providing details and we will investigate your claim.
}

Copyright and moral rights for the publications made accessible in the public portal are retained by the authors and/or other copyright owners and it is a condition of accessing publications that users recognise and abide by the legal requirements associated with these

- Users may download and print one copy of any publication from the public portal for the purpose of private study or research.

- You may not further distribute the material or use it for any profit-making activity or commercial gain

If the publication is distributed under the terms of Article $25 \mathrm{fa}$ of the Dutch Copyright Act, indicated by the "Taverne" license above, 


\section{Assessing Antioxidant Activity}

M.J.T.J. Arts 
(C) Mariken Arts, Maastricht 2007

Cover design: Roger Bartholomé

ISBN 978-90-5278-615-5

Production: Datawyse / Universitaire Pers Maastricht

\section{nutín}

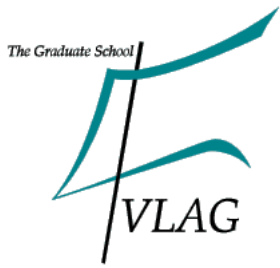

The study presented in this thesis was performed at the Nutrition and Toxicology Research Institute Maastricht (NUTRIM) which participates in the Graduate School VLAG (Food Technology, Agrobiotechnology, Nutrition and Health Sciences), accredited by the Royal Netherlands Academy of Arts and Sciences.

The printing of this thesis was financially supported by the Dr. Ir. Van de Laar Stichting. 


\section{Assessing Antioxidant Activity}

\section{PROEFSCHRIFT}

ter verkrijging van de graad van doctor

aan de Universiteit Maastricht, op gezag van de Rector Magnificus, Prof. mr. G.P.M. F. Mols, volgens het besluit van het College van Decanen,

in het openbaar te verdedigen op donderdag 31 mei 2007 om 14.00 uur

door

Mariken J.T.J. Arts

geboren te Deurne op 18 juli 1973 
Promotor:

Prof. dr. A. Bast

\section{Copromotores:}

Dr. G.R.M.M. Haenen

Dr. H.-P. Voss, Zoeterwoude

\section{Beoordelingscommissie:}

Prof. dr. R.P. Mensink (voorzitter)

Dr. J. Dallinga

Prof. dr. M.P. van Dieijen- Visser

Dr. C.G. Schalkwijk

Prof. dr. W.J.F. van der Vijgh (Vrije Universiteit Amsterdam) 
Voor mijn ouders 



\section{Contents}

Chapter 1

General Introduction

Chapter 2

Structure and activity in assessing antioxidant activity in vitro and in vivo. A critical appraisal illustrated with the flavonoids

\section{Chapter 3}

A critical appraisal of the use of the antioxidant capacity

(TEAC) assay in defining optimal antioxidant structures

\section{Chapter 4}

Antioxidant capacity of reaction products limits the applicability of the Trolox Equivalent Antioxidant Capacity (TEAC) assay

\section{Chapter 5}

A new approach to assess the total antioxidant capacity using the TEAC assay

\section{Chapter 6}

Masking of antioxidant capacity by the interaction of flavonoids with protein

\section{Chapter 7}

Interactions between flavonoids and proteins: effect on the total antioxidant capacity

\section{Chapter 8}

The involvement of reactive glucose-derived species (RGS) in diabetes. Implication for antioxidant treatment

\section{Chapter 9}

Oxidative degradation of lipids during mashing

Chapter 10

Summary and perspective

Samenvatting

Dankwoord

Curriculum Vitae 



\section{Chapter 1}

General introduction 


\section{General introduction}

Free radicals play a crucial role in the pathogenesis of several human diseases and ageing. They are (by)products of various endogenous processes or a result of external factors, such as irradiation and xenobiotics. In food products free radicals are also known to cause damage, resulting in off taste or a reduced shelf-life.

Antioxidants protect against free radicals and they are therefore essential in obtaining and preserving good health. In food products they act as preservatives. Much attention has been given to the flavonoids, a class of polyphenols with strong antioxidant activities, which are ubiquitously present in a broad range of dietary products.

In order to identify the most potent antioxidants, the antioxidant profiles of numerous compounds are frequently compared. For this purpose a wide array of antioxidant assays is available. One of the most frequently applied assays is the Trolox Equivalent Antioxidant Capacity (TEAC) assay.

The aim of this thesis is to study antioxidant activity and to examine the factors that describe and determine this activity of antioxidants.

\section{Outline of this thesis}

- Chapter 2 critically evaluates the assessment of antioxidants in vitro and in vivo.

- Chapter 3 focuses on the applicability of the TEAC assay to predict the antioxidant activity of a compound. A comparison of the TEAC with other antioxidant screenings assays is made.

- The contribution of reaction products to the TEAC is examined, as described in Chapter 4 . Based on this, the applicability of the TEAC assay for the construction of structure activity relationships (SARs) is evaluated.

- The antioxidant activity of reaction products is further studied in Chapter 5. A modified TEAC procedure, that includes the scavenging effect of oxidation products, is presented.

- Chapter 6 describes the effect of interactions between different ingredients in complex mixtures on the TEAC.

- In Chapter 7, the effect of the interaction between flavonoids and proteins on the antioxidant capacity is examined. The possible consequences of masking are discussed. 
- In Chapter 8 the protection against reactive glucose-derived species (RGS) and reactive oxygen species (ROS) is compared. A suggestion for the protection against RGS is made.

- An evaluation on the role of oxidative lipid degradation during mashing is made in Chapter 9. Suggestions are made in order to minimize oxidative damage and preserve antioxidants in this phase of the brewing process. 



\section{Chapter 2}

Structure and activity in assessing antioxidant activity in vitro and in vivo

\section{A critical appraisal illustrated with the flavonoids}

Guido R.M.M. Haenen

Mariken J.T.J. Arts

Aalt Bast

Michael D. Coleman

Environmental Toxicology and Pharmacology 21, 191-198, 2006 


\begin{abstract}
Structure-activity relationships are indispensable to identify the most optimal antioxidants. The advantages of in vitro over in vivo experiments for obtaining these relationships are, that the structure is better defined in vitro, since less metabolism takes place. It is also the case that the concentration, a parameter that is directly linked to activity, is more accurately controlled. Moreover, the reactions that occur in vivo, including feed-back mechanisms, are often too multi-faceted and diverse to be compensated for during the assessment of a single structure-activity relationship. Pitfalls of in vitro antioxidant research include: (i) by definition, antioxidants are not stable and substantial amounts of oxidation products are formed and (ii) during the scavenging of reactive species, reaction products of the antioxidants accumulate. Another problem is that the maintenance of a defined concentration of antioxidants is subject to processes such as oxidation and the formation of reaction products during the actual antioxidant reaction, as well as the compartmentalization of the antioxidant and the reactive species in the in vitro test system. So determinations of in vitro structure-activity relationships are subject to many competing variables and they should always be evaluated critically.
\end{abstract}




\section{Introduction}

Damage inflicted by free radicals and other reactive species is involved in various patho-physiological processes including necrosis and ischemiareperfusion damage, and is implicated in numerous deceases. The pivotal role of radicals in patho-physiology forms the rational for antioxidant intervention. For example, national heart associations advocate the use of a diet rich in fruits and vegetables to reduce the risk of cardiovascular diseases. Opinio communis is that the antioxidants in such a diet might be responsible for the beneficial effect. The validity of the recommendation has been proven by several epidemiological studies that show a negative correlation between fruit and vegetable intake and the risk of cardiovascular disease [1-3]. There is no consensus on the contribution of individual antioxidants, on the beneficial effects and on the actual molecular mechanisms of action. Knowledge on these subjects is needed to rationalize and optimize antioxidant intervention [4].

A problem is that the variety in natural antioxidants is profuse; an important class of antioxidants, the flavonoids, comprises over 5.000 chemically different compounds. The number of antioxidants becomes even more overpowering when (semi-)synthetic antioxidants present as additives, in supplements or in nutraceuticals are also considered. In addition, the point of interaction on free radical mediated processes may differ between antioxidants. The choice of in vitro or in vivo models for the investigation of antioxidant mechanisms depends on a number of factors. Considering the huge number of antioxidant compounds and the diversity in their modes of action, in vivo studies are not always applicable because of their low throughput and their non-specific endpoints. Concise in vitro models are therefore necessary to screen antioxidant activity. Nonetheless, the biological effect of any compound in vivo or in vitro depends on the structure of the compound and the concentration of the compound. In general, antioxidant structure and concentration are better defined and controlled during in in vitro studies compared to in vivo studies. In this paper, the assessment of antioxidant activity is critically evaluated. The points for attention will be illustrated with a specific group of antioxidants, i.e. the flavonoids, narrowed down to the flavonols with quercetin as the most studied compound. The remarks can, nevertheless, be applied to antioxidants in general. It will be demonstrated that despite the alleged simplicity of in vitro testing, even elementary aspects of structure and activity are more complex that they first appear, so critical evaluation is essential for meaningful study design and data interpretation. 


\section{Structure-activity relationships}

High throughput in vitro screening will reveal the antioxidant activity of many compounds. The rational extension of screening is to establish the dependence of the observed efficacy on the chemical structure. In this way, not only the most potent agent within a series is found, but also the efficacy of untested antioxidants can be predicted. More importantly, clues for the identification or design of even more potent antioxidants are obtained. Additionally, a structure-activity relationship helps to elucidate the molecular mechanism of action of a group of compounds.

In a series of substituted phenols, it was found that the ability of a compound to scavenge peroxynitrite $(\mathrm{ONOOH})$ highly correlates with the electron donating activity of the various substituent groups in the molecule [5]. The explanation for this relationship is that the electron donation from the substituent to the oxygen of the phenolic OH-group weakens the $\mathrm{O}-\mathrm{H}$ bond. This makes it easier to donate hydrogen to peroxynitrite. Hydrogen donation is therefore probably the key event in the scavenging of peroxynitrite by phenolic compounds.

The structure-activity relationship of substituted phenols formed the basis of a more complex structure-relationship constructed in polyphenols, i.e. flavonoids. Close examination of the data obtained in in vitro experiments on peroxynitrite scavenging of flavonoids, of which some are depicted in Table 1, revealed that two different groups within the flavonols have the ability to scavenge peroxynitrite [5-7]. One group is in ring $B$, the other group is in the $A C$ ring. A flavonol is a potent peroxynitrite scavenger when ring $B$ is a catechol group (two $\mathrm{OH}$-groups at positions $3^{\prime}$ and 4', substitution on only one of one of the $\mathrm{OH}$-groups is allowed) or when the $\mathrm{AC}$ ring has three $\mathrm{OH}$-groups at positions 3,5 and 7 (substitution on the $5-$ and $7-\mathrm{OH}$ group is allowed, but not on the $3-\mathrm{OH}$ group). This structure-activity relationship of flavonoids is consistent with that of substituted phenols. This indicates that the molecular mechanism for scavenging peroxynitrite by flavonols and phenols is similar. Identical results were obtained for the scavenging of nitrosoperoxycarbonate, the reactive species formed out of peroxynitrite in the presence of carbon dioxide (unpublished results).

Preliminary structure-activity relationships on the antioxidant activity of flavonoids are mainly descriptive in nature and sometimes linked to simple parameters such as the number of $\mathrm{OH}$-groups [8]. As can be deduced from the structure-activity relationship of substituted phenols, the real situation is much more complex. Not only the number but also 
the position of the groups on the molecule affects the electron donating effect and the scavenging potency of the molecules [5,9]. This is underlined by the large difference in activity between apigenin $\left(5,7,3^{\prime}\right.$ trihydroxy flavone) and galangin (3,5,7-trihydroxy flavone). Both of these flavonoids have three $\mathrm{OH}$-groups on the same backbone, only the positioning of one of the $\mathrm{OH}$-groups on the backbone differs. Apigenin is a poor scavenger of peroxynitrite $\left(\mathrm{IC}_{50}=199 \mu \mathrm{M}\right)$ whereas galangin is a potent one $\left(\mathrm{IC}_{50}=1 \mu \mathrm{M}\right)$. The difference in potency between apigenin and galangin, however, fits into the relationship described above, which incorporates two different sites of reactivity. Apigenin fails to meet the requirements of either scavenging group; galangin has the active $A C$ group. In scavenging peroxynitrite, more that one moiety within the flavonoids can independently give a potent activity. This has complicated the construction of a valid structure-activity relationship.

\section{Stability of the antioxidant}

Antioxidant stability has a strong bearing on the potency and persistence of the net cellular protective effect of the molecule. The choice of model, either in vitro or in vivo, can thus have considerable influence on the performance of an antioxidant molecule under study. A major feature of in vivo test systems is metabolism of the antioxidant. This may occur either near the site of sampling, or remotely in distant tissues. Metabolites vary in stability and are not always active, but sometimes they can make a substantial contribution to the overall antioxidant effect [10]. Shortly after oral intake of R-lipoic acid in man, the concentration of the metabolite R3-keto lipoic acid in the blood exceeds that of R-lipoic acid, while the antioxidant activity of the parent compound and metabolite are comparable [11]. Apparently, the effect of R-lipoic acid in vivo cannot be ascribed per se to a single compound. In in vitro models, metabolism is usually negligible. Moreover, many in vitro models lack the feed-back mechanisms which operate in vivo that are aimed at maintaining a well defined and delicate homeostasis. Unfortunately, these homeostatic mechanisms complicate in vivo models and can attenuate the measured potency of test compounds. Some in vitro model systems use complete human cells such as erythrocytes, which have intact homeostatic systems; however, the complexity of the cell model can make interpretations problematic [12].

Aside from metabolism of the antioxidant, maintaining an adequate concentration of a given agent in in vitro studies is also problematic, due to their intrinsic instability. Antioxidants are designed to react readily with 
oxidizing species and are often extensively oxidized during incubations at atmospheric oxygen tension. Even during a relatively short incubation time, the concentration can drop drastically. For quercetin, a reduction in concentration from 50 to $5 \mu \mathrm{mol}$ within $6 \mathrm{~h}$ is observed (Fig. 1). In literature, incubation times of over $48 \mathrm{~h}$ have been reported, however, according to our studies, at the end of this length of incubation period, no quercetin will be present. This means that in studies with such incubation periods, the observed activity is clearly not related to the antioxidant in the initial concentration. The average concentration of the compound is lower than the presumed concentration, indicating that the potency of the compound is underestimated.

Table 1. Peroxynitrite scavenging of several flavonoids.<smiles>O=c1cc(-c2cc[c-]cc2)oc2ccccc12</smiles>

\begin{tabular}{|c|c|c|c|c|c|c|c|}
\hline \multicolumn{8}{|c|}{ Substituent } \\
\hline compound & 3 & 5 & 7 & $3^{\prime}$ & $4^{\prime}$ & $I C_{50}$ & $\begin{array}{l}\text { Active } \\
\text { moiety }\end{array}$ \\
\hline quercetin & $\overline{\mathrm{OH}}$ & $\mathrm{OH}$ & $\mathrm{OH}$ & $\overline{\mathrm{OH}}$ & $\overline{\mathrm{OH}}$ & 0.15 & $\begin{array}{c}A C \text { ring and } \\
B \text { ring }\end{array}$ \\
\hline rutin & ORu & $\mathrm{OH}$ & $\mathrm{OH}$ & $\mathrm{OH}$ & $\mathrm{OH}$ & 0.47 & $B$ ring \\
\hline mono HER & ORu & $\mathrm{OH}$ & $\mathrm{OEtOH}$ & $\mathrm{OH}$ & $\mathrm{OH}$ & 0.30 & $\mathrm{~B}$ ring \\
\hline ti HER & ORu & $\mathrm{OH}$ & $\mathrm{OEtOH}$ & $\mathrm{OH}$ & $\mathrm{OEtOH}$ & 2.5 & $\mathrm{~B}$ ring \\
\hline tri HER & ORu & $\mathrm{OH}$ & $\mathrm{OEtOH}$ & $\mathrm{OEtOH}$ & $\mathrm{OEtOH}$ & 162 & none \\
\hline tetra HER & ORu & OEtOH & OEtOH & OEtOH & OEtOH & 225 & none \\
\hline tri HEQ & $\mathrm{OH}$ & $\mathrm{OH}$ & $\mathrm{OEtOH}$ & $\mathrm{OEtOH}$ & OEtOH & 0.58 & $A C$ ring \\
\hline galangin & $\mathrm{OH}$ & $\mathrm{OH}$ & $\mathrm{OH}$ & $\mathrm{H}$ & $\mathrm{H}$ & 1.0 & $A C$ ring \\
\hline apigenin & $\mathrm{H}$ & $\mathrm{OH}$ & $\mathrm{OH}$ & $\mathrm{OH}$ & $\mathrm{H}$ & 199 & none \\
\hline tetra $\mathrm{MQ}$ & $\mathrm{OH}$ & $\mathrm{OCH}_{3}$ & $\mathrm{OCH}_{3}$ & $\mathrm{OCH}_{3}$ & $\mathrm{OCH}_{3}$ & 6.1 & $A C$ ring \\
\hline penta MQ & $\mathrm{OCH}_{3}$ & $\mathrm{OCH}_{3}$ & $\mathrm{OCH}_{3}$ & $\mathrm{OCH}_{3}$ & $\mathrm{OCH}_{3}$ & 216 & none \\
\hline
\end{tabular}

HER, Hydroxyethylrutoside; $M Q$, methylquecetin; $\mathrm{Ru}$, rutinosyl; $\mathrm{Et}, \mathrm{CH}_{2} \mathrm{CH}_{2}$. The activity is expressed as the $\mathrm{IC}_{50}$, the concentration of the compound protecting against half of the effect of peroxynitrite (in $\mu \mathrm{M}$ ). The lower the $\mathrm{IC}_{50}$, the more potent the compound. Two groups within the tested compound have the ability to scavenge peroxynitrite.

One group is ring B. When ring B is a catechol (OH-groups at positions $3^{\prime}$ and $\left.4^{\prime}\right)$, the compound is a potent scavenger (the $\mathrm{IC}_{50}$ is low). One of the groups may be substituted (as in tri HER). When both $\mathrm{OH}$-groups are substituted, ring $\mathrm{B}$ loses its peroxynitrite scavenging activity (as in tetra HER). 
The other group is the $\mathrm{AC}$ ring. When the $\mathrm{AC}$ ring has $\mathrm{OH}$ substituents at positions 3,5 and 7 , the compound is a potent scavenger. The 5 or $7 \mathrm{OH}$-group may be substituted (as in tri $\mathrm{HEQ}$ and tetra MQ). When the $3-\mathrm{OH}$ group is substituted (as in tri HER or penta MQ), the $A C$ ring loses its peroxynitrite scavenging.

The $\mathrm{OH}$-groups that are thought to interact with peroxynitrite are given in a bold format. In quercetin both active moieties are present. Data are taken from Haenen et al. (1997) and from Heijnen et al. (2001).

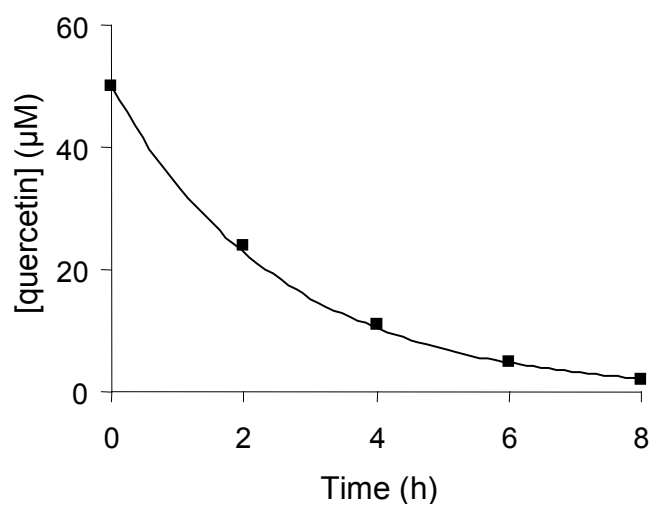

Fig. 1. The time course of the concentration of quercetin, initial concentration $50 \mu \mathrm{M}$, in cell culture medium.

\section{Toxicity of reaction products}

Reaction products that are formed during the oxidation of an antioxidant can have profound effects [4]. One of these products is hydrogen peroxide [13]. Hydrogen peroxide is formed in relatively high amount from agents such as quercetin. Some of the reported effects of several flavonoids might actually be due to hydrogen peroxide generation [14]. The other products formed out of flavonoids during oxidation are quinones and quinonemetides [15,16]. The quinone/quinonemethide of quercetin $(Q Q)$ is depicted in Fig. 2. This product is toxic due to its ability to react with sulfhydryl groups, including protein thiols. It should be realized that these reaction products are formed not only as a result of auto-oxidation; they are also generated by the actual antioxidant reaction [10]. In scavenging a reactive species, quercetin is also converted into $Q Q$. The formation of reactive products forms an integral part of the mode of action of scavenging antioxidants. In these products some of the reactivity of the species that has been neutralized is retained. It has been demonstrated that catechol-containing antioxidants, including quercetin, essentially shift oxidative damage from lipid peroxidation to thiol arylation [17]. This means that although the scavenger directly blocks free radical 
induced toxicity, this toxicity is exchanged for another type of toxicity that is caused by the reaction product of the scavenger.

The accumulation of reaction products in in vitro studies can be high compared to the in vivo situation. This is due to the relatively high oxidative stress normally applied in vitro and the clearance of compound that only occurs in vivo. Additionally, in vivo endogenous antioxidants may recycle the antioxidant from the reaction product, e.g. the reduction of $Q Q$ to quercetin by ascorbate. The endogenous antioxidants may also protect against the toxicity of the reaction product, e.g. glutathione effectively protects against $Q Q$ toxicity [18]

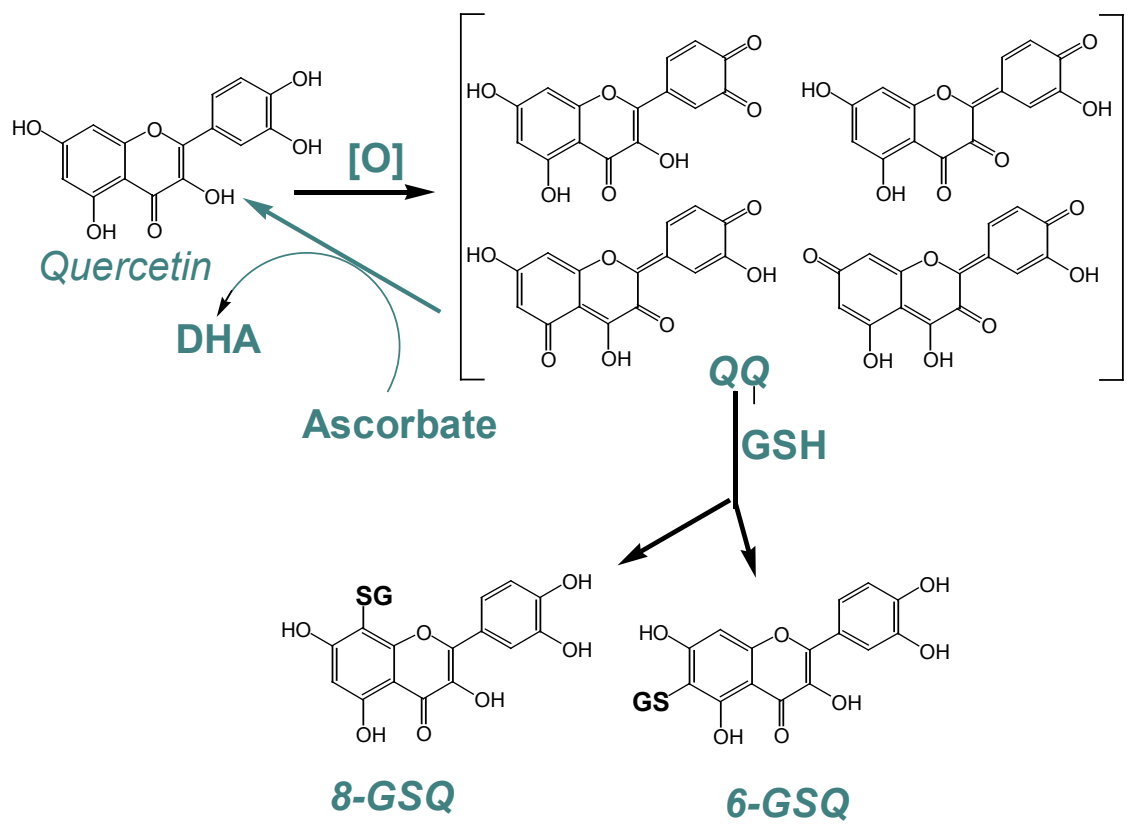

Fig. 2. Reactions of the oxidation product of quercetin. When quercetin is oxidized, an oquinone/quinonemethide (referred to as $Q Q$ ) is formed. In the figure, the four tautomeric forms of $Q Q$ are given. Quercetin can be regenerated from $Q Q$ by ascorbate, resulting in the formation of dehydroascorbate. $Q Q$ can also react with glutathione (GSH), thereby forming 6-glutathionylquercetin (6-GSQ) and 8-glutathionylquercetin (8-GSQ). The reaction of $Q Q$ with thiols such as $G S H$ is much faster that the reaction of $Q Q$ with ascorbate. When GSH levels are low, $Q Q$ can also react with protein thiols, which will lead to toxicity.

\section{Antioxidant effect of reaction products}

Apart from the residual reactivity of the reactive species that has been scavenged, the reaction product of a scavenger often also contains some 
residual antioxidant activity of the parent antioxidant. In this paradox, the presence of more than one group that has antioxidant activity within a single molecule may play a role. Quercetin efficiently protects against lipid peroxidation. During this protection quercetin is consumed, probably due to the scavenging reaction that has been discussed in the previous paragraph. Interestingly, the protection continues when all the quercetin is consumed (Fig. 3). This can only be attributed to the antioxidant activity of a reaction product. Possibly, one of the two-antioxidant groups present in quercetin (i.e. either the B-ring or the AC-ring) is still present and active in this reaction product.

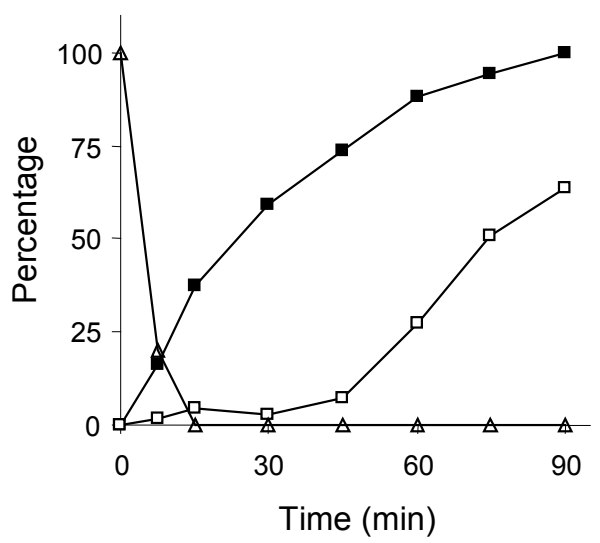

Fig. 3. Time course of lipid peroxidation (squares) and quercetin concentration (triangles) in rat liver microsomes. Lipid peroxidation was induced by 2,2'-azibis(2-amidinopropane) and assessed as the amount of thiobarbituric reactive material that is formed. The incubation mixture contained no quercetin (filled symbols) or $5 \mu \mathrm{M}$ quercetin (open symbols). The protection provide by the addition of quercetin continues even when all the quercetin has disappeared. Apparently, a reaction product of quercetin contributes to the protective effect. A typical experiment $(n=3)$ is shown.

A similar contribution of the reaction products to the overall antioxidant effect of quercetin is seen in the Trolox Equivalent Antioxidant Capacity (TEAC) assay. In this assay, the capacity of an antioxidant to scavenge the relatively stable ABTS (2,2'-azinobis-(3-ethylbenzothiazoline-6sulfonic acid) radical (ABTS*) is quantified. The advantage of the assay is its simplicity and ease of operation. The $\mathrm{ABTS}^{\circ}$ is intensely colored and when it reacts with an antioxidant the color disappears. The capacity of a compound is related to that of a reference compound, trolox. By definition, trolox has a TEAC of 1. The TEAC of quercetin is 6.24 [19]. This means that one molecule of quercetin scavenges on average 6.24 times as much $\mathrm{ABTS}^{\circ}$ than trolox. The high TEAC value of quercetin 
indicates that reaction products have to participate in the scavenging of quercetin. Detailed examination of the reactions that take place during the determination of the TEAC value indeed reveals the high contribution of reaction products to this value [20].

Essentially, the TEAC value of a compound is the antioxidant capacity of the parent compound plus the potential antioxidant capacity of the reaction product(s) $[9,19,20]$. This means that the actual TEAC of a compound cannot be ascribed solely to the parent compound. This hampers the use of the TEAC assay for ranking antioxidants. Since the TEAC value is not related to one structure, the TEAC assay cannot be used for constructing structure-activity relationships [20]. Numerous studies on a TEAC based structure-activity relationship have been published, indicating that this observation is not generally appreciated or understood. In other assays such as the Oxygen Radical Absorbance Capacity (ORAC) and Ferric Reducing Antioxidant Potential (FRAP) assay the reaction product(s) also may contribute, and the structureactivity relationships on antioxidant activity based on these assays should also be evaluated with great care.

As also mentioned in the previous paragraph, the accumulation of reaction products in vivo is expected to be lower than that in in vitro test systems. In vivo, radical stresses are relative low, the reaction products of the antioxidants are excreted from the body and endogenous antioxidants may restore the reaction product to the parent antioxidant. Therefore, the contribution of reactive products of antioxidants is likely to be overestimated in in vitro assays.

\section{Concentration of the antioxidant}

One of the advantages of in vitro testing over in vivo testing is the ease at which a certain concentration is reached. With the volume of the incubation, the amount of antioxidant that has to be introduced in the test system to achieve a certain concentration can be accurately calculated and maintained. In addition, if experimental incubation times are kept short enough to ensure that no substantial metabolism can take place, then the concentration of the test compound is easier to control as it is less likely to fall drastically during the study period.

The problem with concentration already addressed above is consumption of the antioxidant either due to a limited stability of the antioxidant, or as a result of the actual scavenging reaction. Another potential problem is the lipophilicity of the antioxidant. The partition coefficient over octanol/water $(P)$ of quercetin is relatively high; for quercetin $P$ equals 1000 . In cell 
culture or in assays with lipid membranes, the volume of the aqueous phase is much larger than that of the lipid phase (membrane). Consequently, the concentration of quercetin in the membrane is much higher as calculated, since the calculation is based on a homogeneous distribution of the compound over the incubation mixture.

For rutin, that is, quercetin with a sugar-moiety attached to the molecule, the P-value is 4 . During the process of lipid peroxidation, for example, equal concentrations of rutin and quercetin in the aqueous phase will result in a large difference in concentration of both compounds in the membrane. Despite controlling the concentration in the aqueous phase, the concentration at the site of action might fluctuate between different test compounds depending on a difference in lipophilicity.

In lipid peroxidation, not only lipophilicity but also the amphiphilic character of compounds seems to play a role. The antioxidant may well be located precisely in a compartment where the reactive species inflicts damage. The antioxidant moiety of vitamin $E$ is the phenolic group of its chroman head. This group is thought to be located in the lipid membrane near the aqueous phase at a site favorable for scavenging radicals involved in lipid peroxidation [21]. Unfortunately, the concentration of an antioxidant at the precise site of action in two-phase systems usually is not well evaluated or understood. This hampers a straightforward comparison of compounds, since activity is directly related to the concentration at the site of action. It is often incorrectly assumed that the concentration in the aqueous solution is identical to the concentration at the site of action.

Beside potential accumulation in a lipid phase, flavonoids may also bind to proteins. Binding of flavonoids to proteins reduces the antioxidant capacity $[22,23]$. Protein bound flavonoids locally still display antioxidant activity [24]. Although binding does reduce the antioxidant activity in the solution, proteins that have flavonoids bound are probably well protected against radical damage.

\section{Concentration of the reactive species}

Apart from the concentration of the antioxidant, also the concentration of the reactive species has to be evaluated critically. The stability of the reactive species is, by definition, limited. Peroxynitrite, for one, reacts instantaneously with carbon dioxide to form nitrosoperoxycarbonate. Peroxynitrite and nitrosoperoxycarbonate have a half-life at physiological conditions of less than a second. When peroxynitrite is used in a test tube assay, the incubation mixture has to be mixed vigorously when 
peroxynitrite is introduced [25]. This procedure prevents artifacts caused by locally high concentrations of peroxynitrite.

Peculiarly, peroxynitrite is also used in studies using isolated organs or cells. Peroxynitrite is added to the medium surrounding the organ and is then expected to diffuse to the organ. The time needed for diffusion, effectively exceeds the half-life of peroxynitrite or nitrosoperoxycarbonate. The concentration of peroxynitrite or nitrosoperoxycarbonate that the organ actually encounters is, therefore, not controlled and well below the concentration that is intended. In most cases it is likely that hardly any peroxynitrite or nitrosoperoxycarbonate will reach the organ and that the observed effects are due to decomposition products formed from the peroxynitrite or nitrosoperoxycarbonate. The peroxynitrite is introduced in a compartment (i.e. the aqueous solution surrounding the organ) other than the compartment containing the biomolecules peroxynitrite is intended to react with (i.e. in or on the organ). Experiments with scavengers added to the medium [26] are, therefore, of limited value. The scavengers are in the same compartment as peroxynitrite. Protection by the scavenger against the deleterious effects on the organ provoked by addition of peroxynitrite is no proof that these effects are directly mediated by peroxynitrite or nitrosoperoxycarbonate. In these experiments, the activity of the scavengers is overestimated.

Procedures have been proposed to circumvent the problem of the limited stability of peroxynitrite [27]. The strategy used is based the generation of peroxynitrite in situ using NO donors like $\sin -1$ and superoxide anion generators like xanthine oxidase. The problems encountered were the intrinsic toxicity of $\sin -1$ and the generation of vast amounts of the antioxidant, urate, by xanthine oxidase [27]. Nevertheless, the idea of generating peroxynitrite in situ is elegant. There is a need for in vitro models more closely mimicking the in vivo situation. In this respect, coincubation with inflammatory cells seems a promising way to induce reactive species in cell cultures, rather than superfluous studies on isolated organs using cumulative dose response curves of peroxynitrite.

\section{Site specific scavenging}

As described above, equilibration of antioxidant and reactive species in different compartments drastically reduces the efficacy of the antioxidant since the concentration of the antioxidant at the site of action is quite low. However, when the radical and antioxidant are present on the same 
location, this will boost antioxidant activity. This is observed in assessing the hydroxyl radical scavenging activity of some flavonoids [28].

Due to the extremely low half-life of the hydroxyl radical, hydroxyl radical scavenging has to be assessed by generation of the hydroxyl radical in situ. The combination of reduced iron and hydrogen peroxide gives the hydroxyl radical in the well-known Fenton reaction:

$$
\mathrm{Fe}^{2+}+\mathrm{H}_{2} \mathrm{O}_{2} \rightarrow \mathrm{Fe}^{3+}+\mathrm{OH}^{-}+\mathrm{OH}^{\cdot}
$$

In the presence of the strong iron chelator EDTA, the hydroxyl radical scavenging activities of the flavonoids given in Table 2 reached from one to four times the activity of the known hydroxyl radical scavenger, mannitol. In the absence of EDTA, the hydroxyl radical scavenging activity of some of the flavonoids was much higher, the activity of the most potent one increased by a factor 40 . The hydroxyl radical scavenging activity of mannitol is not affected by the absence of EDTA. The explanation for the increase in hydroxyl radical scavenging activity of some of the flavonoids is that they are potent chelators of iron. By chelating iron, the scavenger is present at the site where the radical is being formed. This phenomenon is called site-specific scavenging. Site specific scavenging is also expected to occur in vivo, indicating the relevance of the observation.

When EDTA has been added to the incubation mixture, EDTA binds tightly to the iron and prevents the chelation of iron by the flavonoids [28]. The iron-EDTA complex still generates radicals in the Fenton reaction. In fact, hydroxyl radical production proceeds more effectively with the ironEDTA complex as with free iron. The scavenging activity of the compounds in the presence of EDTA is only achieved by "normal" radical scavenging of hydroxyl radicals in the buffer. The observation that the scavenging activity of mannitol is not affected by the presence of EDTA indicates that there is no site-specific scavenging by mannitol. The 40fold decrease in the activity of monoHER caused by the inclusion of EDTA in the experiment (Table 2) and the very high rate constant observed in the experiment without EDTA (Table 2) demonstrate an exceptionally potent site-specific scavenging effect of monoHER.

In chelating iron, an important role is attributed to the $3-\mathrm{OH}$ group in the $A C$ ring and the catechol group in ring B [28]. These groups also have a prominent role in the scavenging activity of flavonoids [5]. The structureactivity relationships for iron chelating and radical scavenging are, however, not identical. This means that the overall structure-activity 
relationship for site specific scavenging (comprising both iron chelating and radical scavenging) is a mixed one. In the in vivo activity of antioxidants even more processes come into play, e.g. lipophilicity, metabolism and binding to proteins. This means that in vivo data are too multi-faceted for a practicable deduction of a meaningful structureactivity relationship.

Table 2. Hydroxyl radical scavenging of several flavonoids.

\begin{tabular}{|c|c|c|}
\hline & \multicolumn{2}{|c|}{$k_{s}\left(10^{9} M^{-1} s^{-1}\right)$} \\
\hline compound & With EDTA & Without EDTA \\
\hline mono HER & 3.9 & 161 \\
\hline di HER & 8.2 & 15 \\
\hline tri HER & 10 & 19 \\
\hline tetra HER & 11 & 8.4 \\
\hline mannitol & 2.8 & 3.4 \\
\hline
\end{tabular}

The apparent second-order rate constant $\left(k_{\mathrm{s}}\right)$ of the scavenging reaction is given. The higher the $k_{\mathrm{s}}$ value, the more potent the scavenger is. Hydroxyl radicals were generated in situ by the Fenton reaction. The results obtained in the absence or presence of EDTA are given. Mannitol was used as reference compound. The chemical structure of the flavonoids is given in Table 1. Results are taken from Haenen et al. (1993).

\section{Conclusion}

Antioxidant research highlights specific considerations related to the chemical nature and role of these agents, as well as more general arguments relating to the study design, vis-à-vis in vitro versus in vivo studies. The chemical instability that is essential for the cellular benefits of antioxidants creates difficulties in their successful analysis, which if not fully appreciated, can lead to erroneous study design and low value data. Indeed, in the appraisal of in vitro data on the activity of antioxidants, the formation of reactive products and compartmentalization should also be assessed.

The reaction products are generated either by the limited stability of the antioxidant or by the actual display of the antioxidant activity. These reaction products can have a positive or negative contribution to the overall activity of the antioxidant. As a consequence of the accumulation of reaction products, the observed activity cannot be ascribed per se to one structure.

The formation of reaction products also reduces the concentration of the parent antioxidant. Regarding concentration, compartmentalization should also be considered. Like the formation of reaction products, 
compartmentalization can have a positive or negative contribution to the overall activity. The concentration of an antioxidant is usually not well defined and controlled. Moreover, the concentration at the actual site of action between different antioxidants tested in a given concentration, can differ. This hampers a straightforward comparison of antioxidants and the construction of structure-activity relationships.

The evaluation of antioxidant capability crystallizes many of the general arguments both for and against the use of in vitro, as opposed to in vivo techniques. An added dimension to this discussion is that in comparison with other research areas, many more safe and meaningful studies with antioxidants can be carried out in humans, because of the relatively low toxicity of antioxidants and the development of many sensitive and easily applicable experimental analytical techniques. However, although in vivo studies are realistic, they are also incredibly multi-faceted, with factors such as antioxidant metabolism, instability, low throughput, concentration limitations and homeostatic system inputs that come into the equation. This makes it difficult to arrive at definite conclusions on antioxidant mechanisms and capability. As outlined in this review, in vitro systems can be much simpler, controllable and are indispensable for screening antioxidants with regard to structure/activity and elucidation of the mode of action. However, in vitro systems can deviate substantially from in vivo situation. Perhaps a useful view is that in the early stages of antioxidant evaluation, in vitro studies are of greatest value. Nonetheless, elementary aspects as structure and activity always need to be critically evaluated. Mindful of complications such as the contribution of reaction products and non-physiological compartmentalizations of the agents tested, the predictive value of the in vitro studies could be greatly improved. In vitro studies provide an opportunity to deduce the initial features of a novel series of antioxidants and these data can be carried forward to the more complex, less controllable, but nonetheless "real" in vivo situation. In this way the health effects and the actual mode of action of different antioxidants can be elucidated. This offers the opportunity to rationalize and optimize antioxidant intervention. 


\section{References}

1. Ness, A.R. and J.W. Powles (1997) Fruits and vegetables and cardiovascular disease: a review, Int. J. Epidemiol. 26, 1-13.

2. Bazzano, L.A., M.K. Serdula and S. Lui (2003) Dietary intake of fruits and vegetables and risk of cardiovascular disease, Curr. Artheroscler. Rep. 5, 492-499.

3. Vanharanta, M., S. Vopuotilainen, T.H. Rissanen, H. Aldercreutz and J.T. Salonen (2003) Risk of cardiovascular disease-related and all-cause death according to serum concentrations of enterolactone: Kuopoi Ischaemic Heart Disease Risk Factor Study, Arch. Intern. Med. 163, 1099-1104.

4. Haenen, G.R.M.M. and A. Bast (2002) The use of vitamin supplements in selfmedication, Therapié $57,119-122$.

5. Heijnen, C.G., G.R.M.M. Haenen, J.A.J.M. Vekemans and A. Bast (2001) Peroxynitrite scavenging of flavonoids: structure activity relationship, Environ. Toxicol. Pharmacol. 10, 199-206.

6. Haenen, G.R.M.M., J.B.G. Paquay, R.E.M. Korthouwer and A. Bast (1997) Peroxynitrite scavenging by flavonoids, Biochem. Biophys. Res. Commun. 236, 591-593.

7. Heijnen, C.G., G.R.M.M. Haenen, R.M. Oostveen, E.M. Stalpers and A. Bast (2002) Protection of flavonoids against lipid peroxidation: the structure activity relationship revisited, Free Rad. Res. 36, 575-581.

8. Cao, G., E. Sofic and R.L. Prior (1997) Antioxidant and prooxidant behavior of flavonoids: structure-activity relationships, Free Radic. Biol. Med. 22, 749-760.

9. Arts, M.J.T.J., J.S. Dallinga, H.P. Voss, G.R.M.M. Haenen and A. Bast (2002) A critical appraisal of the use of the trolox equivalent antioxidant (TEAC) assay in defining optimal antioxidant structures, Food Chemistry 80, 409-414.

10. Bast,A. and G.R.M.M. Haenen (2002) The toxicity of antioxidants and their metabolites, Environ. Toxicol. Pharmacol. 11, 251-258.

11. Biewenga, G.P., G.R.M.M. Haenen and A. Bast (1998) The role of lipoic acid in the treatment of diabetic polyneuropathy, Drug Metab. Rev. 29, 1025.

12. Coleman, M.D., S. Fernandez and L. Khanderia (2003) A novel clinical monitoring method to evaluate a triple antioxidant combination (Vitamins $E, C$ and a-lipoic acid) in diabetic volunteers using in vitro methaemoglobin formation, Environ. Toxicol. Pharmacol. $14,33-42$.

13. Halliwell, B., M.V. Clement, J. Ramalingam and L.H. Long (2000) Hydrogen peroxide ubiquitous in cell culture and in vivo?, IUBMB Life 50, 251-257.

14. Wee, L.M., L.H. Long, M. Whiteman and B. Halliwell (2003) Factors affecting the ascorbate- and phenolic-dependent generation of hydrogen peroxide in Dulbecco's Modified Eagles Medium, Free Rad. Res, 1123-1130.

15. Galati, G., M.Y. Moridani, T.S. Chan and P.J. O'Brien (2001) Peroxidative metabolism of apigenin and naringenin versus luteolin and quercetin: glutathione oxidation and conjugation, Free Radic. Biol. Med. 30, 370.

16. Awad, H.M., M.G. Boersma, S. Boeren, H. Van der Woude, J. Van Zanden, P.J. Van Bladeren, J. Vervoort and I.M. Rietjens (2002) Identification of o-quinone/quinone methide metabolites of quercetin in a cellular in vitro system, FEBS Lett. 520, 30-34.

17. Boots, A., G.R.M.M. Haenen, G.J.M. Hartog and A. Bast (2002) Oxidative damage shifts from lipid peroxidation to thiol arylation by catechol-containing antioxidants, Biochim. Biophys. Acta 1583, 279-284.

18. Boots, A., G.R.M.M. Haenen and A. Bast (2003) Oxidized quercetin reacts with thiols rather than with ascorbate: implications for quercetin supplementation, Biochem. Biophys. Res. Commun. 308, 560-565.

19. Arts, M.J.T.J., J.S. Dallinga, H.P. Voss, G.R.M.M. Haenen and A. Bast (2004) A new approach to assess the total antioxidant capacity using the TEAC assay, Food Chemistry 88, 567-570.

20. Arts, M.J.T.J., H.P. Voss, G.R.M.M. Haenen and A. Bast (2004) Antioxidant capacity of reaction products limits the applicability of the Trolox Equivalent Antioxidant Capacity (TEAC) assay, Food Chem. Toxicol. 42, 45-49. 
21. Afri, M., B. Ehrenberg, Y. Talmon, J. Schmidt, Y. Cohen and A.A. Frimer (2004) Active oxygen chemistry within the liposomal bilayer. Part III: locating Vitamin E, ubiquinol and ubiquinone and their derivatives in the lipid bilayer, Chem. Phys. Lipids 131, 107-121.

22. Arts, M.J.T.J., G.R.M.M. Haenen, H.P. Voss and A. Bast (2001) Masking of antioxidant capacity by the interaction of flavonoids with protein, Food Chem. Toxicol. 39, 787-791.

23. Arts, M.J.T.J., G.R.M.M. Haenen, L.C. Wilms, A.J.N. Beetstra, C.G.M. Heijnen, H.-P. Voss and A. Bast (2002) Interactions between flavonoids and proteins: effect on the total antioxidant capacity, J. Agric. Food Chem. 50, 1184-1187.

24. Rohn, S., H.M. Rawel and J. Kroll (2004) Antioxidant activity of protein-bound quercetin, J. Agric. Food Chem. 52, 4725-4729.

25. Kooy, N.W., J.A. Royall, H. Ischropoulos and J.S. Beckman (1994) Peroxynitritemediated oxidation of dihydrorhodamine 123, Free Radic. Biol. Med. 16, 149-156.

26. Zhu, X., L.M.A. Heunks, E.M.M. Versteeg, H.F.M. Van der Heijden, L. Ennen, T.H. Van Kuppevelt, J. Vina and P.N.R. Dekhuijzen (2005) Hypoxia-induced dysfunction of rat diaphragm: role of peroxynitrite, Am. J. Physiol. Lung Cell. Mol. Physiol. 288, 16-26.

27. Wang, C. and W.M. Dean (2004) Peroxynitrite delivery methods for toxicity studies Chem. Res. Toxicol. 17, 32-44.

28. Haenen, G.R.M.M., F.P. Jansen and A. Bast (1993) The antioxidant properties of five O-( $\beta$-hydroxyethyl)-rutosides of the flavonoid mixture Venuruton, Phlebol. S1, 10-17. 



\title{
Chapter 3
}

\section{A critical appraisal of the use of the antioxidant capacity (TEAC) assay in defining optimal antioxidant structures}

\author{
Mariken J. T. J. Arts \\ J. Sebastiaan Dallinga \\ Hans-Peter Voss \\ Guido R. M. M. Haenen \\ Aalt Bast
}

Food Chemistry 80, 409-414, 2003 


\begin{abstract}
In the Trolox Equivalent Antioxidant Capacity (TEAC) assay, the capacity of a compound to scavenge the ABTS radical (ABTS*) is assessed. The aim of the present study is to evaluate the applicability of the TEAC assay to predict the antioxidant effectivity of a compound. For this purpose the TEAC assay is compared with other screening assays, such as superoxide scavenging, peroxynitrite scavenging and lipid peroxidation. Of the structurally related compounds, catechol, resorcinol and hydroquinone, resorcinol has the highest TEAC. In contrast, resorcinol appears to have a much lower antioxidant activity than catechol and hydroquinone in other in vitro assays. Similar discrepancies were observed with the flavonoids, chrysin and galangin. The TEAC values of chrysin and galangin are comparable, whereas galangin appears to be a much better antioxidant in other assays. The relatively high TEAC values of chrysin and resorcinol are due to the ability of the reaction products, formed by the reaction of the parent compound with ABTS', to further react with $\mathrm{ABTS}^{\circ}$. With catechol, hydroquinone and galangin, these reaction products do not react with $\mathrm{ABTS}^{\circ}$ and therefore make no contribution to the TEAC. The possible contribution of reaction products to the TEAC of a compound hampers the use of the TEAC assay for constructing structure-activity relationships (SARs).
\end{abstract}




\section{Introduction}

Oxidative stress is involved in the pathogenesis of various chronic diseases, such as cardiovascular disease and cancer [1]. Antioxidants protect against free radicals and are therefore important in obtaining and preserving good health. In this respect, much attention has been given to the flavonoids, a class of polyphenols with strong antioxidant activities.

Within the wide range of methods used to screen antioxidants, the Trolox Equivalent Antioxidant Capacity (TEAC) assay is very popular. This assay is based on the scavenging of the relatively stable blue/green $A B T S$ radical $\left(A B T S^{*}\right)$, converting it into a colorless product. The degree of this decolorization reflects the amount of $\mathrm{ABTS}^{\bullet}$ that has been scavenged and can be determined spectrophotometrically. The TEAC value is assigned by comparing the scavenging capacity of an antioxidant to that of trolox.

The TEAC assay is evaluated using three structurally related compounds. The TEAC values of these compounds are compared to their antioxidant activities in several antioxidant assays. Based on the results, the applicability of the TEAC assay for predicting the antioxidant effectivity of a compound is discussed.

\section{Materials and methods}

\section{Chemicals}

2,2'-Azino-bis-(3-ethylbenzthiazoline-6-sulfonic acid) (ABTS), 6-hydroxy2, 5,7,8-tetramethylchroman-2-carboxylic acid (trolox), resorcinol, hydroquinone, catechol, xanthine, xanthine oxidase, Nitro Blue Tetrazolium (NBT), ascorbic acid, solid $\mathrm{KO}_{2}$ and dihydrorhodamine-123 were obtained from Sigma and $\mathrm{K}_{2} \mathrm{~S}_{2} \mathrm{O}_{8}$ and $\mathrm{FeSO}_{4}$ were obtained from Merck. Nitrogen monoxide was obtained from AGA (Hamburg, Germany). All other chemicals were of analytical grade purity.

\section{TEAC assay}

The TEAC assay, described by Van den Berg, Haenen, Van den Berg, and Bast [2] and by $\mathrm{Re}$ et al. [3] has been used with minor modifications. This assay assesses the total radical scavenging capacity, based on the ability of a compound to scavenge the stable ABTS radical (ABTS ${ }^{\circ}$ ). $\mathrm{ABTS}^{\bullet}$ was formed by adding $\mathrm{K}_{2} \mathrm{~S}_{2} \mathrm{O}_{8}$ to $\mathrm{ABTS}$ [3]. The reaction of $A B T S^{\bullet}$ with antioxidants was determined spectrophotometrically at $734 \mathrm{~nm}$. The 
degree of the decolorization gives the antioxidant capacity, which can be converted into TEAC-values.

The ABTS ${ }^{\bullet}$ solution was diluted with phosphate buffered saline (PBS), $\mathrm{pH}$ 7.4 , to a final absorbance of the control of $0.7 \pm 0.02$ at $734 \mathrm{~nm}$ at $37^{\circ} \mathrm{C}$. Stock solutions of trolox, catechol, resorcinol and hydroquinone were prepared in ethanol.

\section{Superoxide scavenging (SOS)}

Superoxide $\left(\mathrm{O}_{2}{ }^{--}\right)$scavenging was tested in a competition assay in which xanthine-xanthine oxidase was used as an $\mathrm{O}_{2}{ }^{--}$generator. Uric acid was produced in the same stoichiometry as $\mathrm{O}_{2}{ }^{-{ }^{-}}$. The reduction of NBT by $\mathrm{O}_{2}{ }^{--}$is monitored spectrophotometrically at $550 \mathrm{~nm}$ at $25^{\circ} \mathrm{C}$ for $3 \mathrm{~min}$. $\mathrm{O}_{2}{ }^{\circ-}$ scavenging activity of the compounds was determined by competition of the compound with NBT for the $\mathrm{O}_{2}{ }^{--}$. The compounds tested did not affect uric acid production, determined at $290 \mathrm{~nm}$, indicating that the antioxidants did not influence the $\mathrm{O}_{2}{ }^{--}$production by inhibiting xanthine oxidase. The effectivity is expressed as the concentration of scavenger that inhibits NBT reduction for $50 \%\left(\mathrm{IC}_{50}\right)$.

\section{Peroxynitrite synthesis and peroxynitrite scavenging (PON)}

Potassium oxoperoxonitrite(1-) (ONOOK) was produced from the reaction of solid $\mathrm{KO}_{2}$ with NO-gas as described by Koppenol et al.[4]. Peroxynitrite scavenging was measured by the oxidation of dihydrorhodamine-123 (DHR), as described by Kooy et al. [5]. Fluorescence measurements were performed on a SPF-500C ${ }^{\mathrm{TM}}$ spectrophotometer (SLM AMINCO) at $37^{\circ} \mathrm{C}$ with excitation and emission wavelengths of, respectively, 500 and $536 \mathrm{~nm}$. The effects are expressed as the concentrations capable of inhibiting fifty percent of the oxidation of DHR $\left(I_{50}\right)$.

\section{Preparation of microsomes for lipid peroxidation}

To obtain microsomes, livers from male Wistar rats (200-250 g) were used. After decapitation, the livers were removed and homogenized (1:2, $\mathrm{w} / \mathrm{v})$ in ice-cold sodium phosphate buffer $(50 \mathrm{mM}, \mathrm{pH} 7.4)$ containing 0.1 $\mathrm{mM}$ EDTA. The homogenate was centrifuged at $10,000 \mathrm{~g} \mathrm{(20} \mathrm{min} \mathrm{at}$ $\left.4{ }^{\circ} \mathrm{C}\right)$. The supernatant was centrifuged at $10,000 \mathrm{~g}\left(20 \mathrm{~min}\right.$ at $\left.4{ }^{\circ} \mathrm{C}\right)$ and again at $65,000 \mathrm{~g}\left(60 \mathrm{~min}\right.$ at $\left.4^{\circ} \mathrm{C}\right)$. Subsequently, the microsomal pellet was resuspended in the phosphate buffer $(2 \mathrm{~g} \mathrm{liver} / \mathrm{ml})$ and stored at $-80^{\circ} \mathrm{C}$. Before using the control microsomes, they were thawed and washed twice with ice-cold Tris- $\mathrm{HCl}$ buffer $(50 \mathrm{mM}, \mathrm{pH} 7.4)$ containing $150 \mathrm{mM} \mathrm{KCl}$. 


\section{Lipid peroxidation}

Microsomes (final concentration approximately $1 \mathrm{mg}$ protein/ $\mathrm{ml}$ ) were incubated in Tris- $\mathrm{HCl} / \mathrm{KCl}(50 \mathrm{mM} / 150 \mathrm{mM}, \mathrm{pH} 7.4)$ at $37^{\circ} \mathrm{C}$ in a shaking water bath. Ascorbic acid $(0.2 \mathrm{mM})$ was neutralized with $\mathrm{KOH}$ before addition. Reactions were started by adding a freshly prepared FeSO4 solution $(10 \mu \mathrm{M})$. Lipid peroxidation was assayed by measuring thiobarbituric acid (TBA)-reactive material, as described previously by Haenen and Bast [6]. The reaction in an aliquot of the incubation mixture $(0.3 \mathrm{ml})$ was stopped by mixing with ice-cold TBA-trichloroacetic acid (TCA)-HCl-butylhydroxytoluene (BHT) solution (2 ml). After heating (15 min at $80^{\circ} \mathrm{C}$ ) and centrifugation (5 min) the absorbance at 535 versus $600 \mathrm{~nm}$ was determined. The TBA-TCA-HCl solution was prepared by dissolving $1.68 \mathrm{~g} \mathrm{TCA}$ and $41.60 \mathrm{mg}$ TBA in $10 \mathrm{ml} 0.125 \mathrm{M} \mathrm{HCl}$. One $\mathrm{ml}$ BHT-solution $(1.5 \mathrm{mg} / \mathrm{ml}$ ethanol) was added to $10 \mathrm{ml}$ TBA-TCA-HCl. The added test compounds did not interfere with the assay in the concentrations used. Results are expressed as means \pm SEM.

\section{Results}

The reaction of the three isomers, catechol, resorcinol and hydroquinone, with $\mathrm{ABTS}^{\circ}$ was examined. The TEAC at $6 \mathrm{~min}$, calculated from the experiment depicted in Fig. 1, of resorcinol was $2.49 \pm 0.01$ whereas the TEAC values of catechol and hydroquinone were respectively, $1.45 \pm 0.02$ and $1.33 \pm 0.06$.

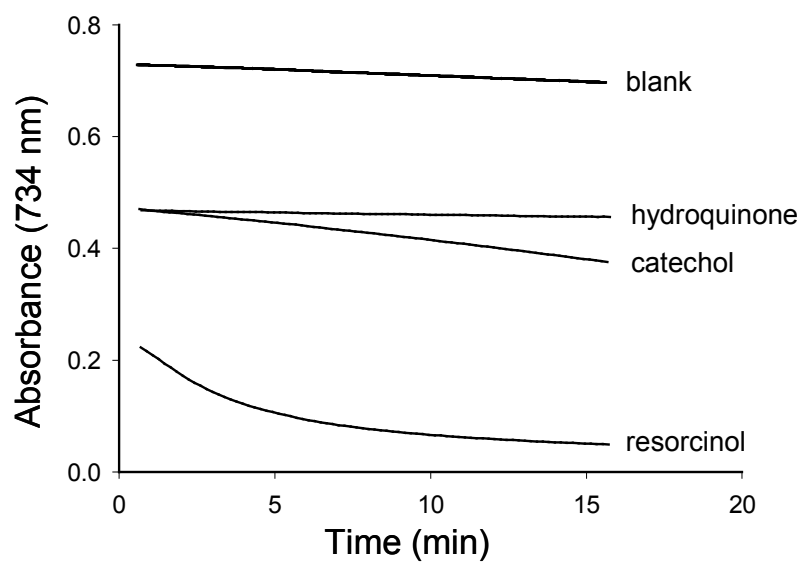

Fig. 1. The reaction of catechol, hydroquinone and resorcinol with ABTS over time. The absorbance at $734 \mathrm{~nm}$, due to ABTS', is followed in time. The initial concentration of the tested compounds is $10 \mu \mathrm{M}$. 
In superoxide scavenging, or in the inhibition of lipid peroxidation, as well as in peroxynitrite scavenging, resorcinol appeared to have a poor antioxidant activity. In these assays hydroquinone and catechol were 101000 times more potent than resorcinol (Fig. 2).

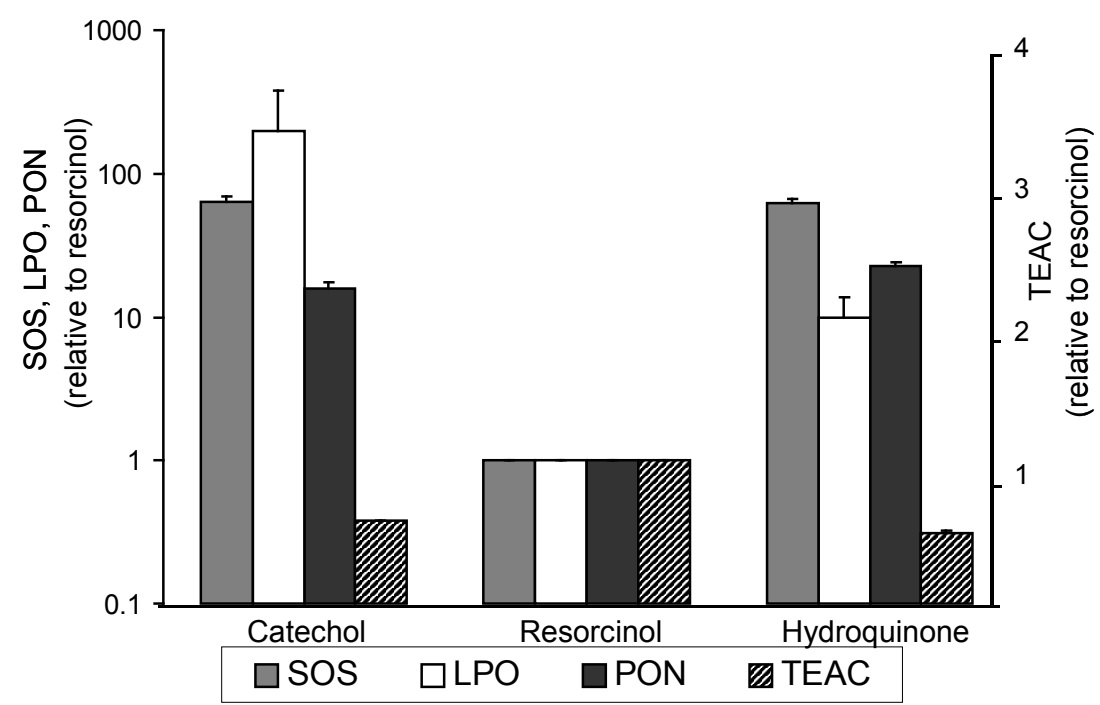

Fig. 2. The antioxidant profile of catechol, resorcinol and hydroquinone. The left $Y$-axis is for superoxide scavenging activity $\left(\mathrm{IC}_{50}\right.$ catechol: $0.014 \mu \mathrm{M}, \mathrm{IC}_{50}$ resorcinol: $0.91 \mu \mathrm{M}, \mathrm{IC}_{50}$ hydroquinone: $0.014 \mu \mathrm{M})$, inhibition of lipid peroxidation $\left(\mathrm{IC}_{50}\right.$ catechol: $10 \mu \mathrm{M}, \mathrm{IC}_{50}$ resorcinol: $1556 \mu \mathrm{M}, \mathrm{IC}_{50}$ hydroquinone: $\left.156 \mu \mathrm{M}\right)$ and peroxynitrite scavenging $\left(\mathrm{IC}_{50}\right.$ catechol: $2 \mu \mathrm{M}, \mathrm{IC}_{50}$ resorcinol: $42.5 \mu \mathrm{M}, \mathrm{IC}_{50}$ hydroquinone: $\left.1.89 \mu \mathrm{M}\right)$. The right axis is for the TEAC-values (catechol: 1.4, resorcinol: 2.5, hydroquinone: 1.3). The activities of catechol and hydroquinone are related to those of resorcinol.

A closer look at the time course of the ABTS ${ }^{\bullet}$ consumption in the TEAC assay revealed that resorcinol induced, besides a fast reaction, a slow reaction (Fig. 1). The TEAC value was determined at $6 \mathrm{~min}$ and, within these $6 \mathrm{~min}$, the slow reaction had already made a substantial contribution. Moreover, the reaction of resorcinol with $\mathrm{ABTS}^{\bullet}$ continued after $6 \mathrm{~min}$.

The slow reaction of resorcinol with $\mathrm{ABTS}^{\bullet}$ was examined in more detail by monitoring the changes in the absorbance spectrum during the reaction (Fig. 3). Resorcinol does not absorb between the 300 and 800 $\mathrm{nm}$. ABTS ${ }^{\circ}$ showed an absorbance maximum at $734 \mathrm{~nm}$. Within ten seconds after adding resorcinol to the $\mathrm{ABTS}^{\bullet}$ solution, a product was detected with an absorbance maximum at $540 \mathrm{~nm}$. Subsequently, this 
product disappeared and another product appeared with an absorbance maximum of $470 \mathrm{~nm}$. In the conversion of the first product into the second one, an isosbestic point was found at $500 \mathrm{~nm}$. During the formation of the second product, the ABTS ${ }^{\bullet}$ concentration also decreased, which was deduced from the reduction of the absorbance at $734 \mathrm{~nm}$. The increase in absorbance in curves $0-4$ of Fig. 3 at $470 \mathrm{~nm}$-due to the formation of the second product-was linearly related to the decrease in absorbance at $550 \mathrm{~nm}$-due to the disappearance of the first product-and to the decrease in absorbance at $734 \mathrm{~nm}$-due to the disappearance of ABTS ${ }^{\circ}$. Based on this linearity and the presence of an isosbestic point, it was concluded that the first product, formed in the reaction of resorcinol with

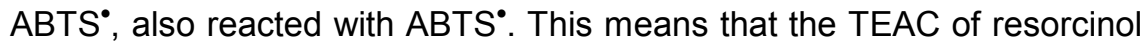
does not reflect the antioxidant capacity of resorcinol itself, but rather is the sum of the antioxidant capacity of resorcinol and the reaction product(s).

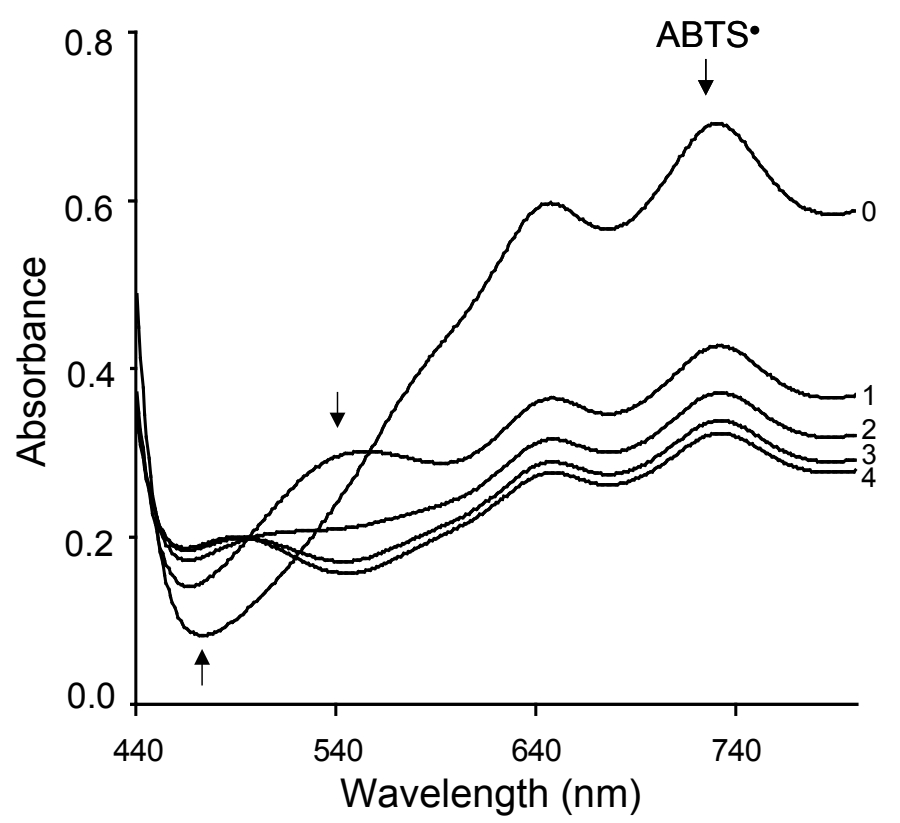

Fig. 3. Reaction of resorcinol with $A B T S^{*}$, followed spectrophotometrically. Repetitive scans were made. The final concentration of resorcinol is $10 \mu \mathrm{M}$. Resorcinol does not absorb between 440 and $800 \mathrm{~nm}$. Spectrum 0 was recorded just before the antioxidant was added, and gives the spectrum of the ABTS ${ }^{*}$ solution. Spectrum 1 was recorded $10 \mathrm{~s}$ after the start of the reaction with the addition of ABTS ${ }^{\circ}$. The scan time is 30 seconds. The time between the consecutive spectra is 96 seconds. 
The reactivity of the reaction products of catechol and hydroquinone with ABTS $^{\circ}$ was much lower than that of the product formed with resorcinol. The difference in reactivity of the reaction product obtained with hydroquinone and catechol compared to that obtained with resorcinol explains the high TEAC of resorcinol compared to hydroquinone and catechol.

The reaction of $\mathrm{ABTS}^{*}$ with chrysin and galangin, two flavonoids that differ only in one $\mathrm{OH}$ group, was also followed over the course of time. In the case of chrysin, the obtained spectrum was comparable to that of resorcinol, i.e. the appearance of reaction products that were subsequently consumed in the reaction with ABTS (data not shown). Galangin, however, showed no evidence for intermediate reaction products at all (data not shown). As reported previously, the TEAC values of the compounds at $\mathrm{t}=6 \mathrm{~min}$ were comparable. However, the antioxidant activity, e.g. peroxynitrite scavenging $\left(\mathrm{IC}_{50}\right.$ galangin $=1.02 \pm 0.11 \mu \mathrm{M} ; \mathrm{IC}_{50}$ chrysin $=295 \pm 26 \mu \mathrm{M})$ and lipid peroxidation $\left(\mathrm{IC}_{50}\right.$ galangin $=1.7 \pm 0.12$ $\mu \mathrm{M} ; I_{50}$ chrysin $=29 \pm 0.95 \mu \mathrm{M}$ ) of galangin were superior to that of chrysin. Apparently the TEAC does not have to reflect the antioxidant activity and the relatively high TEAC of chrysin is caused by the contribution of reaction products to the TEAC.

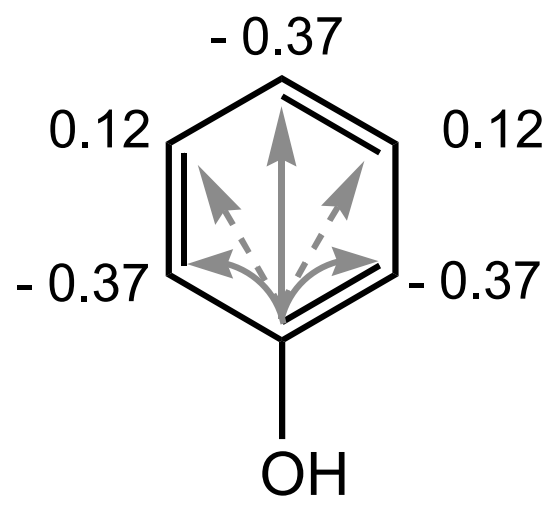

Fig. 4. The Hammet sigma values $(\sigma)$ of an aromatic hydroxyl group. A hydroxyl substituent on an aromatic ring has an electron withdrawing effect on the 3 position $(\sigma=+0.12)$ and an electron donating effect on the 2 and 4 position $(\sigma=-0.37)$. The $\sigma$-values are from Hansch and Leo [7].

\section{Discussion}

The applicability of the TEAC was evaluated using resorcinol, catechol and hydroquinone. Resorcinol appeared to have a much higher TEAC 
value than catechol and hydroquinone. This means that resorcinol can be qualified as the best antioxidant of the three compounds with the TEAC assay. This is in line with the higher TEAC of resorcylicate $(3,5-$ dihydroxybenzoate) than protocatechuate (3,4- dihydroxybenzoate) or 2,5-dihydroxybenzoate, as reported previously [8].

Compared to phenol, the reaction of resorcinol with a radical would theoretically be reduced by the electron-withdrawing effect of the $\mathrm{OH}$ group in the meta position. An OH-group on the ortho or para position has an electron donating effect [7] ( Fig. 4). This means that both catechol and hydroquinone are expected to react faster with a radical than resorcinol. Apparently, the high TEAC of resorcinol does not fit with the expected low reactivity of resorcinol.

However, in the inhibition of lipid peroxidation, the superoxide-scavenging assay and in the peroxynitrite-scavenging assay, catechol and hydroquinone are much better antioxidants than resorcinol. The high TEAC value of resorcinol can be explained by the contribution of reaction products to the TEAC. In the other assays these reaction products make no contribution and the activity of the parent compound only is determined. The relatively high contribution of the reaction product of $\mathrm{ABTS}^{\circ}$ and resorcinol is the reason why the rank order in the TEAC assay is not comparable with the rank order found in other assays.

A comparable discrepancy between TEAC and antioxidant activity is seen with the flavonoids, chrysin and galangin. The TEAC of the two compounds are comparable. The TEAC of chrysin $(1.43 \pm 0.07)$ reported in literature [8] is even higher than that of galangin (1.22 \pm 0.02$)$ [9]. However, the antioxidant activity of galangin is superior to that of chrysin. Apparently, the TEAC does not have to correlate with the antioxidant activity. An explanation for this discrepancy is that the TEAC assay measures the total amount of radicals scavenged over a period of time. Both the parent compound and the reaction products can contribute. Most antioxidant activity assays, however, determine the rate at which a radical is scavenged by an antioxidant. This is an activity of the parent compound.

Previously, we have found that the total amount of $A B T S^{\bullet}$ scavenged by a compound correlates with the biological activity in a selected group of flavonoids [10]. The rate at which the ABTS ${ }^{\bullet}$ is scavenged shows a less good correlation. It is noteworthy that the number of compounds tested within this study was small and that the correlation might have been coincidental. The present study clearly demonstrates a fundamental characteristic of the TEAC assay, i.e. the potential contribution of reaction products. The possible contribution of reaction products to the TEAC 
value of a compound hampers the use of the TEAC assay for the construction of SARs. In a SAR the activity has to be attributed to a single molecular structure only [7]. TEAC-based SARs have frequently been constructed [8,11,12]. When these SARs are examined in detail, inconsistencies are expected to be found.<smiles></smiles>

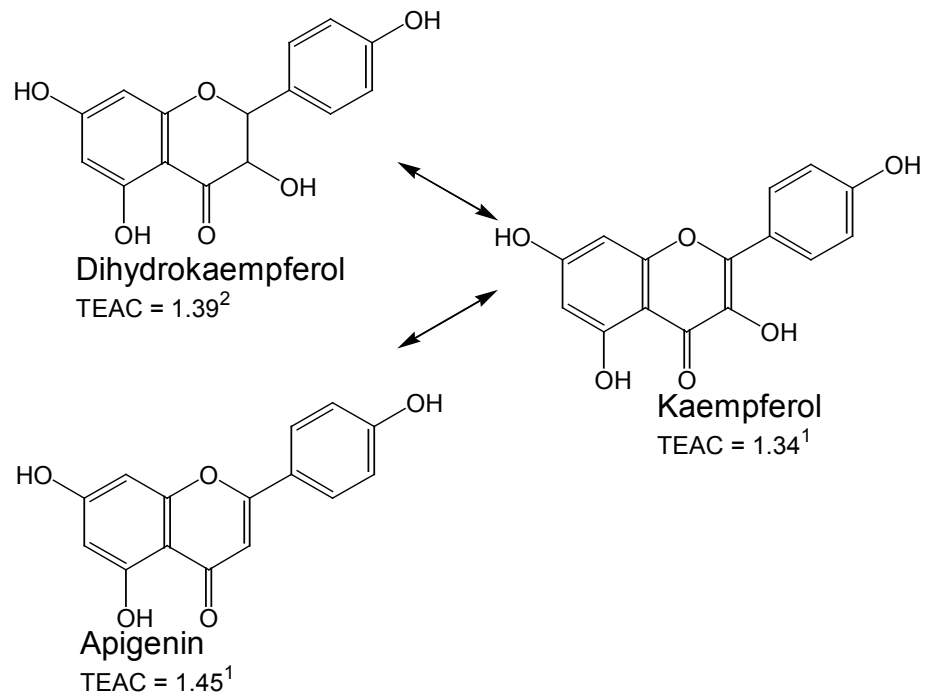

Fig. 5. Structures of several flavonoids and their TEAC values at 6 min. ${ }^{1}$ Data have been taken from Rice-Evans et al. [8] and Lien et al. [11]. ${ }^{2}$ Data have been taken from Lien et al. [11].

Rudimentary SARs on the antioxidant activities of flavonoids indicate that the antioxidant activity of flavonoids depends on the number of free $\mathrm{OH}$ - 
groups [13]. This is challenged by the difference in activities of catechol, resorcinol and hydroquinone.

Lien et al. have constructed a QSAR based on the number of $\mathrm{OH}$ substituents, also incorporating-to some extent- the location [11]. When this QSAR is applied to myricetin and quercetin or to apigenin and kaempferol, two pairs of compounds that differ only in one OH-group (Fig. 5), myricetin has a higher predicted value than quercetin (3.55 versus 3.10) and kaempferol has a higher predicted TEAC value than apigenin (2.31 versus 1.45), according to the SAR. However, the measured TEAC value of myricetin is lower than the value of quercetin (3.10 versus 4.7 ) and the measured value of kaempferol is lower than that of apigenin (1.34 versus 1.85). Apparently, the SAR that correlates the number of $\mathrm{OH}$-moieties to the TEAC is not consistent.

Plumb et al. stated that removal of the 2,3 double bond drastically reduces the antioxidant activity [12], which does not hold for dihydrokaemferol compared to kaempferol (Fig. 5). Based on the TEAC values, Rice-Evans et al. reported that a criterion for maximal radical scavenging is "the combination of the $5-\mathrm{OH}$ group in the A ring with the 3$\mathrm{OH}$ group and the 4-oxo function in the $\mathrm{C}$ ring with the 2,3-double bond" [8]. This aspect of the SAR does not apply for dihydrokaempferol, which lacks the 2,3-double bond, and apigenin, that lacks the 3-OH group. Apigenin does not have a lower TEAC value than kaempferol. These inconsistencies illustrate the limitations of the TEAC assay in constructing SARs.

Most other screening assays have shortcomings as well. Appropriate control experiments are often needed. It should be noted that the different potencies of catechol, resorcinol and hydroquinone in the inhibition of lipid peroxidation is primarily due to differences in electron-donating effect and not to other factors, such as differences in iron chelation or lipophilicity. Moreover, none of the compounds affected xanthine oxidase in the superoxide scavenging assay.

In the case of the TEAC assay, reaction products were found to contribute and it is impossible to correct for this. In fact, a difference in TEAC value is primarily caused by a difference in reactivity of the reaction products. This makes this assay inappropriate for SARs.

The TEAC assay is, however, useful in tracking down unknown antioxidants in complex mixtures [14]; however, one has to be aware of possible interactions, which might result in masking $[15,16]$. 


\section{References}

1. Halliwell, B. and J.M.C. Gutteridge (1999) Free radicals in biology and medicine. 3rd ed., Oxford University Press, New York.

2. Van den Berg, R., G.R.M.M. Haenen, H. van den Berg and A. Bast (1999) Applicability of an improved TEAC assay for evaluation of antioxidant capacity measurements of mixtures, Food Chem. 66, 511-517.

3. Re, R., N. Pellegrini, A. Proteggente, A. Pannala, M. Yang and C. Rice-Evans (1999) Antioxidant activity applying an improved ABTS radical cation decolorization assay, Free Rad. Biol.Med. 26, 1231-1237.

4. Koppenol, W.H., R. Kissner and J.S. Beckman (1996) Syntheses of peroxynitrite: to go with the flow or on solid grounds? Meth. Enzymology 269, 296-302.

5. Kooy, N.W., J.A. Royall, H. Ischiropoulos and J.S. Beckman (1994) Peroxynitritemediated oxidation of dihydrorhodamine 123, Free Rad. Biol. Med. 16, 149-156.

6. Haenen, G.R.M.M. and A. Bast (1983) Protection against lipid peroxidation by a microsomal glutathione-dependent labile factor, FEBS Letters 159, 24-28.

7. Hansch, C. and A. Leo (1995) Exploring QSAR. Fundamentals and applications in chemistry and biology, American Chemical Society, Washington DC.

8. Rice-Evans, C.A., N.J. Miller and G. Paganga (1996) Structure-antioxidant activity relationships of flavonoids and phenolic acids, Free Rad. Biol.Med. 20, 933-956.

9. Williamson, G., G.W. Plumb and M.T. Garcia-Conesa (1999) Glycosylation, esterification and polymerization of flavonoids and hydroxycinnamates: effects on antioxidant properties, Basic Life Sci. 66, 483-494.

10. Van den Berg, R., G.R.M.M. Haenen, H. van den Berg, W. van der Vijgh and A. Bast (2000) The predictive value of the antioxidant capacity of structurally related flavonoids using the trolox equivalent antioxidant capacity (TEAC) assay, Food Chem. 70, 391-395.

11. Lien, E.J., S. Ren, H.H. Bui and R. Wang (1999) Quantitative structure-activity relationship analysis of phenolic antioxidants, Free Rad. Biol. Med. 26, 285-294.

12. Plumb, G.W., K.R. Price and G. Williamson (1999) Antioxidant properties of flavonol glycosides from green beans, Redox Rep. 4, 123-127.

13. Cao, G., E. Sofic and R.L. Prior (1997) Antioxidant and prooxidant behaviour of flavonoids: structure-activity relationships, Free Rad. Biol. Med. 22, 749-760.

14. Van Overveld, F.W.P.C., G.R.M.M. Haenen, J. Rhemrev, J.P.W. Vermeiden and A. Bast (2000) Tyrosine as important contributor to the antioxidant capacity of seminal plasma, Chem. Biol. Interact. 127, 151-161.

15. Arts, M.J.T.J., G.R.M.M. Haenen, H.-P. Voss and A. Bast (2001) Masking of antioxidant capacity by the interaction of flavonoids with protein, Food Chem. Toxicol. 39, 787-791.

16. Arts, M.J.T.J., G.R.M.M. Haenen, L.C. Wilms, A.J.N. Beetstra, C.G.M. Heijnen, H.-P. Voss and A. Bast (2002) Interactions between flavonoids and proteins: effect on the total antioxidant capacity, J. Agricul. Food Chem. 50, 1184-1187. 


\section{Chapter 4}

\section{Antioxidant capacity of reaction products limits the applicability of the Trolox Equivalent Antioxidant Capacity (TEAC) assay}

Mariken J. T. J. Arts

Guido R. M. M. Haenen

Hans-Peter Voss

Aalt Bast

Food and Chemical Toxicology 42, 45-49, 2004 


\begin{abstract}
The Trolox Equivalent Antioxidant Capacity (TEAC) assay is based on the scavenging of the 2,2'-azinobis-(3-ethylbenzothiazoline-6-sulfonic acid) (ABTS) radical (ABTS ) converting it into a colorless product. The degree of decolorization induced by a compound is related to that induced by trolox, giving the TEAC value. The assay is frequently used for constructing structure activity relationships (SARs). HPLC analysis of the reaction mixture, obtained after scavenging of ABTS ${ }^{\bullet}$ by the flavonoid chrysin, shows that a product is formed that also reacts with $A B T S^{\circ}$. The product has a higher antioxidant capacity and reacts faster with $A B T S^{\circ}$ than the parent compound, chrysin. In contrast to the reaction product of chrysin, the reaction product of trolox, which is formed during scavenging of ABTS $^{\circ}$, i.e. trolox quinone, does not react with ABTS'. The experiments show that the TEAC is the antioxidant capacity of the parent compound plus the potential antioxidant capacity of the reaction product(s). This means that the TEAC assay does not necessarily reflect the antioxidant effect of only one structure. This hampers the applicability of the assay for the construction of SARs and for ranking antioxidants.
\end{abstract}




\section{Introduction}

Free radicals play a crucial role in the pathogenesis of several human diseases, such as cancer, rheumatoid arthritis and various neurodegenerative and pulmonary diseases [1]. Antioxidants protect against these radicals and are therefore important tools in obtaining and preserving good health. Therefore the antioxidant profiles of numerous compounds, both natural and synthetic, are frequently compared in order to identify the most potent ones.

One of these assays was based on the peroxidase activity of haem containing proteins, resulting in the conversion of the colorless ABTS into the blue green ABTS radical (ABTS*). Originally, this activity was used to determine the haemoglobin content of tissue samples [2]. In this haemoglobin assay reductive compounds such as vitamin $C$ interfere, since they react with $\mathrm{ABTS}^{\bullet}$ giving a colorless non-radical product. This disadvantage was put to use in the TEAC assay. Originally the TEAC assay was based on the reduction of the accumulation of ABTS formed by the peroxidase activity of metmyoglobin by antioxidants [3]. A major impediment of this assay is that compounds might inhibit the peroxidase activity [4]. Therefore, the assay has been adapted by using pre-formed $\mathrm{ABTS}^{\bullet}[5,6]$. In the assay, the decolorisation of ABTS ${ }^{\bullet}$ by a compoundthat reflects the amount of ABTS that has been scavenged- after a fixed period of time (usually 5 or $6 \mathrm{~min}$ ) is related to that of trolox.

The TEAC assay is frequently used to rank antioxidants and for the construction of structure activity relationships (SARs). There are indications that the TEAC value does not exactly correlate with the antioxidant activity. For example, chrysin has a relatively high TEAC value while its antioxidant activity in most other assays [7] is relatively low. The aim of this study is to critically review what is being measured in the TEAC assay. Based on this, the applicability of the TEAC assay is evaluated.

\section{Materials and methods}

\section{Chemicals}

2,2'-Azinobis-(3-ethylbenzothiazoline-6-sulfonic acid) (ABTS), 6-hydroxy2, 5,7,8-tetramethylchroman-2-carboxylic acid (Trolox) and chrysin were obtained from Sigma and potassium persulfate (di-potassium peroxodisulfate) was obtained from Merck. All other chemicals were of analytical grade purity. 


\section{TEAC assay}

The standard TEAC assay described by $[5,6]$ has been used with minor modifications for determination of the TEAC value. This assay assesses the total radical scavenging capacity based on the ability of a compound to scavenge the stable ABTS radical (ABTS ${ }^{\circ}$ ) in $6 \mathrm{~min}$. The blue-green $\mathrm{ABTS}^{\circ}$ was produced through the reaction between $7 \mathrm{mM}$ ABTS and 2.45 $\mathrm{mM}$ potassium persulfate in water. This solution was stored in the dark for $12-16 \mathrm{~h}$ before use. The extinction coefficient of ABTS ${ }^{\bullet}$ at $734 \mathrm{~nm}$ is $1.5 \times 10^{4} \mathrm{~mol}^{-1} \mathrm{I} \mathrm{cm}^{-1}$.

The concentrated ABTS solution was diluted with phosphate buffered saline (PBS), $\mathrm{pH} 7.4$ to a final absorbance of $0.70 \pm 0.02$ at $734 \mathrm{~nm}$ at $37^{\circ} \mathrm{C}$ (i.e. an ABTS concentration of approximately $47 \mu \mathrm{M}$ ). Stock solutions of trolox, and chrysin were prepared in ethanol. Ten microliters of an antioxidant containing solution were added to $990 \mu \mathrm{LBCTS^{ \circ }}$ solution and the absorbance at $734 \mathrm{~nm}$ was measured in time. This was compared to a blank where $10 \mu \mathrm{l}$ of the solvent was added to $990 \mu \mathrm{l}$ of the ABTS solution. The reduction in absorbance $6 \mathrm{~min}$ after addition of the antioxidant was determined. The TEAC of the antioxidant was calculated by relating this decrease in absorbance to that of a trolox solution on a molar basis.

\section{The total scavenging capacity}

To quantify the total amount of ABTS ${ }^{\bullet}$ that can be scavenged by chrysin or trolox, the initial concentration of the antioxidant was kept constant at 2.5 or $10 \mu \mathrm{M}$ respectively. The initial concentration of $\mathrm{ABTS}^{\bullet}$ was varied from $0 \mu \mathrm{M}$ up to approximately $40 \mu \mathrm{M}$ ABTS ${ }^{\circ}$ and the absorbance of the $\mathrm{ABTS}^{\circ}$ at $734 \mathrm{~nm}$ was measured $6 \mathrm{~min}$ after starting the reaction. Also the concentration of chrysin or trolox in the incubation mixture, as well as the concentration of their products, formed by the reaction between the antioxidants and $\mathrm{ABTS}^{\circ}$, was measured. For these determinations an HPLC method was used at 6 min after starting the reaction.

\section{HPLC-analysis}

Fifty microliters of the mixture were injected into the HPLC system to measure the concentration chrysin or trolox and the products. Simultaneously, the amount of ABTS ${ }^{\circ}$ was assessed spectrophotometrically at $734 \mathrm{~nm}$. HPLC conditions were: UV-Visdetector wavelength for chrysin $270 \mathrm{~nm}$, detector wavelength for trolox $290 \mathrm{~nm}$; flow rate $1 \mathrm{ml} / \mathrm{min}$; column Nucleosil C18, $5 \mu \mathrm{m}, 15 \mathrm{~cm} \times 3.2 \mathrm{~mm}$ 
(Supelco inc.) The mobile phase was $45 \%$ PBS/55\% methanol containing $2 \%(\mathrm{v} / \mathrm{v})$ formic acid.

The concentration of the products of chrysin is estimated by assuming that one mole chrysin gives one mole of product.

\section{Results}

Fig. 1 depicts the reduction of the absorbance at $734 \mathrm{~nm}$ in the course of time after addition of chrysin or trolox to an ABTS solution. The chemical structures of these antioxidants have been given in Fig. 2. Trolox shows a very fast reduction in absorbance and the reaction is completed within seconds (Fig. 1). When higher concentrations of trolox are used, the reaction is also completed within seconds (data not shown). Chrysin induces -on a molar basis- a higher degree of decolorization than trolox. Based on the reduction of the absorbance at $734 \mathrm{~nm}$ in the incubation mixture with chrysin after $6 \mathrm{~min}$, it was calculated that the TEAC of chrysin is 2.2. It should be noted however, that the reaction of chrysin with $\mathrm{ABTS}^{\bullet}$ has not been finished within the 6 -min period.

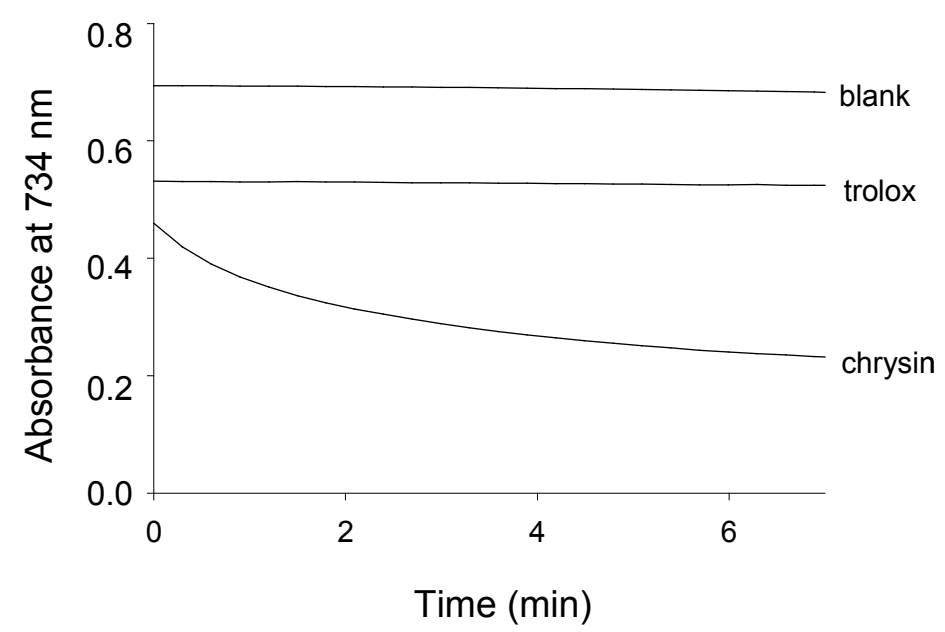

Fig. 1. Reaction of trolox and chrysin with the ABTS*. The reduction of the $\mathrm{ABTS}^{*}$ concentration expressed as the absorbance at $734 \mathrm{~nm}$ is followed in time. The first $15 \mathrm{~s}$ are not recorded since this time period was needed to transfer the incubation mixture into the spectrophotometer. Initial concentrations of the antioxidants are $5 \mu \mathrm{M}$. 
<smiles>Cc1c(C)c2c(c(C)c1O)CCC(C)(C(=O)O)O2</smiles>

trolox<smiles>O=c1cc(-c2ccccc2)oc2cc(O)cc(O)c12</smiles>

chrysin

Fig. 2. The structure of trolox and chrysin.

In the experiment depicted in Fig. 3 the reaction between chrysin and ABTS $^{\bullet}$ was examined using another procedure. A fixed concentration of chrysin $(2.5 \mu \mathrm{M})$ was mixed with an increasing concentration of ABTS $^{\bullet}$ (varying from $0 \mu \mathrm{M}$ up to approximately $40 \mu \mathrm{M}$.) The mixture was analyzed $6 \mathrm{~min}$ after the addition of chrysin, because this is the time usually used for assessing the TEAC. Increasing the initial concentration of $\mathrm{ABTS}^{\bullet}$ reduced the concentration of chrysin that could be detected after $6 \mathrm{~min}$. The tangent of the chrysin curve at low ABTS ${ }^{\bullet}$ concentration crosses the $\mathrm{x}$-axis at an initial $\mathrm{ABTS}^{\bullet}$ concentration of $5 \mu \mathrm{M}$, indicating that $2.5 \mu \mathrm{M}$ chrysin is able to scavenge $5 \mu \mathrm{M}$ ABTS ${ }^{\bullet}$. This means that the stoichiometry of the reaction of chrysin with $\mathrm{ABTS}^{\bullet}$ is $1: 2$.

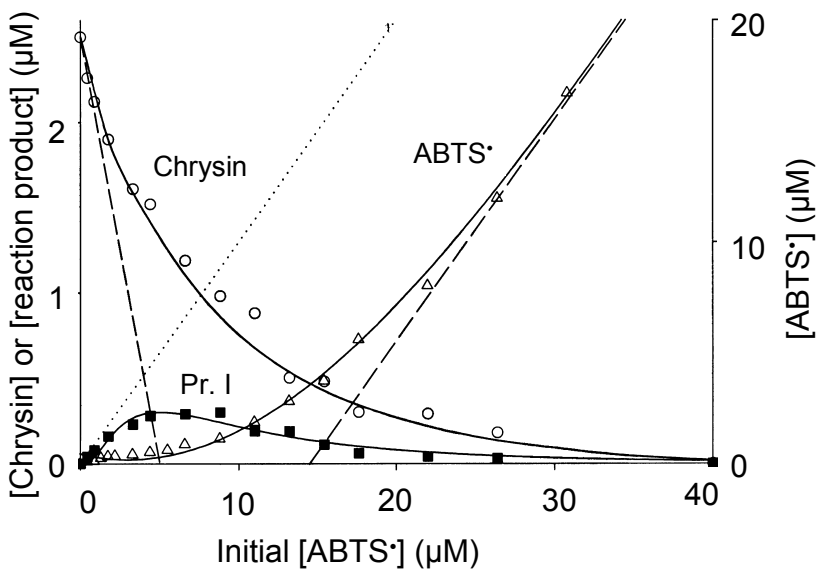

Fig. 3. The concentration of chrysin, $A B T S^{\bullet}$ and product (Pr. I) formed after addition of a variable initial concentration of $\mathrm{ABTS}^{*}$ to a solution of $2.5 \mu \mathrm{M}$ chrysin. The initial concentration of $\mathrm{ABTS}^{\circ}$ varied from $0 \mu \mathrm{M}$ up to approximately $40 \mu \mathrm{M}$. The mixture was analyzed after $6 \mathrm{~min}$. The dotted line represents the concentration of ABTS when no chrysin is added to the mixture. The dashed lines show the tangent lines of the initial chrysin consumption and of the ABTS that has not been consumed. 
At a low ABTS\%chrysin ratio, a product appears in the HPLC analysis of the reaction mixture (Fig. 4, Pr.I, Fig. 3). The concentration of this product is maximal at an initial $\mathrm{ABTS}^{\circ}$ concentration of $8.8 \mu \mathrm{M}$. The $\mathrm{ABTS}$ \%chrysin ratio at that point is 3.5 . Above this ratio the concentration of this product drops, and at a ratio of 12 (initial ABTS concentration of $30 \mu \mathrm{M}$ ) almost no product is detected. From the low ABTS\%chrysin ratio, when the concentration of the product is the highest, it can be deduced that the reaction rate of the product with $\mathrm{ABTS}^{\bullet}$ exceeds that of chrysin with $\mathrm{ABTS}^{\bullet}$ by far.

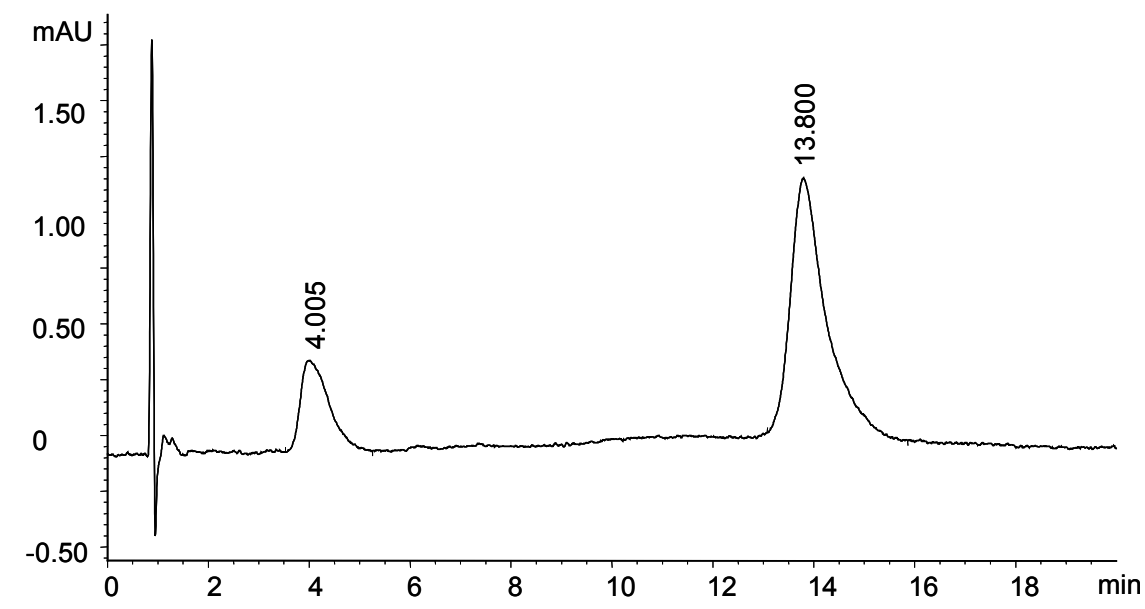

Fig. 4. HPLC chromatogram of chrysin and the reaction product 6 min after mixing the compounds with the ABTS ${ }^{\bullet}$ solution. Retention times of chrysin and the reaction product are respectively 13.8 and $4 \mathrm{~min}$. The initial concentrations of chrysin and $\mathrm{ABTS}^{\bullet}$ were respectively $2.5 \mu \mathrm{M}$ and $20 \mu \mathrm{M}$.

At low ratio $A B T S^{\circ}$ /chrysin most of the added $\mathrm{ABTS}^{\circ}$ is consumed. At an initial $\mathrm{ABTS}^{\circ}$ concentration above $30 \mu \mathrm{M}$, the slope of the ABTS concentration curve is 1 , indicating that when extra $A B T S^{*}$ is added, this is not consumed. The tangent of the ABTS ${ }^{\circ}$ curve at that point shows that an ABTS ${ }^{\circ}$ concentration of $14.5 \mu \mathrm{M}$ can be scavenged by addition of 2.5 $\mu \mathrm{M}$ chrysin, meaning that one molecule chrysin consumes 5.8 molecules of ABTS ${ }^{\circ}$. The calculated contribution of chrysin and the product to the total amount of $\mathrm{ABTS}^{*}$ scavenged is shown in Fig. 5. The total amount of $\mathrm{ABTS}^{\circ}$ that disappears, due to the reaction of chrysin itself with $\mathrm{ABTS} \mathrm{S}^{\circ}$, is about $30 \%$. Apparently, the other $70 \%$ of the ABTS has reacted with reaction product(s). 


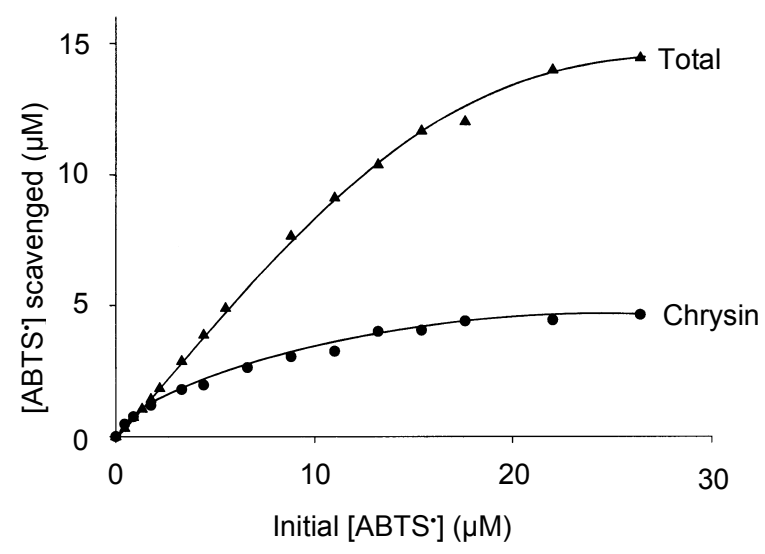

Fig. 5. The calculated concentration of ABTS that is scavenged by chrysin itself and the total concentration of ABTS that has disappeared after 6 min calculated from the data presented in Fig. 3. A variable initial concentration of ABTS ${ }^{\circ}$ was used. The initial concentration of chrysin was $2.5 \mu \mathrm{M}$.

The reaction mixture of $A B T S^{\bullet}$ and trolox was also analyzed with HPLC and the results have been summarized (Fig. 6). The initial concentration of trolox added was $10 \mu \mathrm{M}$. Increasing the initial concentration of ABTS results in a decrease of the trolox concentration. The stoichiometry of the reaction of trolox with $A B T S^{\bullet}$ is 1.9 . In the reaction of trolox with $\mathrm{ABTS}^{\bullet}$, trolox quinone is formed. Trolox quinone does not react with ABTS ${ }^{\circ}$.

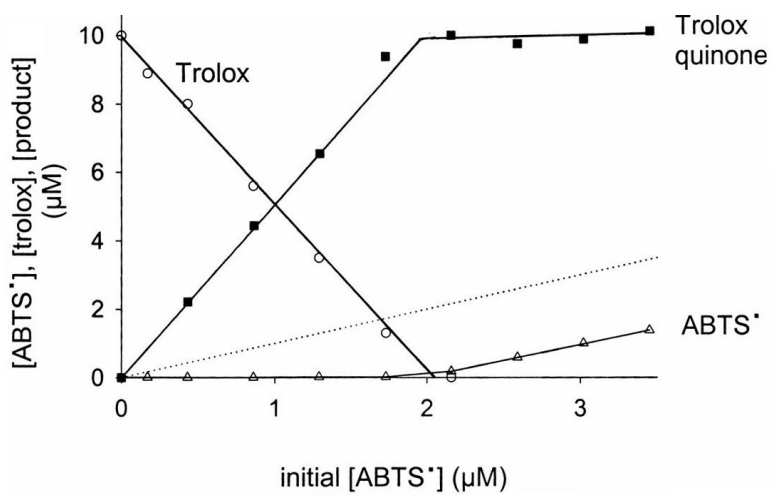

Fig. 6. The concentration of trolox, ABTS ${ }^{*}$ and quinone formed after addition of a variable initial concentration of $\mathrm{ABTS}^{\bullet}$ to a solution of $10.0 \mu \mathrm{M}$ trolox. The mixture was analyzed after $6 \mathrm{~min}$. The dotted line represents the concentration of $\mathrm{ABTS}^{\bullet}$ if no trolox is added to the mixture. 


\section{Discussion}

Chrysin has a relatively high TEAC compared to its moderate antioxidant activity in other assays [7]. Therefore the reaction of chrysin with ABTS ${ }^{\circ}$ was examined in more detail in order to evaluate what is being measured in the TEAC assay. It was found that products, formed during the reaction between chrysin and $A B T S^{\circ}$, also react with $A B T S^{\circ}$. When chrysin is added to an $\mathrm{ABTS}^{\circ}$ solution, firstly a fast reaction occurs and subsequently the reaction proceeds slowly. The reaction is not completed after 6 min, contrary to the reaction between trolox and ABTS', which is finished within seconds. In the reaction between trolox and ABTS ${ }^{\circ}$, trolox quinone is formed, that does not react with ABTS:

It has been reported that in the reaction of trolox with ABTS a trolox radical is formed as intermediate product [8]. The stoichiometry of this reaction is 1 . Analysis of the reaction of trolox with $\mathrm{ABTS}^{\circ}$ shows, however, that the stoichiometry of the reaction of trolox with ABTS ${ }^{*}$ is 1.9 (Fig. 6). This suggests that the trolox radical, formed as a product of the reaction of trolox and $A B T S^{\circ}$, reacts fast with a second $A B T S^{\circ}$. The observed stoichiometry is not exactly 2 . This may be due to competing reactions e.g. between two trolox radicals $[8,9]$. The trolox radical has to be qualified as a potent antioxidant in this assay. Already in 1955, Boozer et al. demonstrated that phenolic antioxidants react with radicals in a 1: 2 stoichiometry [10].

HPLC analysis of the reaction of chrysin with $\mathrm{ABTS}^{\bullet}$ at 6 min shows that the stoichiometry of the reaction is, comparable to that of trolox, namely 2. In analogy with trolox, an intermediate radical product, i.e. the chrysin radical, is expected to be involved in the reaction of chrysin with ABTS . In contrast to trolox, the relatively stable reaction product that was detected with HPLC also reacts with $\mathrm{ABTS}^{\circ}$. One molecule of chrysin finally leads to the consumption of 5.8 molecules of $A B T S^{\bullet}$ in a sequential reaction. Thus, the product from chrysin and $A B T S^{\circ}$, which was detected with HPLC, is capable of consuming 3.8 molecules of ABTS". This means that the product reacts with more $\mathrm{ABTS}^{\circ}$ molecules than chrysin itself. Analysis of the data showed that the product also has a higher reactivity towards $\mathrm{ABTS}^{\circ}$ than chrysin (Fig. 5). Therefore the product can be qualified as a better antioxidant than the parent compound, chrysin. It should be noted that in the reaction between the product and $\mathrm{ABTS}^{\circ}$ also intermediate products will participate and therefore a straightforward comparison between the antioxidant activity of chrysin and the product is not possible. 
In comparing Fig. 1 and Fig. 3 it has to be noted that the initial concentration of chrysin in Fig. $1(5 \mu \mathrm{M})$ is different from that of Fig. $3(2.5$ $\mu \mathrm{M})$. The $A B T S \%$ chrysin ratio in Fig. 1 is $47 / 5=9.4$. At this ratio in Fig. 3 (initial concentration of $\mathrm{ABTS}^{\circ} \approx 23 \mu \mathrm{M}$ ) the $\mathrm{ABTS}^{\circ}$ consumed was ca. 14 $\mu \mathrm{M}$ i.e. $5.6 \mu \mathrm{M}$ ABTS ${ }^{\circ}$ per $\mu \mathrm{M}$ chrysin (14/2.5). This nicely corresponds to the $5.0 \mu \mathrm{M} \mathrm{ABTS}{ }^{\circ}$ per $\mu \mathrm{M}$ chrysin (i.e. 25/5) found in Fig. 1, where the reaction has not reached completion. As shown in Fig. 3 and Fig. 5, at the $A B T S^{*}$ chrysin ratio used in Fig. 1 the major part of the ABTS is consumed in a reaction with the reaction product (and not in the reaction with chrysin). This confirms the substantial contribution of the reaction product in the "standard" TEAC assay.

The product formed from chrysin is expected to be more hydrophylic than the parent compound (shorter retention time, as shown in Fig. 4). Moreover, the reaction rate of the product with $\mathrm{ABTS}^{\bullet}$ exceeds that of chrysin with $A B T S^{\circ}$ by far. In trolox, there is a ring opening to give the quinone in the reaction with $\mathrm{ABTS}^{\circ}$. A comparable ring opening in chrysin would yield a chalcone-like product. Recently, it has been reported that chalcones are potent antioxidants [11]. Based on this information we speculate that the reaction product formed might be a chalcone-like product.

As demonstrated in this study, the TEAC of chrysin is in fact the sum of several compounds, including chrysin, chrysin radical and the product that was detected by HPLC and other products. The reactivity of these products explains the relatively high capacity of chrysin. As shown in this study, one molecule chrysin can lead to the consumption of 5.8 molecules of ABTS (Fig. 3). Trolox scavenges $1.9 \mathrm{ABTS}^{\circ}$. This gives chrysin a "true" TEAC value of 3.05 (i.e. 5.8/1.9). This is higher than the observed TEAC value of 1.43 reported in literature [12] or 2.2, based on the results found in Fig. 1. The lower observed TEAC compared to the "true" TEAC is due to the fact that the reactions are not completed under the conditions used to determine the TEAC.

Quercetin is reported to have a TEAC-value of 4.7 [12] to 6.4 [4] depending on the assay conditions. This means that one molecule of quercetin reacts with at least 4.7-6.4 times as much ABTS as trolox (i.e. $4.7 \times 1.9=8.9$ to 12.2 molecules of $\mathrm{ABTS}^{\circ}$ ) within the time period measured. The quercetin radical, a reaction product and probably also further reaction products have to contribute to obtain such a high TEAC. Previously, it has also been reported that partially oxidized flavonoids can have a substantial antioxidant activity [13-15].

In summary, the TEAC assay measures the antioxidant capacity of the parent compound plus that of reaction products. These reaction products 
may have a considerable contribution to the TEAC. As shown for trolox and chrysin, the contribution of products is not similar for antioxidants. The relatively high TEAC of chrysin-compared to its moderate antioxidant activity-is due to the formation of reaction products that also scavenge ABTS ${ }^{\circ}$. A reaction product was found that proved to have a higher antioxidant capacity than the parent compound. The contribution of reaction products hampers the use of the TEAC for constructing SARs; in a SAR the activity has to be related to one structure only. Nevertheless, TEAC (like-) assays are still frequently applied to rank antioxidants or to construct SARs without taking the limitations of the assay into account. It should be realized that a similar impediment as we described here for the TEAC assay (i.e. the substantial contribution of reaction products to the overall observed effect of an antioxidant) may also be found in other screenings assays, based on assessing the total antioxidant capacity, e.g. the oxygen radical absorbance capacity assay (ORAC) [16].

Despite its drawbacks, the TEAC assay is a useful tool for tracking down unknown antioxidants in complex mixtures. For this application, the TEAC assay has been used with success $[17,18]$; however, one has to be aware of possible complications [19]. 


\section{References}

1. Halliwell, B. and J.M.C. Gutteridge, Free Radicals in Biology and Medicine. (third ed.), Oxford University Press, New York (1999).

2. Marklund, S. (1979) A simple specific method for the determination of the hemoglobin content of tissue homogenates, Clin. Chim. Acta 92, 229-234.

3. Miller, N.J., C.A. Rice-Evans, M.J. Davies, V. Gopinathan and A. Milner (1993) A novel method for measuring antioxidant capacity and its application to monitoring the antioxidant status in premature neonates, Clin. Sci. 84, 407-412.

4. Strube, M., G.R.M.M. Haenen, H. van den Berg and A. Bast (1997) Pitfalls in a method for assessment of total antioxidant capacity, Free Rad. Res. 26, 515-521.

5. Van den Berg, R., G.R.M.M. Haenen, H. van den Berg and A. Bast (1999) Applicability of an improved Trolox equivalent antioxidant capacity (TEAC) assay for evaluation of antioxidant capacity measurements of mixtures, Food Chem. 66, 511-517.

6. Re, R., N. Pellegrini, A. Proteggente, A. Pannala, M. Yang and C. Rice-Evans (1999) Antioxidant activity applying an improved ABTS radical cation decolorization assay, Free Radical Biol. Med. 26, 1231-1237.

7. Heijnen, C.G.M., G.R.M.M. Haenen, J.A.J.M. Vekemans and A. Bast (2001) Peroxynitrite scavenging of flavonoids: structure activity relationship, Environ. Toxicol. Pharmacol. 10, 199-206

8. Aliaga, C. and E. Lissi (1998) Reaction of 2,2'-azinobis (3-ethylbenzothiazoline-6-sulfonic Acid (ABTS) derived radicals with hydroperoxides. Kinetics and mechanism, Int. J. Chem. Kin. $30,565-570$.

9. Campos, A. and E. Lissi (1997) Kinetics of the reaction between 2,2'-azinobis (3ethylbenzothiazoline-6-sulfonic acid (ABTS) derived radical cations and phenols, Int. J. Chem. Kin. 29, 219-224.

10. Boozer, C.E., G.S. Hammond, C.E. Hamilton and J.N. Sen (1955) Air oxidation of hydrocarbons. The stoichiometry and fate of inhibitors in benzene and chlorobenzene, $\mathrm{J}$. Am. Chem. Soc. 77, 3233-3237.

11. Rezk, B., G.R.M.M. Haenen, W.J.F. van den Vijgh and A. Bast (2002) The antioxidant activity of phloretin: the disclosure of a new antioxidant pharmacophore in flavonoids, Biochem. Biophys. Res. Commun. 295, 9-13.

12. Rice-Evans, C.A., N.J. Miller and G. Paganga (1996) Structure-antioxidant activity relationships of flavonoids and phenolic acids, Free Radical Biol. Med. 20, 933-956.

13. Kondo, K., M. Kurihara, N. Miyata, T. Suzuki and M. Toyoda (1999) Scavenging mechanisms of (-)-epigallocatechin gallate and (-)-epicatechin gallate on peroxyl radicals and formation of superoxide during the inhibitory action, Free Radical Biol. Med. 27, 855863.

14. Dangles, O., G. Fargeix and C. Dufour (1999) One-electron oxidation of quercetin and quercetin derivates in protic and non protic media, J. Chem. Soc. Perkin Trans. 2, 13871395.

15. Dangles, O., G. Fargeix and C. Dufour (2000) Antioxidant properties of anthocyanins and tannins: a mechanstic investigation with catechin and the $3^{\prime}, 4$ ', 7-trihydroxyflavylium ion, J. Chem. Soc. Perkin Trans. 2, 1653-1663.

16. Ou, B., M. Hampsch-Woodill and R.L. Prior (2001) Development and validation of an improved oxygen radical absorbance capacity assay using fluorescein as the fluorescent probe, J. Agric. Food Chem. 49, 4619-4626.

17. Van Overveld, F.W.P.C., G.R.M.M. Haenen, J. Rhemrev, J.P.W. Vermeiden and A. Bast (2000) Tyrosine as important contributor to the antioxidant capacity of seminal plasma, Chem. Biol. Interact. 127, 151-161.

18. Miller, N.J. and C.A. Rice-Evans (1997) The relative contributions of ascorbic acid and phenolic antioxidants to the total antioxidant activity of orange and apple fruit juices and blackcurrant drink, Food Chem. 60, 331-337.

19. Arts, M.J.T.J., G.R.M.M. Haenen, H.-P. Voss and A. Bast (2001) Masking of antioxidant capacity by the interaction of flavonoids with protein, Food Chem. Toxicol. 39, 787-791. 


\title{
Chapter 5
}

\section{A new approach to assess the total antioxidant capacity using the TEAC assay}

\author{
Mariken J. T. J. Arts \\ J. Sebastiaan Dallinga \\ Hans-Peter Voss \\ Guido R. M. M. Haenen \\ Aalt Bast
}

Food Chemistry 88, 567-570, 2004 


\begin{abstract}
The trolox equivalent antioxidant capacity (TEAC) assay is a popular method for assessing the capacity of a compound to scavenge ABTS radicals (ABTS ${ }^{\circ}$ ). Under the conditions in which the assay is performed, the reaction between most antioxidants and $\mathrm{ABTS}^{\circ}$ does not reach completion within the time span applied. This leads to an underestimation of the TEAC of these antioxidants. In the present study, incubations with different concentrations of $A B T S^{*}$ and a fixed concentration of antioxidant were performed. The decrease in $\mathrm{ABTS}^{\circ}$ concentration in 6 min was plotted against the initial concentration of $A B T S^{\circ}$ and fitted by an exponential function. Extrapolation of the fit to an infinite excess of ABTS ${ }^{\circ}$ gives the maximal concentration of ABTS ${ }^{*}$ that can be scavenged by the antioxidant at the concentration employed. This can be used to determine the actual TEAC of antioxidants, i.e. the total antioxidant capacity.
\end{abstract}




\section{Introduction}

The trolox equivalent antioxidant capacity (TEAC) assay [1] is widely applied to assess the amount of radicals that can be scavenged by an antioxidant, i.e. the antioxidant capacity [2-4]. In the most recent version of this assay, an antioxidant is added to a pre-formed ABTS radical (ABTS ${ }^{*}$ ) solution and, after a fixed time period, the remaining $A B T S^{\bullet}$ is quantified spectrophotometrically [5-7]. The reduction in ABTS concentration, induced by a certain concentration of antioxidant, is related to that of trolox and gives the TEAC value of that antioxidant. The assay is rapid, easy and correlates with the biological activity of antioxidants $[8,9]$.

A major problem associated with the TEAC assay is that substantial differences in reported TEAC values of an antioxidant are observed, e.g. the TEAC of quercetin varies from 3.1 [6] to 6.4 [5]. The variation cannot only be ascribed to differences in procedure. Also, with the same procedure, the TEAC of a compound may vary. With the same method, the TEAC of quercetin at a concentration of 1.5 or $1.0 \mu \mathrm{M}$ is reported to be 5.6 or 6.4 , respectively [5]. The aim of this study is to develop a procedure to determine the true total antioxidant capacity of a compound that is independent of the concentration of the antioxidant.

\section{Materials and methods}

\section{Chemicals}

2,2'-Azinobis-(3-ethylbenzothiazoline-6-sulfonic acid) (ABTS), 6-hydroxy2, 5,7,8-tetramethylchroman-2-carboxylic acid (trolox), quercetin, chrysin, rutin, catechol and resorcinol were obtained from Sigma (St. Louis, USA) and potassium persulfate (di-potassium peroxodisulfate) was obtained from Merck (Darmstadt, Germany). All other chemicals were of analytical grade.

\section{Preparation of the ABTS solution}

A $7 \mathrm{mM}$ solution of $A B T S$ in milli-Q was prepared and $A B T S^{\bullet}$ was formed after addition of potassium persulfate to the mixture in a final concentration of $2.45 \mathrm{mM}$. After a 12-16 $\mathrm{h}$ incubation at room temperature, the stock solution was diluted with PBS until an absorbance of $0.7( \pm 0.02)$ at $734 \mathrm{~nm}$ was reached [6]. 


\section{Preparation of the antioxidant solutions}

Solutions of antioxidants were prepared in ethanol. To exclude the influence of light, the solutions were prepared in the dark.

To a fixed concentration of an antioxidant, $A B T S^{\circ}$ in a variable concentration was added. The concentration of $A B T S^{\bullet}$ was varied from 0 to approximately $45 \mu \mathrm{M}$ in several different incubations. After a $6 \mathrm{~min}$ incubation at $37^{\circ} \mathrm{C}$, the absorbance at $734 \mathrm{~nm}$ was determined. The concentration of $\mathrm{ABTS}^{-}$was calculated, using a molar extinction coefficient of $1.5 \times 10^{4} \mathrm{M}^{-1}$ [6]. The reduction in ABTS concentration was derived from the absorbance at $734 \mathrm{~nm}$ of the reference (only containing ABTS $^{\circ}$ ) and the incubation containing the fixed concentration of antioxidant plus the same concentration of ABTS ${ }^{\circ}$.

The reduction in $\mathrm{ABTS}^{\bullet}$ concentration was plotted against the initial concentration of ABTS . The curve was fitted according to the exponential function, $y=C\left(1-e^{\left(-b^{*} x\right)}\right)$ using Sigma Plot (version 4.01) on a conventional personal computer. In this formula, $y$ is the reduction in ABTS concentration, $x$ is the initial ABTS ${ }^{\circ}$ concentration and $C$ is the maximal amount of $\mathrm{ABTS}^{\bullet}$ scavenged by the antioxidant at the concentration tested. In the procedure employed, the maximal initial concentration of ABTS ${ }^{\circ}$ was $45 \mu \mathrm{M}$. For accurate results, the antioxidant in the concentration used, had to give a value of $C$ between 2.5 and $25 \mu \mathrm{M}$. When values of $C$ below or above these limits were obtained, the concentration of the antioxidant has to be adjusted accordingly. The TEAC was determined by dividing $C$ by the concentration of antioxidant and by 1.9. The latter factor (1.9) is the number of molecules that can be scavenged per trolox [10]. It should be noted that, in the literature, the TEAC of a compound is often incorrectly expressed as $\mathrm{mM}$. As can be inferred from the procedure described above, the TEAC of a compound is a relative value and has no dimension.

\section{Results}

Various antioxidants behave differently in the TEAC assay. The reference compound in the TEAC assay is trolox. Trolox reacts instantaneously with ABTS $^{\bullet}$ (Fig. 1). Within the time needed to put the sample into the spectrophotometer, the reaction of trolox with $A B T S^{\circ}$ is completed. Already, with a small excess of ABTS $^{\bullet}$, the total amount of $A B T S^{\bullet}$ that reacts with trolox can be determined. It was found that $1.9 \mu \mathrm{mol} \mathrm{ABTS}^{\circ}$ was consumed per $\mu \mathrm{mol}$ trolox [10]. The TEAC value of trolox is 
independent of the concentration of trolox, as was also previously reported [5].

Rutin reacts more slowly than trolox with $\mathrm{ABTS}^{\bullet}$ and, within $6 \mathrm{~min}$, the reaction is not completed (Fig. 1). To quantify the total amount of $\mathrm{ABTS}^{\bullet}$ that can be scavenged by rutin, the initial concentration of the antioxidant was kept constant and the initial concentration of ABTS $^{\bullet}$ was varied from $0 \mu \mathrm{M}$ up to approximately $45 \mu \mathrm{M}$ ABTS ${ }^{\circ}$. Six minutes after starting the reaction, the absorbance of the $\mathrm{ABTS}^{\circ}$ at $734 \mathrm{~nm}$ was measured. The difference in the concentration of $A B T S^{\circ}$ between the reference (containing a variable amount of $\mathrm{ABTS}^{\circ}$ and no rutin) and that of the sample (containing both the fixed concentration of rutin and the same concentration of $\mathrm{ABTS}^{\bullet}$ as the reference) was determined. This was used to determine the reduction in $\mathrm{ABTS}^{\circ}$ concentration in the sample.

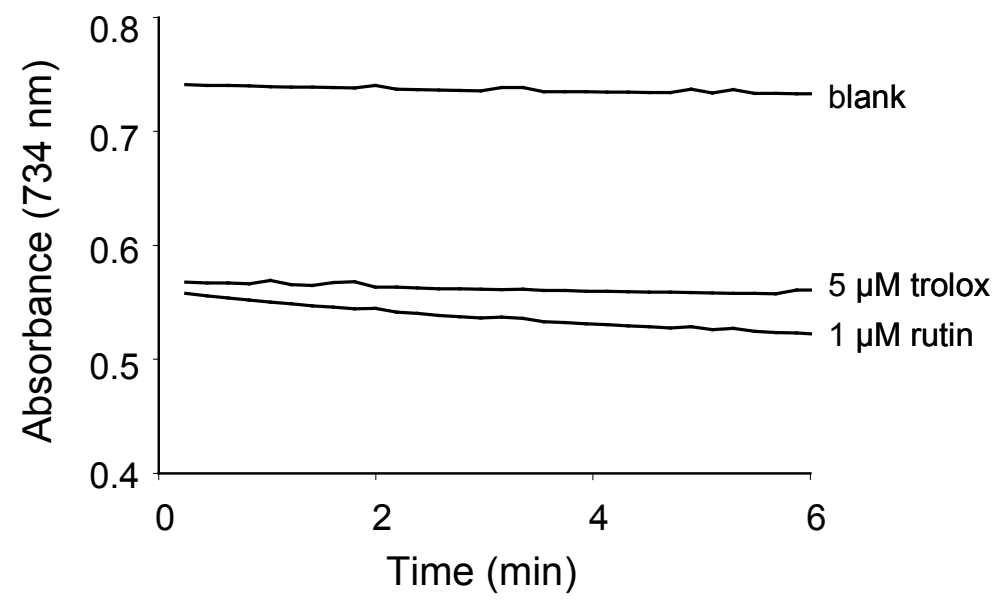

Fig. 1. Reaction of trolox and rutin with $A B T S^{\bullet}$. The absorbance at $734 \mathrm{~nm}$, due to $A B T S^{\bullet}$ is followed in time. The initial concentration of trolox and rutin are 5 and $1 \mu \mathrm{M}$, respectively.

Fig. 2 shows that an increase in the initial concentration of $\mathrm{ABTS}^{\bullet}$ results in a higher $\mathrm{ABTS}^{\bullet}$ consumption. This effect decreases at higher initial concentrations of ABTS $S^{\circ}$. The curve is fitted according to an exponential function. This fit gives the total amount of $A B T S^{\bullet}$ that can be scavenged by rutin at the concentration tested, i.e. " $C$ " in the formula described in Section 2. Regression analysis of the value of $C$, obtained at different concentrations of rutin, plotted versus the concentration of rutin (range 0.5 to $1.5 \mu \mathrm{M})$, showed a linear fit $(C=10.7 \times$ [Rutin]; $R=0.99)$. This gives a TEAC value of rutin of 5.66. For accurate results, the concentration of 
antioxidant used, has to give a value of $C$ between 2.5 and $25 \mu \mathrm{M}$. Table 1 shows the total antioxidant capacity values of several antioxidants according to this procedure.

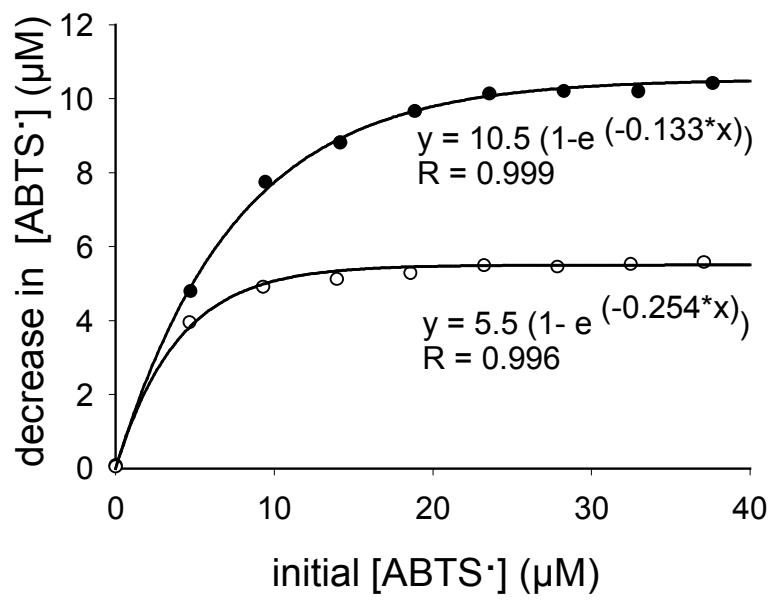

Fig. 2. Consumption of ABTS ${ }^{\bullet}$ by $0.5 \mu \mathrm{M}$ rutin (open symbols) or $1 \mu \mathrm{M}$ rutin (closed symbols) with a variable initial concentration of ABTS . The data were fitted with the exponential function as described in the material and method section. This gives a TEAC of rutin of $5.53(10.5 / 1.9)$ and $5.79(5.5 /(1.9 \times 0.5))$ from the data obtained with 1 and $0.5 \mu \mathrm{M}$, respectively.

Table 1. "New" and previously reported TEAC of several compounds.

\begin{tabular}{|c|c|c|}
\hline Compound & "new" TEAC & Previously reported TEAC \\
\hline \multirow[t]{5}{*}{ Quercetin } & $6.24 \pm 0.07$ & $3.10 \pm 0.05 \quad$ [Re et al., 1999] \\
\hline & & $4.43 \pm 0.02$ [Williamson et al., 1999 ] \\
\hline & & $4.72 \pm 0.10$ [Rice-Evans et al., 1996] \\
\hline & & $4.91 \pm 0.22 \quad$ [Miller et al., 1997$]^{11}$ \\
\hline & & $6.43 \pm 0.27 \quad$ [Van den Berg et al., 1999] \\
\hline \multirow[t]{2}{*}{ Rutin } & $5.66 \pm 0.14$ & $2.40 \pm 0.06$ [Rice-Evans et al., 1996] \\
\hline & & $2.75 \pm 0.05$ [Benavente-Garcia et al., 2000] ${ }^{12}$ \\
\hline Chrysin & $2.43 \pm 0.17$ & $1.43 \pm 0.07$ [Rice-Evans et al., 1996] \\
\hline \multirow[t]{2}{*}{ Catechol } & $1.42 \pm 0.11$ & $1.18 \pm 0.09$ \\
\hline & & $1.4 \pm 0.1$ \\
\hline \multirow[t]{2}{*}{ Resorcinol } & $2.60 \pm 0.20$ & $2.33 \pm 0.10$ \\
\hline & & $2.49 \pm 0.02$ \\
\hline
\end{tabular}

The "new" TEAC was determined according to the procedure determined in the present paper. Various concentrations of each antioxidant were tested and the TEAC is expressed as mean \pm SD. The concentration range was $0.2-0.5 \mu \mathrm{M}$ for quercetin, $0.5-1.5 \mu \mathrm{M}$ for rutin, 
1-5 $\mu \mathrm{M}$ for chrysin, 5-10 $\mu \mathrm{M}$ for catechol and 1-5 $\mu \mathrm{M}$ for resorcinol. The number of concentrations tested varied from 2 to 4 . The TEAC values appeared to be independent of the concentration. The previously reported TEAC values are taken from the indicated references. Various procedures and concentrations have been used. The values of catechol and resorcinol have been obtained in our laboratory using the procedure described by Van den Berg et al. [5] at a concentration of 10 and $5 \mu \mathrm{M}$ (first value) or 5 and $1 \mu \mathrm{M}$ (second value), respectively.

\section{Discussion}

The TEAC assay is widely applied to assess the total amount of radicals that can be scavenged by an antioxidant, i.e. the antioxidant capacity. TEAC values reported in the literature are variable. It appears that the TEAC value largely depends on the assay conditions [5]. The most important reason for this variation is that the reaction of an antioxidant with $\mathrm{ABTS}^{\circ}$ usually does not reach completion within the time span applied. This results in an underestimation of the actual TEAC.

Therefore, we adjusted the assay. In the procedure employed to assess the actual TEAC, the total amount of ABTS that can be scavenged by a certain amount of antioxidant, is calculated by extrapolating to conditions where the reaction between the antioxidant and $A B T S^{\circ}$ has reached completion, i.e. to an infinite excess of ABTS'.

The major limitation of this procedure is that the concentration range of the antioxidant, that can be used, is relatively small. A too high antioxidant concentration would need too much $\mathrm{ABTS}^{\circ}$, giving a too high absorbance for a reliable fit of the curve. A too low concentration of the antioxidant would result in a decrease in ABTS ${ }^{\circ}$ absorbance too low to be measured accurately. Since the antioxidant capacity of compounds varies, the concentration range of different compounds in this assay differs. In the procedure we employed, the maximum concentration of ABTS $^{\circ}$ was $45 \mu \mathrm{M}$, giving an absorbance of 0.7 . The minimal concentration of antioxidant in this assay that gives accurate results has to give at least $2.5 \mu \mathrm{M}$ reduction in the $\mathrm{ABTS}^{\circ}$ concentration; the maximal concentration of antioxidant in the assay has to give a maximal $25 \mu \mathrm{M}$ reduction in the $\mathrm{ABTS}^{\circ}$ concentration.

The total antioxidant capacity represents the sum of the antioxidant capacity of the parent compound and that of the oxidation product(s) of the parent compound [13]. The role of oxidation products of antioxidants that are formed, due to scavenging of reactive species, is becoming better understood. On the one hand, these oxidation products might be toxic [14], on the other hand, a residual antioxidant activity of these oxidation products might make a substantial contribution to the therapeutic effect of the parent compound [13]. Previous procedures to 
determine the total antioxidant capacity by the TEAC assay give an underestimation of the TEAC. The new procedure gives the actual total antioxidant capacity and includes the potential scavenging effect of oxidation products. 


\section{References}

1. Miller, N.J., C.A. Rice-Evans, M.J. Davies, V. Gopinathan and A. Milner (1993) A novel method for measuring antioxidant capacity and its application to monitoring the antioxidant status in premature neonates, Clin. Sci. 84, 407-412.

2. Lien, E.J., S. Ren, H.-H. Bui and R. Wang (1999) Quantitative structure-activity relationship analysis of phenolic antioxidants, Free Radical Biol. Med. 26, 285-294.

3. Plumb, G.W., K.R. Price and G. Williamson (1999) Antioxidant properties of flavonol glycosides from green beans, Redox Rep. 4, 123-127.

4. Rice-Evans, C.A., N.J.Miller and G. Paganga (1996) Structure-antioxidant activity relationships of flavonoids and phenolic acids, Free Radical Biol. Med. 20, 933-956.

5. Van den Berg, R., G.R.M.M. Haenen, H. van den Berg and A. Bast (1999) Applicability of an improved Trolox equivalent antioxidant capacity (TEAC) assay for evaluation of antioxidant capacity measurements of mixtures, Food Chem. 66, 511-517.

6. Re, R., N. Pellegrini, A. Proteggente, A. Pannala, M. Yang and C. Rice-Evans (1999) Antioxidant activity applying an improved ABTS radical cation decolorization assay, Free Radical Biol. Med. 26, 1231-1237.

7. Williamson, G., G.W. Plumb and M.T. Garcia-Conesa (1999) Glycosylation, esterification and polymerization of flavonoids and hydroxycinnamates: Effects on antioxidant properties, Basic Life Sci. 66, 483-494.

8. Van den Berg, R., G.R.M.M. Haenen, H. van den Berg, W. van der Vijgh and A. Bast (2000) The predictive value of the antioxidant capacity of structurally related flavonoids using the trolox equivalent antioxidant capacity (TEAC) assay, Food Chem. 70, 391-395. 9. Rezk, B.M., G.R.M.M. Haenen, W.J.F. van der Vijgh and A. Bast (2003) Tetrahydrofolate and 5-methyltetrahydrofolate are folates with high antioxidant activity. Identification of the antioxidant pharmacophore, FEBS Letters 555, 601-605.

10. Arts, M.J.T.J., G.R.M.M. Haenen, H.-P. Voss and A. Bast (2004) Antioxidant capacity of reaction products limits the applicability of the trolox equivalent antioxidant capacity (TEAC) assay, Food Chem. Toxicol. 42, 45-49.

11. Miller, N.J. and C.A. Rice-Evans (1997) Factors influencing the antioxidant activity determined by the ABTS+ Radical Cation Assay, Free Radical Res. 26, 195-199.

12. Benavente-Garcia, O., J. Castillo, J. Lorente, A. Ortuño and J.A. Del Rio (2000) Antioxidant activity of phenolics extracted from Olea europaea L. leaves, Food Chem. 68, 457-462.

13. Arts, M.J.T.J., J.S. Dallinga, H.-P. Voss, G.R.M.M. Haenen and A. Bast (2002) A critical appraisal of the use of the trolox equivalent antioxidant capacity (TEAC) assay in defining optimal antioxidant structures, Food Chem. 80, 409-414.

14. Bast, A. and G.R.M.M. Haenen (2002) The toxicity of antioxidants and their metabolites, Environm. Toxicol. Pharmacol. 11, 251-258. 



\section{Chapter 6}

\section{Masking of antioxidant capacity by the interaction of flavonoids with protein}

Mariken J. T. J. Arts

Guido R. M. M. Haenen

Hans-Peter Voss

Aalt Bast

Food and Chemical Toxicology 39, 787-791, 2001 


\begin{abstract}
The effect of antioxidants is often executed in complex biological mixtures where various interactions may take place. Therefore, the antioxidant capacity of antioxidants in blood plasma is examined. The assay used is the trolox equivalent antioxidant capacity (TEAC). This method gives the antioxidant capacity of a compound by measuring spectrophotometrically the disappearance of the blue/green stable ABTS [2,2'-azinobis-(3ethylbenzothiazoline-6-sulfonic acid)] radical (ABTS ), caused by scavenging. The results show that the antioxidant capacity of quercetin, rutin, catechin or 7-monohydroxyethylrutoside (monoHER) and blood plasma is not additive. This is partly due to interactions between the antioxidant and plasma proteins. However, the antioxidant capacity of $\alpha-$ tocopherol, which also binds to protein, is not affected by the interaction. This means that besides the antioxidant capacity of the compound itself, the environment in which the antioxidant has to execute its function is important.
\end{abstract}




\section{Introduction}

Free radicals can have a noxious effect on cells, and it is believed that free radical damage is involved in the etiology of several diseases. The radicals are a (by)product of various endogenous processes that can be stimulated by external factors, such as irradiation and xenobiotics [1]. Antioxidants protect against these radicals, and it is important to balance an enhanced radical production with a sufficient supply of antioxidants.

In their protection, the antioxidants form an intricate network [2]. Two antioxidants may interact, resulting in a synergistic effect. An example of such interplay is the co-operation between $\alpha$-tocopherol (vitamin E) and ascorbic acid (vitamin $\mathrm{C}$ ) in the inhibition of lipid peroxidation. In this case, vitamin $\mathrm{E}$ acts as the primary antioxidant, and subsequently the resulting vitamin $E$ radical reacts with vitamin $C$ to regenerate vitamin $E$ [3]. We also find antagonistic effects. For example, glutathione potentiates the pro-oxidant activity of vitamin $\mathrm{C}$ under certain circumstances [4]. A popular method used to evaluate an antioxidant is the trolox equivalent antioxidant capacity (TEAC) assay. In this assay the capacity of a compound to scavenge the stable ABTS [2,2'-azinobis-(3ethylbenzothiazoline-6-sulfonic acid)] radical (ABTS ${ }^{\circ}$ ) gives the antioxidant capacity [5,6]. The TEAC is used for evaluating the antioxidant capacity of both single compounds as well as antioxidant mixtures [7], for example blood plasma. Little is known about the effect of interactions between different ingredients in complex mixtures on the TEAC. In the present study this interaction was studied by adding antioxidants to plasma and assessing the antioxidant capacity of the mixture.

\section{Materials and methods}

\section{Chemicals}

ABTS and 6-hydroxy-2,5,7,8-tetramethylchroman-2-carboxylic acid (Trolox) were obtained from Aldrich Chemical Co. Bovine serum albumin (BSA fraction V), (+)-a-tocopherol, 3,3',4',5,7-pentahydroxy-flavone (quercetin), rutin and (+)-catechin were obtained from Sigma and potassium persulfate (di-potassium peroxydisulfate) and trichloroacetic acid (TCA) from Merck. 7-Monohydroxyethylrutoside (MonoHER) was a generous gift of Novartis (Nyon, Switzerland). All other chemicals were of analytical grade purity. 


\section{Blood plasma}

Human blood was collected in sterile tubes containing EDTA. Plasma was then isolated immediately by centrifugation at $1000 \mathrm{~g}\left(5 \mathrm{~min}\right.$ at $\left.4^{\circ} \mathrm{C}\right)$ and stored at $-80^{\circ} \mathrm{C}$. Deproteinating the plasma was done by adding an equal volume of $10 \%$ TCA followed by centrifugation at $1000 \mathrm{~g} \mathrm{(5} \mathrm{min} \mathrm{at}$ $\left.4^{\circ} \mathrm{C}\right)$.

\section{TEAC assay}

The TEAC assay described by Re et al. [5] (1998) was used with minor modifications. The TEAC assay assesses the total radical scavenging capacity based on the ability of a compound to scavenge the stable ABTS radical. The absorbance of this blue/green radical, produced through the reaction between ABTS and potassium persulfate, was spectrophotometrically determined at $734 \mathrm{~nm}$. The ABTS solution was diluted with PBS, pH 7.4, to a final absorbance of the control of 0.70 $( \pm 0.02)$ at $734 \mathrm{~nm}$ at $37^{\circ} \mathrm{C}$. Adding antioxidants to this radical solution gives a decolorization by scavenging the radical. The degree of the decolorization gives the antioxidants capacity. TEAC values were calculated by dividing the antioxidant-induced reduction in absorbance of the $\mathrm{ABTS}^{\circ}$ solution by the trolox-induced reduction in absorbance of the ABTS solution $(0.0257 \mu \mathrm{M} / \mathrm{cm})$.

The masking is defined as the relative difference between the measured increase in antioxidant capacity due to addition of an antioxidant compared to the calculated increase based on an additive effect at $t=30$ $\min$.

Stock solutions of a-tocopherol, trolox, quercetin, monoHER, rutin and catechin were prepared in ethanol. BSA was dissolved in Milli-Q water. Ten microliters of an antioxidant containing solution and $10 \mu \mathrm{l}$ plasma or $10 \mu \mathrm{l}$ albumin solution was added to PBS (final volume $500 \mu \mathrm{l}$ ) and incubated for $10 \mathrm{~min}$ at $37^{\circ} \mathrm{C}$. For the determination of the antioxidant capacity, $500 \mu \mathrm{lBTS} \mathrm{AB}^{\circ}$ solution was added. Immediately after mixing the compounds, the absorbance was measured in time. Experiments were performed on a Perkin-Elmer spectrophotometer with cell changer fitted with Peltier temperature control.

\section{Results and discussion}

Blood plasma itself has a large antioxidant capacity (at $\mathrm{t}=80 \mathrm{~min} 2000$ times diluted plasma has a TEAC of $10 \mu \mathrm{M}$ ) because it contains a high concentration of various radical scavengers [7]. Plasma appears to 


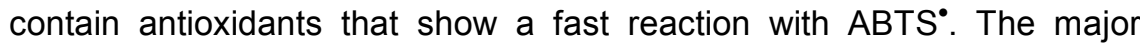
antioxidant capacity, however, is due to a relatively slow reaction with the ABTS

Fig. 1(A) shows the effect of the addition of $\alpha$-tocopherol, a lipophilic antioxidant that shows a fast reaction with ABTS $^{\circ}$, on the total antioxidant capacity. After addition of $\alpha$-tocopherol to plasma, the total capacity is enhanced with the capacity of $\alpha$-tocopherol, which means the effect of $\alpha$ tocopherol addition is additive.
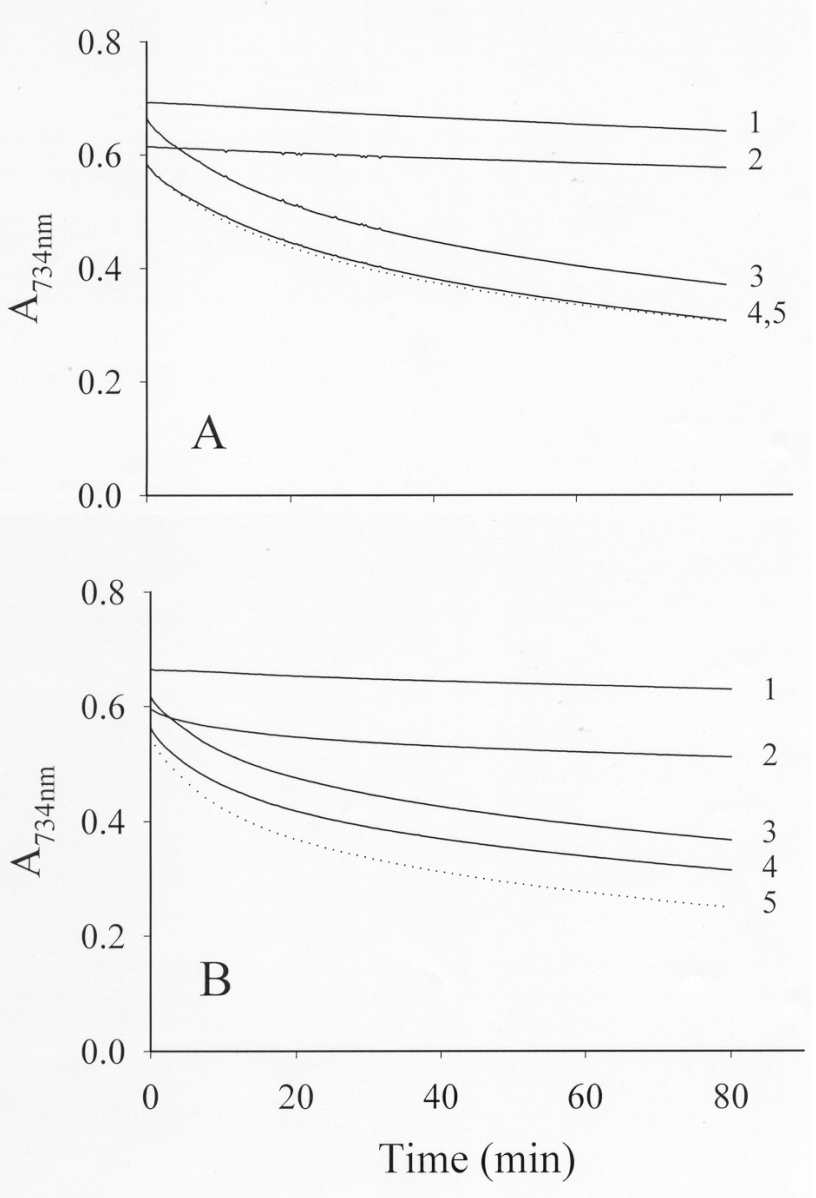

Fig. 1. Effect of (A) $\alpha$-tocopherol and (B) quercetin on the antioxidant capacity of plasma. The reduction of the ABTS concentration expressed as the decrease in absorbance at 734 $\mathrm{nm}$ is followed in time. The curves are: 1 , blank; 2 , antioxidant [either a-tocopherol (5 $\mu \mathrm{M})$ or quercetin $(0.5 \mu \mathrm{M})$ ]; 3 , plasma (2000 times diluted); 4, plasma spiked with antioxidant; 5 , (dotted) calculated value obtained by counting the effect of plasma and antioxidant. 
Fig. 1(B) shows the effect of quercetin on the antioxidant capacity of plasma. Quercetin itself first shows a fast reaction and subsequently a slow reaction with the $\mathrm{ABTS}^{\circ}$, as also reported previously [6]. It is observed that the antioxidant capacity of the plasma is enhanced after addition of quercetin, but the increase is much smaller than the antioxidant capacity that quercetin itself has. This means that a part of the antioxidant capacity is masked. A comparable masking as for quercetin was found for other flavonoids such as rutin, catechin and monoHER (Fig. 2).

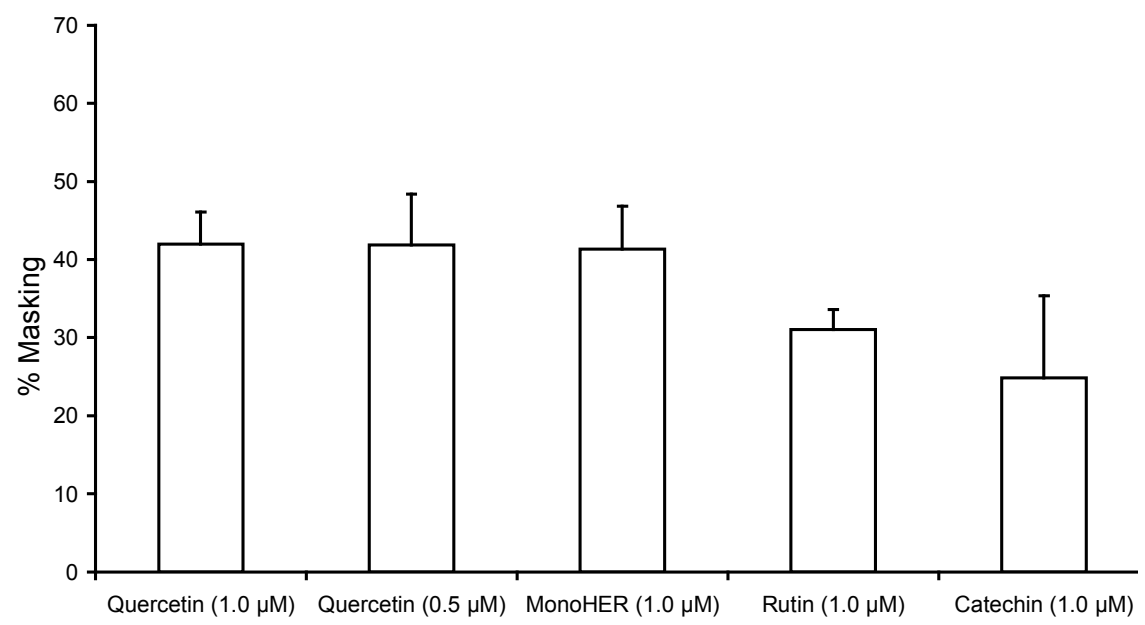

Fig. 2. Masking, the procentual difference between the measured increase in antioxidant capacity due to addition of an antioxidant compared to the calculated increase based on an additive effect, at $\mathrm{t}=30 \mathrm{~min}$ after the addition of various flavonoids to plasma (2000x diluted). Quercetin is tested in a final concentration of 1.0 or $0.5 \mu \mathrm{M}$. The other flavonoids are all tested in final concentrations of $1.0 \mu \mathrm{M}$. The data are expressed as mean \pm S.E.M. of at least triplicate determinations.

Interactions between (poly)phenols and proteins have been described [812]. Little is known about the influence these interactions might have on the antioxidant capacity. To determine whether this masking is caused by interactions with plasma proteins, the experiment with $\alpha$-tocopherol and quercetin with deproteinated plasma was repeated (Fig. 3A,B). The antioxidant capacity of blood plasma is drastically reduced by deproteination (400 times diluted deproteinated plasma has a TEAC of 6 $\mu \mathrm{M})$. 

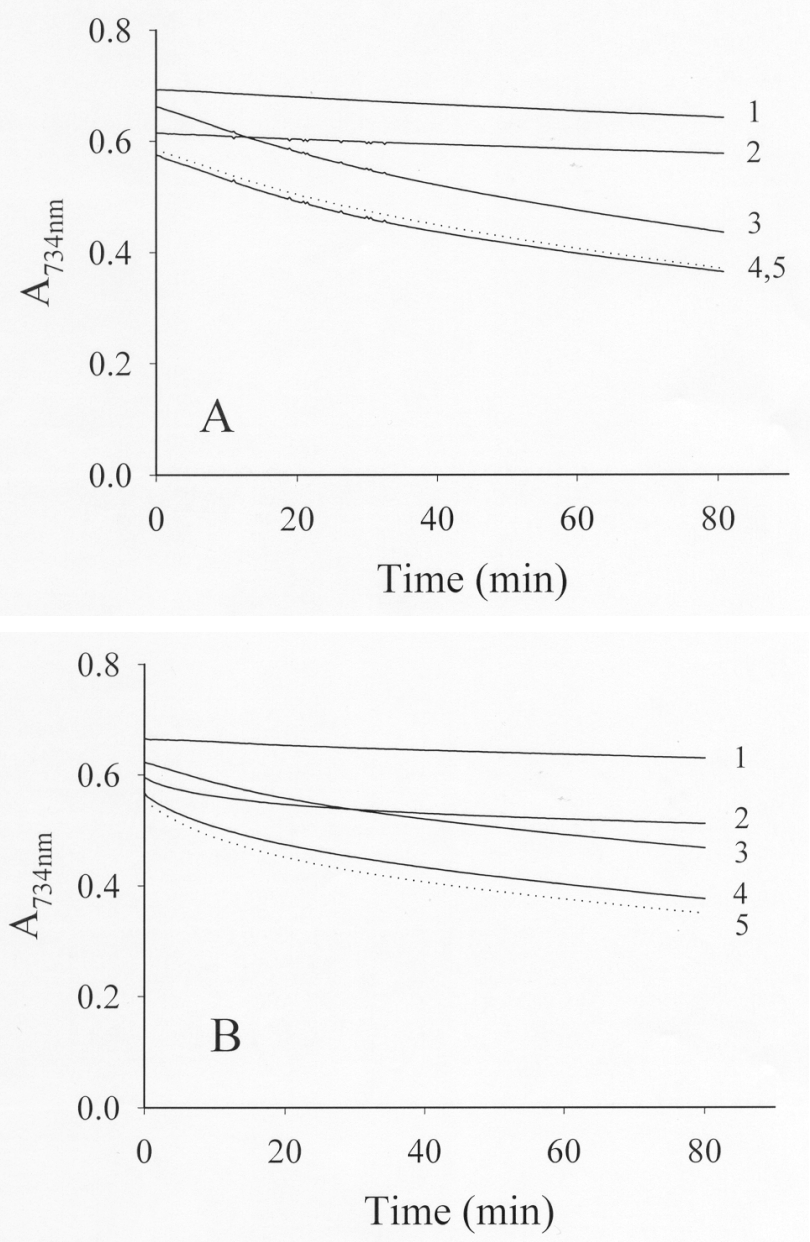

Fig. 3. Effect of (A) $\alpha$-tocopherol $(5 \mu \mathrm{M})$ and (B) quercetin $(0.5 \mu \mathrm{M})$ on the antioxidant capacity of deproteinated plasma. The reduction of the ABTS ${ }^{*}$ concentration expressed as the absorbance at $734 \mathrm{~nm}$ is followed in time. The conditions are as in Fig. 1 with the only difference that deproteinated plasma (400 times diluted) was used.

The addition of a-tocopherol to deproteinated plasma, as shown in Fig. $3 \mathrm{~A}$, remains additive, that is, the calculated antioxidant capacity of the mixture is identical to the observed antioxidant capacity. Addition of quercetin (Fig. 3B) also increased the antioxidant capacity. As was also observed in normal plasma, this increase is smaller than the capacity of quercetin itself. So even in deproteinated plasma, a part of the antioxidant effect is masked. The masking is, however, much smaller in 
deproteinated plasma than in normal plasma (Fig. 1B). This demonstrates that a large part of the masking in normal plasma is caused by interaction of quercetin with protein.

The most abundant protein in blood plasma is albumin. Albumin binds many endogenous and exogenous compounds. This protein, which itself possesses antioxidant capacity, is present in human plasma in concentrations of 35-50 g/l. Fig. 4 shows that a combination of albumin and quercetin results in masking. This masking also occurred with catechin, monoHER and rutin (Fig. 5).

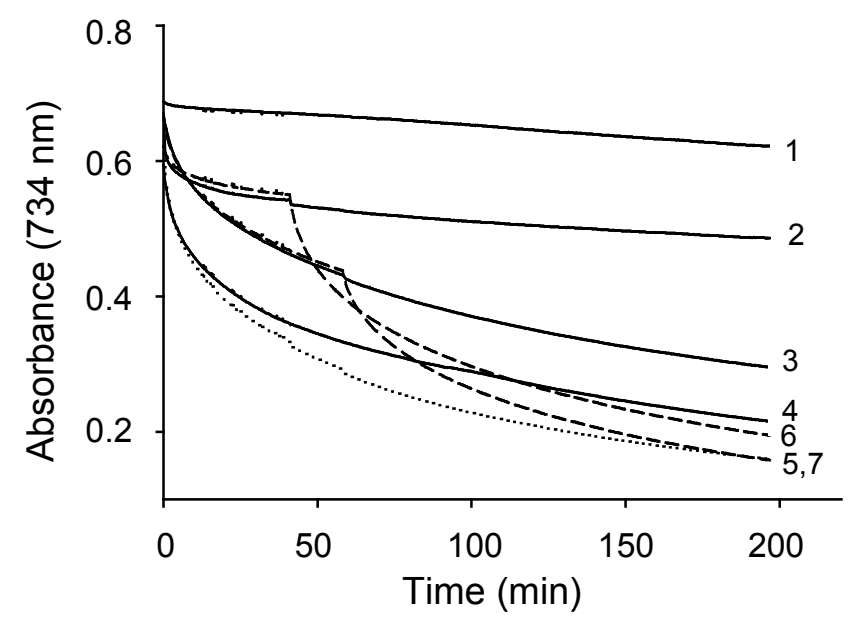

Fig. 4. Effect of quercetin on the antioxidant capacity of bovine serum albumin (BSA). The reduction of the $\mathrm{ABTS}^{\bullet}$ concentration expressed as the absorbance at $734 \mathrm{~nm}$ is followed in time. The curves are: 1 , blank; 2 , quercetin $(0.5 \mu \mathrm{M}) ; 3$, albumin $(0.05 \mathrm{mg} / \mathrm{ml}) ; 4$, albumin spiked with quercetin; 5 , (dotted) calculated value obtained by counting the effect of albumin and quercetin; 6 , quercetin with albumin added at $t=45 \mathrm{~min} ; 7$, albumin with quercetin added at $\mathrm{t}=60 \mathrm{~min}$.

When one compound was allowed to react with $\mathrm{ABTS}$ and subsequently the other compound was added, the masking was reduced (Fig. 4). This indicates that binding is involved in the masking. To further assess the role of protein binding in plasma, plasma was deproteinated first. Quercetin or a-tocopherol was added and subsequently the spiked plasma was deproteinated. Surprisingly, the time course of ABTS decolorization by deproteinated plasma spiked with either quercetin or $\alpha$ tocopherol was identical to the decolorization by deproteinated normal plasma. The most plausible explanation for this lack of effect of either quercetin or a-tocopherol is that both antioxidants bind to protein and coprecipitate during deproteination. TCA was found not to influence the 
antioxidant capacity of quercetin and $\alpha$-tocopherol (data not shown). So both $\alpha$-tocopherol and quercetin bind to plasma proteins. In the case of $\alpha$ tocopherol, this interaction has no effect on the antioxidant capacity. In the case of quercetin, a major part of the antioxidant capacity is masked. Other interactions also take place because in deproteinated plasma spiked with quercetin, substantial masking was still observed. Interactions between (poly)phenols and amino acids or polysaccharides have been described [9], and these interactions might also influence the antioxidant capacity.

Based on our results, it can be concluded that the major part of the masking flavonoids tested is due to binding of the flavonoid to protein. In our experiments we used a relatively low concentration of plasma (2000 times diluted) and a relatively high concentration of flavonoid. These conditions were based on the antioxidant effect found in the TEAC assay. The relative masking of $0.5 \mu \mathrm{M}$ quercetin was identical to that of $1 \mu \mathrm{M}$ quercetin (Fig. 2 and Fig. 5).

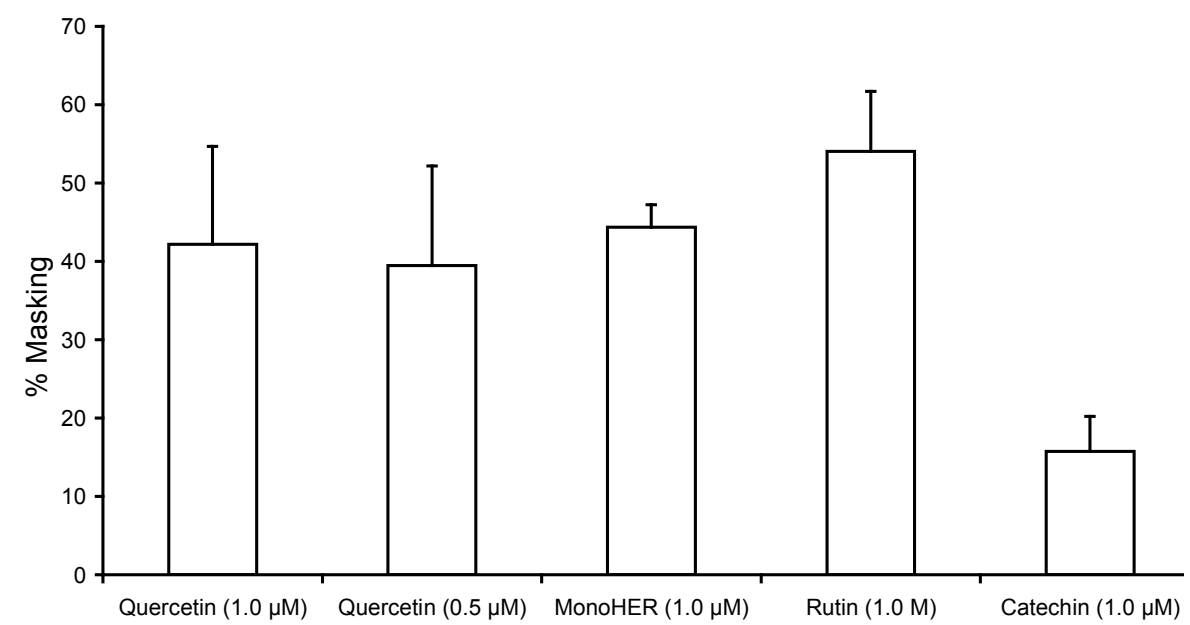

Fig. 5. Masking, the relative difference between the measured increase in antioxidant capacity due to addition of an antioxidant compared to the calculated increase based on an additive effect, at $t=30 \mathrm{~min}$ after the addition of various flavonoids to albumin (final concentration $0.05 \mathrm{mg} / \mathrm{ml}$ ). Quercetin has final concentrations of 1.0 and $0.5 \mu \mathrm{M}$. The other flavonoids all have final concentrations of $1.0 \mu$. The data are the means \pm S.E.M. of triplicate determinations.

The masking of lower concentrations of quercetin could not be evaluated due to the relatively low antioxidant capacity of quercetin in this concentration compared to that of the diluted plasma, resulting in too much imprecision of the results obtained. Decreasing the concentration of 
flavonoids or increasing the concentration of the protein will not reduce the fraction of flavonoid bound and thus not reduce the masking. Therefore we expect that at higher protein concentration or at lower flavonoid concentration the masking is at least the same; however, this cannot be demonstrated by the TEAC assay.

Romay et al. tested the effect of adding antioxidants on the antioxidant capacity of serum and albumin [13]. In this study, it was concluded that the contribution of different antioxidants is additive. The masking of the antioxidant capacity by the interaction of flavonoids with protein, found in the present study, demonstrates that this general statement is incorrect.

Smith et al. also found that binding of phenolic compounds, such as quercetin, fisetin, myricetin and morin, to albumin can influence their activity [12]. Instead of the antioxidant activity, they examined the prooxidant activity, which is also reduced by the interaction with albumin.

A practical implication for the masking can be found in clinical studies. We recently performed a clinical study in which a preparation containing $2 \mathrm{~g}$ of flavonoids (Venoruton Forte; Zyma, Nyon, Switzerland) such as quercetin, rutin and monoHER was administered to seven healthy male volunteers. A problem we envisaged was the expected low bioavailability of the flavonoid and the formation of unknown metabolites that might have antioxidant activity. Therefore we used the TEAC assay to aselectively detect the efficacy of the flavonoid containing preparation on the antioxidant capacity. We found that no significant increase in antioxidant level in the plasma occurred due to the flavonoid intake [TEAC just before administration: $3.79 \mathrm{mM} \pm 0.123$, TEAC $2 \mathrm{~h}$ after administration: $4.00 \pm 0.134$ (average \pm S.E.M.)]. Taking the data from the present study into consideration, the effect of absorbed antioxidants may have been masked. It is therefore not correct to use the TEAC assay for evaluating the effect of the flavonoid containing preparation.

Recently, Boyle et al. also reported that both a single dose (500 mg rutin) as well as prolonged supplementation of a flavonoid (daily $500 \mathrm{mg}$ rutin for 6 weeks) did not result in a detectable effect on the antioxidant capacity in plasma of female volunteers [14]. Beside a possible low bioavailability, masking may also have played an important role in this study. Based on the results presented in our study, we may conclude that, except for the antioxidant capacity of a compound itself, the matrix in which the antioxidant has to execute its job is important. 


\section{References}

1. Halliwell, B. and J.M.C. Gutteridge (1989). In: B. Halliwell, J.M.C. Gutteridge. Free Radicals in Biology and Medicine, 2nd Edition. Clarendon Press, Oxford.

2. Bast, A., G.R.M.M. Haenen and C.J.A. Doelman (1991) Oxidants and antioxidants: state of the art, Am. J. Med. 91, 3C-2S-13S.

3. Packer, J.E., T.F. Slater and R.L. Willson (1979) Direct observation of a free radical interaction between vitamin $\mathrm{E}$ and vitamin C, Nature 278,737-738.

4. Haenen, G.R.M.M. and A. Bast (1983) Protection against microsomal lipid peroxidation by a glutathione dependent heat labile factor, FEBS Letters 159, 24-28.

5. Re, R., N. Pellegrini, A. Proteggente, A. Pannala, M. Yang and C. Rice-Evans (1998) Antioxidant activity applying an improved ABTS radical cation decolorization assay, Free Radical Biol. Med. 26, 1231-1237.

6. Van den Berg, R., G.R.M.M. Haenen, H. van den Berg and A. Bast (1999) Applicability of an improved TEAC assay for evaluation of antioxidant capacity measurements of mixtures, Food Chem. 66, 511-517.

7. Rice-Evans, C. and N. Miller (1997) Measurement of the antioxidant status of dietary constituents, low density lipoproteins and plasma, Prostagl. Leukotr. Essential Fatty Acids 75, 499-505.

8. Haslam, E. (1974) Polyphenol-protein interactions, Biochem. J. 139, 285-288.

9. Haslam, E. (1989) Plant Polyphenols. Vegetable Tannins Revisited, Cambridge University Press, Cambridge.

10. Haslam, E. (1996) Natural polyphenols (vegetable tannins) as drugs: possible modes of action, J. Nat. Prod. 59, 205-215.

11. Luck, G., H. Liao, J. Murray, H. Grimmer, E. Warminski, M. Williamson, H. Lilley and E. Haslam (1994) Polyphenols, astringency and proline-rich proteins, Phytochem. 37, 357371.

12. Smith, C., B. Halliwell and O. Aruoma (1992) Protection by albumin against the prooxidant actions of phenolic dietary components, Food Chem. Toxicol. 30, 483-489.

13. Romay, C., C. Pascual and E. Lissi (1996) The reaction between ABTS radical cation and antioxidants and its use to evaluate the antioxidant status of serum samples Braz. $J$. Med. Biol. Res. 29, 175-183.

14. Boyle, S.P., V.L. Dobson, S.J. Duthie, D.C. Hinselwood, J.A.M. Kyle and A.R. Collins (2000) Bioavailability and efficiency of rutin as an antioxidant: a human supplementation study, Eur. J. Clin. Nutr. 54, 774-782. 



\title{
Chapter 7
}

\section{Interactions between flavonoids and proteins: Effect on the total antioxidant capacity}

\author{
Mariken J. T. J. Arts \\ Guido R. M. M. Haenen \\ Lonneke C. Wilms \\ Sasja A. J. N. Beetstra \\ Chantal G. M. Heijnen \\ Hans-Peter Voss \\ Aalt Bast
}

Journal of Agricultural and Food Chemistry 50, 1184-1187, 2002 


\begin{abstract}
Flavonoids are potent antioxidants. It is also known that flavonoids bind to proteins. The effect of the interaction between tea flavonoids and proteins on the antioxidant capacity was examined. Their separate and combined antioxidant capacities were measured with the Trolox equivalent antioxidant capacity (TEAC) assay. It was observed that the antioxidant capacity of several components of green and black tea with $\alpha-, \beta$-, and $\mathrm{k}$-casein or albumin is not additive; that is, a part of the total antioxidant capacity is masked by the interaction. This masking depends on both the protein and the flavonoid used. Components in green and black tea, which show the highest masking in combination with $\beta$-casein, are epigallocatechin gallate and gallic acid. The results demonstrate that the matrix influences the efficacy of an antioxidant.
\end{abstract}




\section{Introduction}

The intake of flavonoids has been associated with lower incidence of various diseases such as cancer, stroke, and cardiovascular diseases [13]. The positive health effects of these secondary plant metabolites are probably related to their strong antioxidative properties $[4,5]$. Tea, the second most commonly consumed beverage in the world after water, is rich in flavonoids [6]. Tea is produced predominantly in two forms, both originating from Camellia sinensis: green tea, which is prepared from the fresh tea leaf and contains mainly catechins, and black tea, which contains mainly thearubigins and theaflavins due to an extra enzymatic oxidation step during manufacturing [7].

The way tea is consumed varies among populations. In the United Kingdom, Ireland, and Canada tea is consumed with a substantial amount of milk in it [8]. Milk contains various proteins, and interactions between polyphenols and proteins have been reported $[9,10]$. The question arises as to what the effect of such an interaction on the antioxidant capacity is. The aim of the present study is to determine the effect of the interaction between flavonoids and proteins on the total antioxidant capacity [Trolox equivalent antioxidant capacity (TEAC)].

\section{Materials and Methods}

\section{Chemicals}

2,2'-Azinobis(3-ethylbenzothiazoline-6-sulfonic acid) (ABTS), 6-hydroxy2,5,7,8-tetramethylchroman-2-carboxylic acid (Trolox), bovine serum albumin (BSA fraction $V$ ), and $\alpha-, \beta-$, and $k$-casein (from bovine milk) were obtained from Sigma. The tea and tea fractions were gifts from Lipton (Englewood Cliffs, NJ) except epicatechin, which was from Aldrich (Zwijndrecht, The Netherlands). All other chemicals were of analytical grade purity.

\section{TEAC assay}

To measure the antioxidant capacity, the TEAC assay, described by $\operatorname{Re}$ et al. (11), has been used with minor modifications. This method is based on the reaction of the blue/green stable ABTS radical (ABTS $)$, which is formed through the reaction between $A B T S$ and $\mathrm{K}_{2} \mathrm{O}_{8} \mathrm{~S}_{2}$, with antioxidants. In the reaction with an antioxidant, the blue/green color disappears because the ABTS ${ }^{\bullet}$ reacts with the antioxidant. This decolorization is determined spectrophotometrically at $734 \mathrm{~nm}$ after 30 
$\min$. The reduction in absorbance is related to that of Trolox, a synthetic, hydrophilic vitamin $E$ analogue, which gives the TEAC value. The TEAC is calculated as moles of Trolox equivalents per gram of solid. The relative contribution of an ingredient to the TEAC of tea is calculated from the TEAC of this ingredient multiplied by its relative content $(\% \mathrm{w} / \mathrm{w})$ and divided by the TEAC of tea.

Masking of total antioxidant capacity is, as in Arts et al. [10], defined as percent difference between the measured increase in antioxidant capacity due to addition of an antioxidant compared to the calculated increase based on an additive effect at $t=30 \mathrm{~min}$.

Stock solutions of all tea components and Trolox were prepared in ethanol. BSA and the caseins were dissolved in Milli-Q water. The antioxidant and the protein were added to phosphate-buffered saline [(PBS), a $0.01 \mathrm{M}$ phosphate buffer, $\mathrm{pH} 7.4$, containing $154 \mathrm{mM} \mathrm{NaCl}$ ] buffer and incubated for $10 \mathrm{~min}$ at $37^{\circ} \mathrm{C}$. For the determination of the antioxidant capacity, a concentrated $\mathrm{ABTS}^{\circ}$ solution was added, resulting in an absorbance of the blank between 0.68 and 0.72 . Immediately after the addition of the ABTS solution to the incubation mixture, the absorbance was followed in time. Experiments were performed on a Perkin-Elmer spectrophotometer with cell changer fitted with Peltier temperature control. The final concentration of tea and tea components was $1 \mu \mathrm{g} / \mathrm{mL}$ for green tea and the mixed theaflavins and $0.75 \mu \mathrm{g} / \mathrm{mL}$ for black tea. The final concentration of the proteins $(\alpha, \beta$, and $k$-casein and albumin) was $25 \mu \mathrm{g} / \mathrm{mL}$. The results are expressed as mean \pm SD.

\section{Proline ratio}

The amino acid sequences of the different caseins are presented in the Swissprot database [by the Swiss Institute of Bioinformatics (SIB) and the European Bioinformatics Institute (EBI), Switserland]. The proline ratio of a protein was calculated by dividing the total number of proline groups by the total number of amino acids of the protein.

\section{Results}

The composition of the freeze-dried green and black tea extracts used in this study is given in Figure 1. In the production of black tea, most catechins are oxidized, giving other types of polyphenols such as theaflavins and thearubigins [7]. Therefore, the catechin content of green tea is higher than that of black tea. The oxidation is probably also the reason for the higher antioxidant capacity $(7.3 \mathrm{mmol}$ of TEAC/g of freeze- 
dried tea) of green tea compared to black tea $(5.8 \mathrm{mmol}$ of TEAC/g of freeze-dried tea).
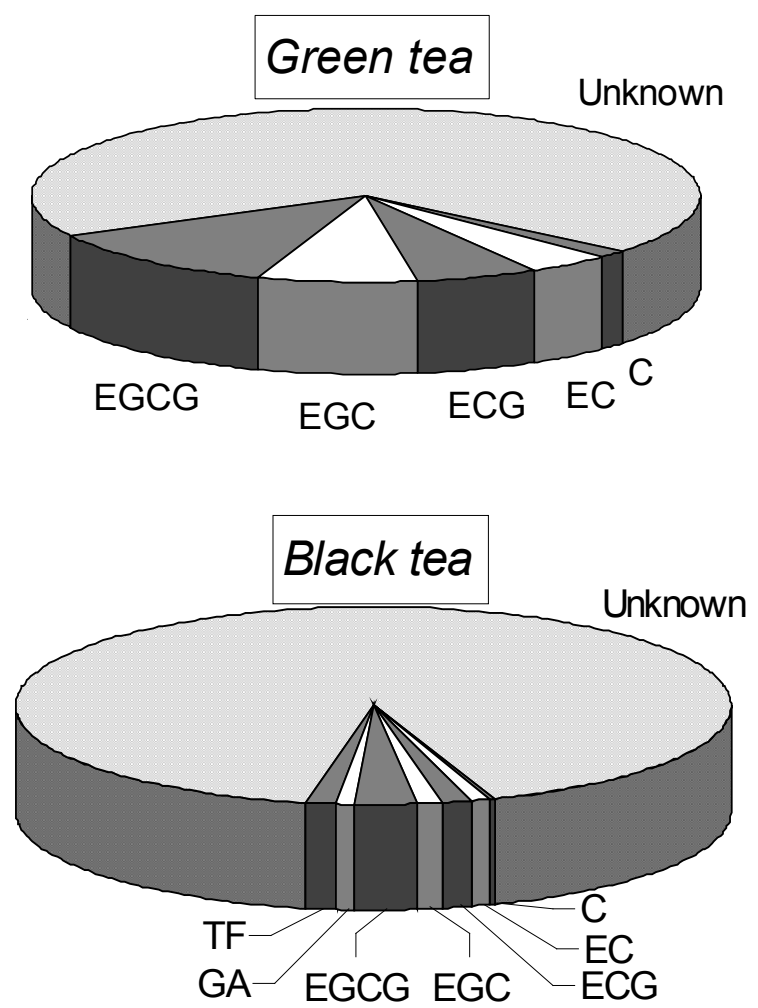

Fig. 1. Relative content of several ingredients in green and black tea. The values, expressed as percentage (w/w) in, respectively, green and black tea, are as follows: catechin (C), 1.3 and $0.3 \%$; epicatechin (EC), 4.2 and $0.8 \%$; epicatechin gallate (ECG), 5.8 and 1.4\%; epigallocatechin (EGC), 7.9 and 1.2\%; epigallocatechin gallate (EGCG), 11.8 and $2.8 \%$; gallic acid (GA), $0.2 \%$ (not shown) and $0.8 \%$. The theaflavin (TF) content of black tea is $1.2 \%$, whereas this type of compound is not present in green tea.

Figure 2 shows the relative contribution of several ingredients to the TEAC values of green and black tea. It can be calculated that the antioxidant capacity of green tea is $93 \%$ due to catechins. Other tea components that make up $69 \%$ of the total weight hardly contribute to the antioxidant capacity $(7 \%)$. In black tea, only a small part of the antioxidant capacity is due to catechins (34\%). The other tea components in black tea, which make up $91.5 \%$ of the total weight, have a much higher 
contribution to the TEAC value $(66 \%)$ than they have in green tea. Probably tannins, polymers of oxidized polyphenols [9], have a significant contribution to the antioxidant capacity of black tea. These tannins are not present in green tea. The relative contribution of the various components of green tea on the total antioxidant capacity is in accordance with the results previously reported by Rice-Evans [12].
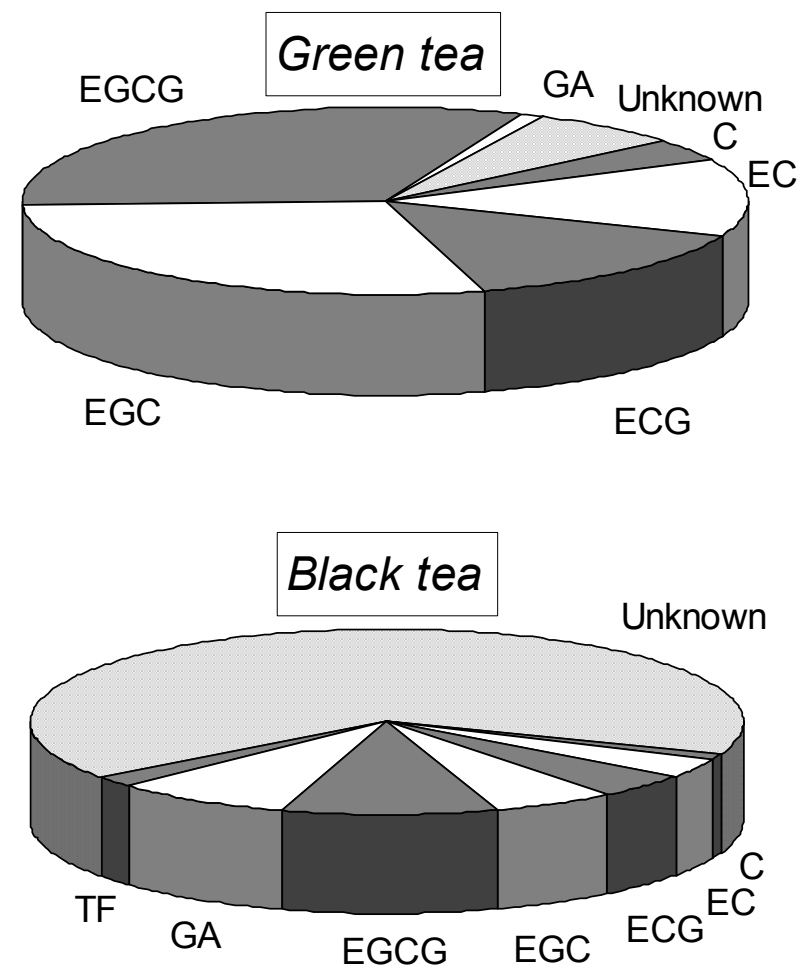

Fig. 2. Relative contribution of the polyphenols to the TEAC of green and black tea. The values are as follows: catechin (C), 3.9 and 1.2\%; epicatechin (EC), 13.4 and $3.2 \%$; epicatechin gallate (ECG), 14.5 and $4.5 \%$; epigallocatechin (EGC), 28.8 and $5.6 \%$; epigallocatechin gallate (EGCG), 31.6 and $9.6 \%$; gallic acid (GA), 1.2 and $8.0 \%$. Theaflavins (TF) contribute $2.0 \%$ to the TEAC black tea. TEAC values of green and black tea are 7.3 and $5.8 \mathrm{mmol}$ of $\mathrm{TEAC} / \mathrm{g}$, respectively.

The effect of the interaction between flavonoids and proteins on the total antioxidant capacity was examined. It was observed that addition of catechin to $\beta$-casein increases the antioxidant capacity of the $\beta$-casein solution, but the increase is smaller than the antioxidant capacity of 
catechin itself. Twenty percent of the antioxidant capacity was masked (Figure 3).

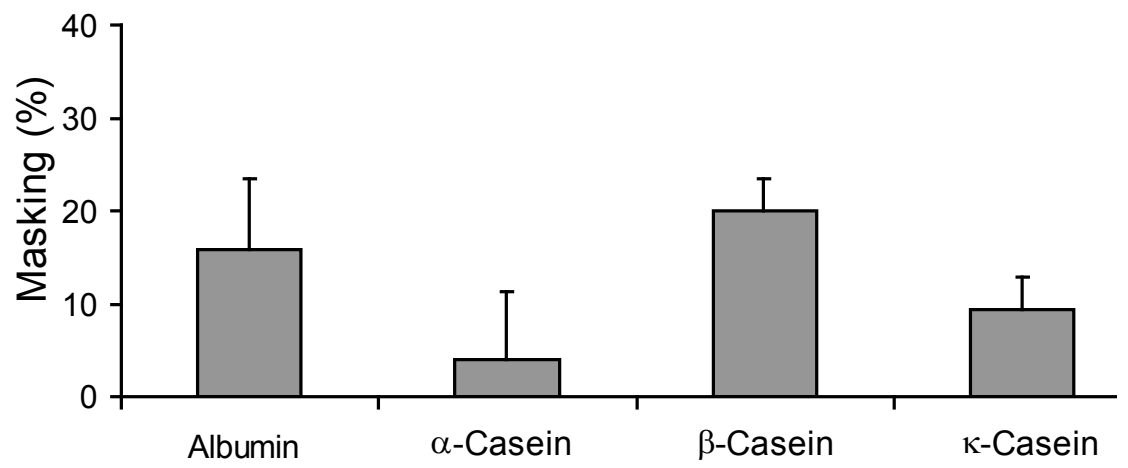

Fig. 3. Masking of the antioxidant capacity of catechin with different proteins.

This masking has been determined for four different proteins in combination with catechin (Figure 3). The masking of the antioxidant capacity of catechin was most pronounced with albumin $(21.1 \pm 4.1 \%)$ and $\beta$-casein $(20.0 \pm 3.5 \%)$, whereas the masking with $\alpha$ - and $k$-casein was less. The high masking observed with $\beta$-casein compared to $\alpha$ - and $\mathrm{K}$-casein can be explained by the relatively large amount of proline groups in the protein. Proline groups have a strong affinity for the hydroxyl groups of catechin [13]. $\beta$-Casein, which consists of 224 amino acids of which 35 are prolines, has a proline ratio of 0.156 . The proline ratios of $\alpha$-casein and $k$-casein are 0.075 and 0.105 , respectively. The rank order of masking observed with these three proteins is identical to the rank order of the proline ratio of the proteins, indicating that the proline groups are indeed involved in the masking.

Masking not only depends on the protein, it also greatly depends on the flavonoid (Figure 4). Different tea components display different extents of masking with $\beta$-casein. A gallate group coupled to the flavonoid on position 3 increases the extent of masking (epicatechin gallate, $30.0 \pm$ $2.3 \%$ ); however, a 5'-OH group, converting ring B into a pyragollol group similar to that in gallate, decreases the extent of masking (epigallocatechin, $8.8 \pm 2.6 \%$ ). In epigallocatechin gallate, containing both a gallate group at position 3 and a pyragollol group in ring $B$, the opposite effect of both structural modifications appears to level out. The masking of the antioxidant capacity of green and black tea by $\beta$-casein is, respectively, $14.1 \pm 2.6$ and $31.4 \pm 2.1 \%$. 


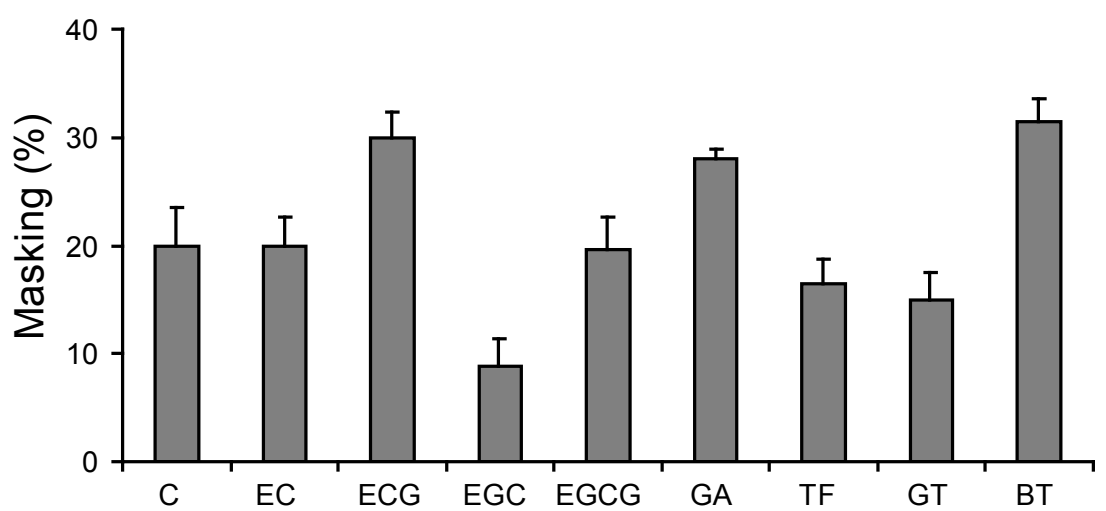

Fig.4. Masking of tea and several tea fractions with $\beta$-casein. Tea components examined are catechin (C), epicatechin (EC), epicatechin gallate (ECG), epigallocatechin (EGC), epigallocatechin gallate (EGCG), gallic acid (GA), theaflavins (TF), green tea (GT) and black tea (BT).

The relative contributions to the masking of green and black tea by the interaction of different tea components with $\beta$-casein can be calculated on the basis of the relative abundance of the components and their masking (Figure 5). Possible synergistic or antagonistic interactions between the components that may occur are not incorporated in this estimation. The masking of green tea can for almost $80 \%$ be explained by the masking of catechins in the tea. In black tea these catechins play a much smaller role $(16 \%)$. In green tea almost half of the masking is due to epigallocatechin gallate and epicatechin gallate. In black tea gallic acid has the highest contribution of the compounds that were examined.
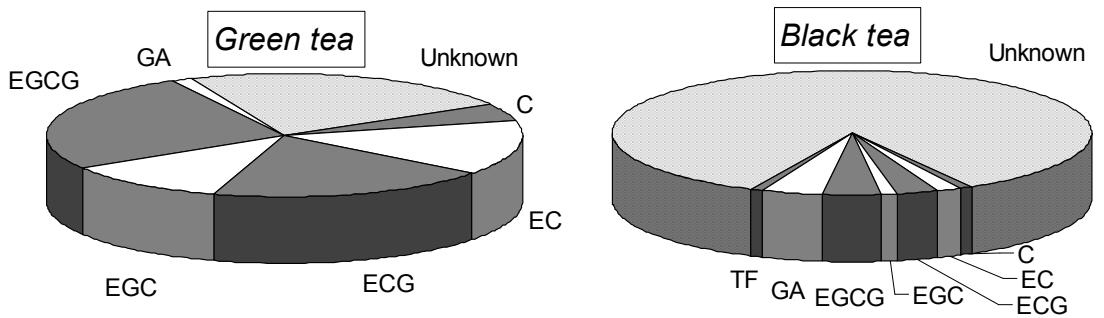

Fig. 5. Relative contribution of the polyphenols to the masking of green and black tea with $\beta$-casein. The values are as follows: catechin (C), 4.5 and $0.7 \%$; epicatechin (EC), 14.5 and 1.7\%; epicatechin gallate (ECG), 19.1 and 2.9\%; epigallocatechin (EGC), 11.4 and $1.1 \%$; epigallocatechin gallate (EGCG), 26.2 and $4.0 \%$; gallic acid (GA), 1.2 and $4.2 \%$. The contribution of theaflavins (TF) to the masking of black tea is $0.6 \%$. 


\section{Discussion}

The aim of the present study is to determine the effect of the interaction between flavonoids and proteins on the total antioxidant capacity. It was found that the antioxidant capacity of a mixture of flavonoids and proteins is less than the sum of the antioxidant capacity of flavonoid and protein separately. The degree of this masking depends on both the type of polyphenol and the type of protein.

The result of this masking is in the first place that the antioxidants do not reach their optimum scavenging capacity in the matrix. For example, addition of milk to tea is expected to reduce the antioxidant capacity of the antioxidants present in tea. This might also occur in other products containing both polyphenols and proteins. The decreased antioxidant capacity is expected to result in a faster oxidation of the product.

Another consequence of the interaction with proteins might be a decreased bioavailability of the antioxidants. The interaction, resulting in protein-polyphenol complexes, can be both reversible and irreversible depending on $\mathrm{pH}$, temperature, and protein and flavonoid concentrations [13]. The fate of these complexes in the gastrointestinal tract is not known. Serafini et al. found that addition of milk to black tea abolishes the increase of the antioxidant potential observed when tea is consumed without milk [14]. However, other studies show no or no relevant effect of proteins on the bioavailability or on the antioxidant capacity of tea polyphenols [4,15].

After absorption in the gastrointestinal tract, the antioxidants enter the bloodstream. Here the matrix also affects the antioxidant capacity. Binding to albumin results in a substantial masking of the antioxidant capacity of flavonoids [10]. Recently, Van den Berg et al. reported that the antioxidant capacity correlates well with physiological processes such as protection against lipid peroxidation [16]. Binding also decreases the free concentration of the antioxidant. This means that in addition to the intrinsic activity of a compound, bioavailability and metabolism, the binding to proteins also has to be considered for the efficacy of a flavonoid in vivo.

In conclusion, the interaction of flavonoids with proteins affects the antioxidant efficacy of the flavonoids. Although the effect on the bioavailability is not equivocal, the interaction will reduce the antioxidant capacity of the flavonoids both in products and in vivo. Apparently, the matrix influences the efficacy of antioxidants. 


\section{References}

1. Hertog, M.G., E.J. Feskens, P.C. Hollman, M.B. Katan and D. Kromhout (1993) Dietary antioxidant flavonoids and risk of coronary heart disease: the Zutphen elderly study, Lancet 342, 1007-1011.

2. Keli, S.O., M.G. Hertog, E.J. Feskens and D. Kromhout (1996) Dietary flavonoids, antioxidant vitamins, and incidence of stroke, Arch. Intern. Med. 156, 637-642

3. Yang, C.W. and Z.-Y. Wang (1993) Tea and cancer, J. Natl. Cancer Inst. 85, 1038-1049. 4. Van het Hof, K.H., G.A.A. Kivits, J.A. Weststrate and L.B.M. Tijburg (1998) Bioavailability of catechins from tea: the effect of milk, Eur. J. Clin. Nutr. 52, 356-359.

5. Langley-Evans, S.C. (2000) Antioxidant potential of green and black tea determined using the ferric reducing power (FRAP) assay, Int. J. Food Sci. Nutr. 51, 181-188.

6. Paquay, J.B.G., G.R.M.M. Haenen, G. Stender, S.A. Wiseman, L.B.M. Tijburg and A. Bast (2000) Protection against nitric oxide toxicity by tea J. Agric. Food Chem. 48, 57685772.

7. Graham, H.N. (1992) Green tea composition, consumption and polyphenol chemistry. Prev. Med. 21, 334-350.

8. Weisburger, J.H. (1997) Tea and health: a historical perspective, Cancer Lett. 114, 315317.

9. Spencer, C.M., Y. Cai, R. Martin, S.H. Gaffney, P.N. Goulding, D. Magnolato, T.H. Lilley and E. Haslam (1988) Polyphenol complexation-some thoughts and observations, Phytochem. 27, 2397-2409.

10. Arts, M.J.T.J., G. R. M. M. Haenen, H.-P. Voss and A. Bast (2001) Masking of antioxidant capacity by the interaction of flavonoids with protein, Food Chem. Toxicol. 39, 43-47.

11. Re, R., N. Pellegrini, A. Proteggente, A. Pannala, M. Yang and C. Rice-Evans (1998) Antioxidant activity applying an improved ABTS radical cation decolorization assay, Free Radical Biol. Med. 26, 1231-1237.

12. Rice-Evans, C.A., N.J. Miller and G. Paganga (1996) Structure-antioxidant activity relationships of flavonoids and phenolic acids, Free Radical Biol. Med. 20, 933-956.

13. Luck, G., H. Liao, J. Murray, H. Grimmer, E. Warminski, M. Williamson, E.H. Lilley and E. Haslam (1994) Polyphenols, astringency and proline-rich proteins, Phytochem. 37, 357371.

14. Serafini, M., A. Ghiselli and A. Ferro-Luzzi (1996) In vivo antioxidant effect of green and black tea in man, Eur. J. Clin. Nutr. 50, 28-32.

15. Hollman, P.C.H., K.H. van het Hof, L.B.M. Tijburg and M.B. Katan (2001) Addition of milk does not affect the absorption of flavonols from tea in man, Free Radical Res. 34, 297300.

16. Van den Berg, R., G.R.M.M. Haenen, H. van de Berg, W. van der Vijgh and A. Bast (2001) The predictive value of the antioxidant capacity of structurally related flavonoids using the Trolox equivalent antioxidant capacity (TEAC) assay, Food Chem. 70, 391-395. 


\section{Chapter 8}

\section{The involvement of reactive glucose-derived species (RGS) in diabetes}

\section{Implication for antioxidant treatment}

Mariken J.T.J. Arts

Michael D. Coleman

Aalt Bast

Guido R.M.M. Haenen

Submitted for publication 


\begin{abstract}
Diabetes Mellitus (DM) is characterized by elevated levels of glucose in the blood. The disorder is associated with oxidative stress, due to a relatively low level of antioxidants and a relatively high production of reactive oxygen species (ROS). Of these ROS, the hydroxyl radical is the most reactive one. In most theories on the development of diabetic complications this radical has acquired a prominent role.

Glucose is an excellent hydroxyl radical scavenger. The results show that in a glucose-rich environment, such as in poorly regulated DM, hydroxyl radicals are readily converted into reactive glucose-derived species (RGS). The antioxidant protection against these RGS appeared to differ markedly from the protection against hydroxyl radicals. Some compounds that efficiently protected against hydroxyl radicals even appeared to enhance the RGS production, indicating that these "antioxidants" might be contraproductive in DM. The results demonstrate that the efficacy of an antioxidant strongly depends on the type of radical. The implication of our findings for the application of antioxidants in DM is discussed.
\end{abstract}




\section{Introduction}

Diabetes Mellitus (DM) is a chronic and widespread disease caused by insulin resistance, inadequate insulin production or a combination of both. The disorder is characterized by elevated levels of glucose in the blood and is associated with oxidative stress due to a relatively low level of antioxidants and a relatively high production of reactive oxygen species (ROS) [1]. Of these ROS, the hydroxyl radical is the most reactive one. Partially due to this high reactivity, the hydroxyl radical has acquired a prominent role in most theories on the development of diabetic complications.

Many antioxidants, such as vitamin E, vitamin C and flavonoids, are able to scavenge hydroxyl radicals, preventing the toxicity of this ROS from harming human cellular components [1]. In addition, glucose is also an excellent scavenger of hydroxyl radicals [1]. Based on the relatively high concentration of glucose in the blood, especially in poorly regulated DM, hydroxyl radicals will predominantly be scavenged by glucose. It is often not realized that products of scavengers that are formed during the actual antioxidant activity are potentially toxic [2]. Indeed, the formed antioxidant metabolite usually retains some reactivity of the radical it has scavenged. During the scavenging of the hydroxyl radical by glucose, reactive glucose-derived species (RGS) are formed. Surprisingly little is known on the reactivity of RGS, but it's likely that they are involved, for instance, in protein glycosylation, a major toxic process in DM.

The aim of the present study is to determine whether protection against RGS is similar to that of hydroxyl radicals or that a different strategy is needed.

\section{Materials and methods}

\section{Chemicals}

Catechol, phenol, lipoic acid, caffeic acid, para-coumaric acid ( $p-C A)$, glucose, and 5,5-dimethyl-1-pyrroline $\mathrm{N}$-oxide (DMPO) were obtained from Sigma Chemical Company (St. Louis). $\mathrm{FeSO}_{4}$ and hydrogen peroxide $30 \% \quad\left(\mathrm{H}_{2} \mathrm{O}_{2}\right)$ were purchased from Merck. 7Monohydroxyethylrutoside (MonoHER) was a generous gift of Novartis (Nyon, Switzerland). All other chemicals were of analytical grade purity. 


\section{Electron spin resonance spectroscopy}

Electron spin resonance (ESR) spectra were recorded at room temperature using a Bruker EMX 1273 spectrometer equipped with an ER 4119 HS high sensitivity cavity and $12 \mathrm{~kW}$ power supply. The software program used was WIN EPR. Instrument settings were the following: center field, $3488 \mathrm{G}$; sweep width, $65 \mathrm{G}$; modulation amplitude, $1.0 \mathrm{G}$; microwave frequency, $9.86 \mathrm{GHz}$; sweep time, $20.972 \mathrm{~s}$; time constant, $40.96 \mathrm{~ms}$. The number of scans depended on the type of radical that was recorded, i.e. 3 scans for hydroxyl radicals and 10 scans for Reactive glucose-derived species (RGS). Hydroxyl radicals were generated by the Fenton reaction and RGS were formed by addition of glucose to the Fenton reagent. The $\mathrm{pH}$ was kept constant at 7.4. DMPO was used for trapping the generated radicals. Fifty microliters $9.8 \mathrm{mM} \mathrm{H}_{2} \mathrm{O}_{2}, 50 \mu \mathrm{l} 250$ $\mathrm{mM}$ DMPO, $50 \mu \mathrm{l}$ milliQ or $50 \mu \mathrm{l} 500 \mathrm{mM}$ glucose, $50 \mu \mathrm{l}$ buffer (control) or $50 \mu \mathrm{l} 100 \mathrm{mM}$ antioxidant and $50 \mu \mathrm{l}$ of $5 \mathrm{mM} \mathrm{FeSO}_{4}$ were mixed and transferred to a $200 \mu \mathrm{l}$ capillary glass tube. Exactly 90 seconds after addition of the $\mathrm{FeSO}_{4}$, ESR spectra of the DMPO spin adducts were recorded. Subsequent data analysis was performed using the WIN EPR spectrum manipulation program by measuring the relative peak height of the $2^{\text {nd }}$ peak and relate it to the blank. Corrections using adequate blanks have been made.

\section{Statistical analyses}

Differences in ESR signal peak areas between antioxidants and the blank were analyzed by Student $t$ test. P values of 0.01 or less were considered as statistically significant. Results are reported as means \pm SD.

\section{Results}

Hydroxyl radicals are generated using the Fenton reaction, in which $\mathrm{H}_{2} \mathrm{O}_{2}$ and $\mathrm{Fe}^{2+}$ are the radical source. These hydroxyl radicals can be trapped with DMPO resulting in the four-peak DMPO-OH radical signal that is shown in figure $1 \mathrm{~A}$.

Addition of glucose to a solution of Fenton mixture produces RGS, which can also be trapped by DMPO giving rise to a characteristic 6 peak carbon-centered signal, shown in figure 1B. The height of the DMPO-OH signal is drastically reduced by the addition of glucose. Besides the DMPO-RGS signal and the DMPO-OH signal, another signal, designated the DMPO-unknown-radical spin adduct, was detected. 
A

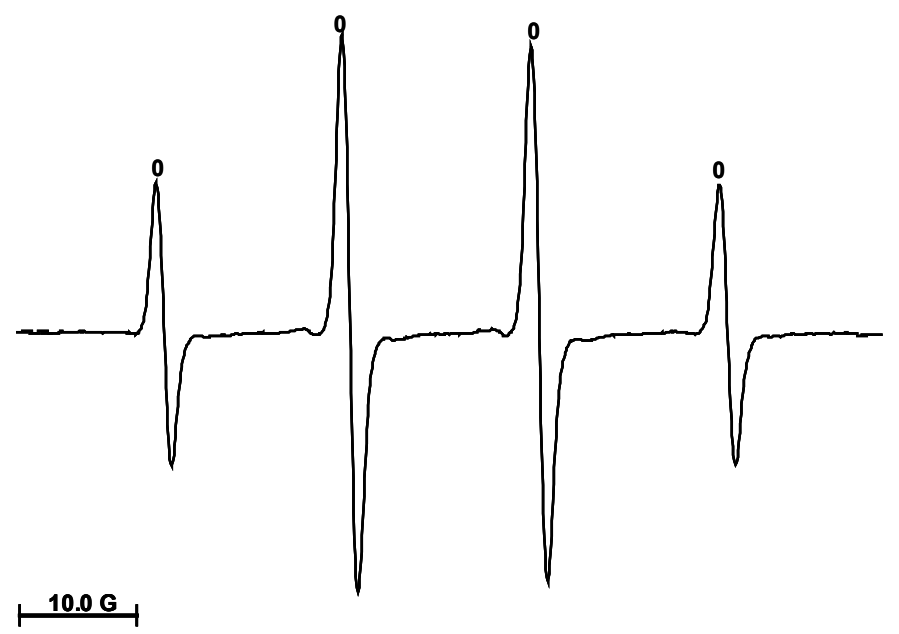

B

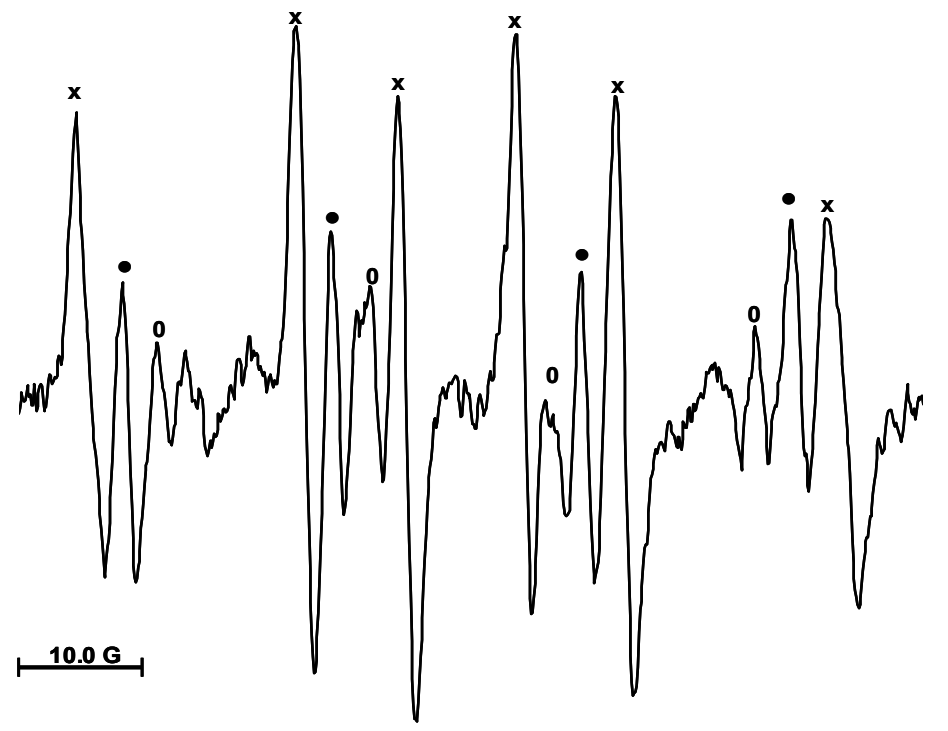

Fig.1. ESR spectra of the DMPO-adducts. The incubation mixture contained $2 \mathrm{mM} \mathrm{H}_{2} \mathrm{O}_{2}$ and $1 \mathrm{mM} \mathrm{Fe}^{2+}$. Without (A) or with $500 \mathrm{mM}$ glucose (B). Details are given in the Materials \& Method section. o: DMPO-OH spin adduct; $\mathrm{x}$ : DMPO-RGS spin adduct; •: DMPO-unknownradical spin adduct 
Raising the concentration of glucose in the range of $0-100 \mathrm{mM}$ results in a decreasing DMPO-OH signal and an increasing DMPO-RGS signal, as can be seen in figure 2 . This indicates that in the presence of glucose, hydroxyl radicals are effectively converted into RGS, confirming the potent hydroxyl radical scavenging activity of glucose.

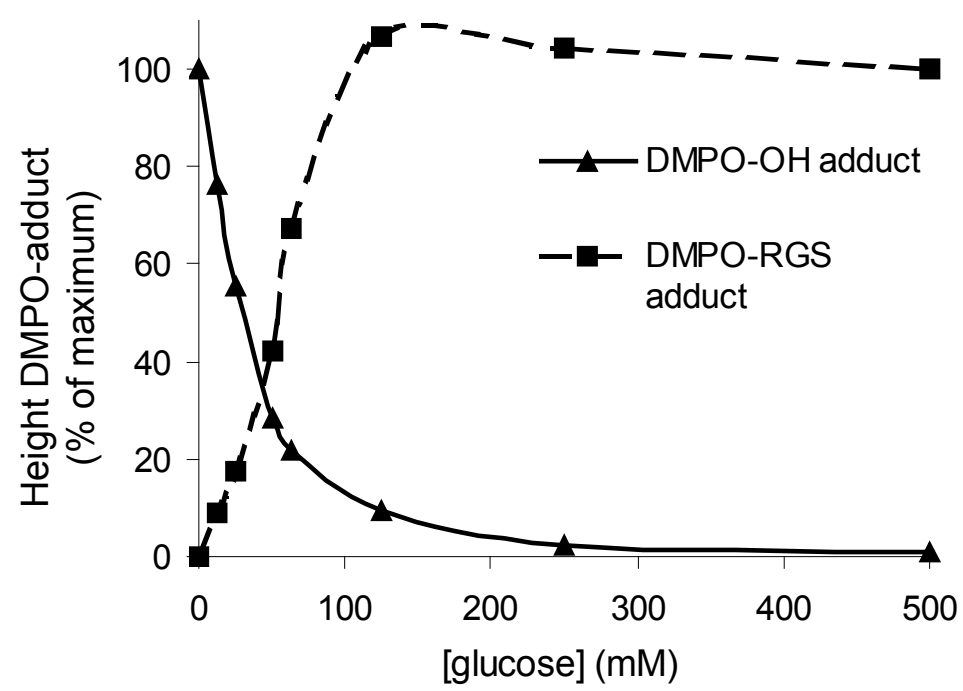

Fig. 2. Scavenging of hydroxyl radical by glucose and formation of RGS. The height of the DMPO spin adduct signal after addition of a variable concentration of glucose to the Fenton reagent $\left(\mathrm{H}_{2} \mathrm{O}_{2}\right.$ and $\left.\mathrm{Fe}^{2+}\right)$ is depicted. The DMPO-OH signal is related to that of incubation without glucose. The DMPO-RGS signal is related to that of incubation containing $500 \mathrm{mM}$ glucose.

Antioxidants, such as catechol, phenol, lipoic acid, p-coumaric acid, caffeic acid and monoHER are able to scavenge hydroxyl radicals (figure 3). Lipoic acid gives the largest effect. The signal of the DMPO$\mathrm{OH}$ spin adduct with lipoic acid is only $10 \%$ of that of the blank.

Remarkably, the effect of some of the studied antioxidants on the scavenging of RGS differs drastically from that of the scavenging of the hydroxyl radial (figure 4). Only two compounds, namely lipoic acid and $p$ coumaric acid, appear to scavenge RGS, which is deduced from the lower DMPO-RGS signal when these compounds were present in the incubation mixture. The other antioxidants tested either do not reduce the DMPO-RGS signal or even enhance it. 


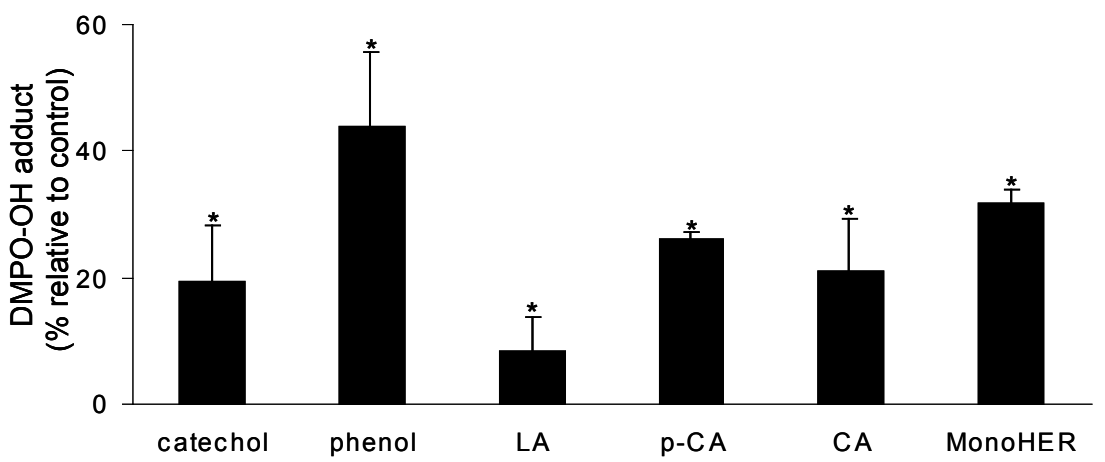

Fig. 3. Scavenging of hydroxyl radical by catechol, phenol, lipoic acid (LA), p-coumaric acid $(p-C A)$, caffeic acid (CA) and monoHER. The DMPO-OH signal with the antioxidant is related to that of the control. The lower the value, the higher the scavenging activity. The concentration of antioxidant was $20 \mathrm{mM}$, except for monoHER that was present in a concentration of $10 \mathrm{mM}$. The data are mean \pm SD of at least six determinations. Statistically significant deviations relative to the control are represented by * $P<0.01$.

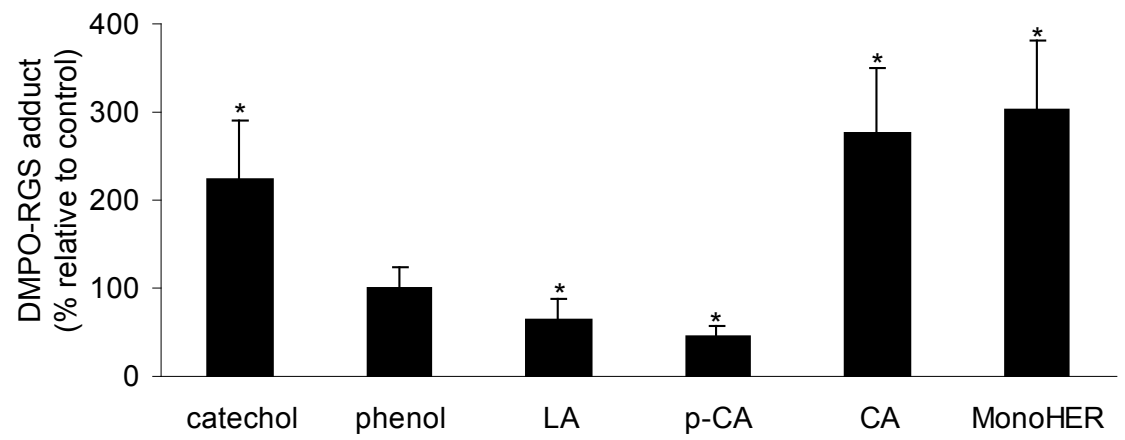

Fig. 4. Scavenging of RGS by catechol, phenol, lipoic acid (LA), p-coumaric acid ( $p$-CA), caffeic acid (CA) and monoHER. The DMPO-RGS signal is related to that of the control. The lower the value, the higher the scavenging activity. The concentration of antioxidant was $20 \mathrm{mM}$, except for monoHER that was present in a concentration of $10 \mathrm{mM}$. The data are mean $\pm S D$ of at least six determinations. Statistically significant deviations relative to the control are represented by $* P<0.01$.

To determine whether the antioxidant effect on DMPO-RGS was not a result of scavenging of the hydroxyl radical, thus due to a decreased RGS production, a control experiment was performed. This was done by assessing the effect of diminishing the glucose concentration on the scavenging of $p$-coumaric acid, the most potent RGS scavenger of the series tested. When the concentration of glucose was $500 \mathrm{mM}, p$ coumaric acid $(20 \mathrm{mM})$ lead to a DMPO-RGS signal that was $37 \pm 5 \%$ of 
the same experimental results in the absence of $p$-coumaric acid. If hydroxyl radical scavenging alone were to be responsible for the effect of $p$-coumaric acid, then the percentage of the DMPO-RGS signal with 250 $\mathrm{mM}$ glucose would have been $18.5 \%$ of the control. If only RGS scavenging plays a role, this percentage would remain at approximately $37 \%$.

It was found that with $p$-coumaric acid at $250 \mathrm{mM}$ glucose concentration, the DMPO-RGS signal is $44 \pm 9 \%$ of the control, indicating that the antioxidant effect is predominantly the result of RGS scavenging. This result could have been anticipated since the glucose concentration $(250 \mathrm{mM}$ or $500 \mathrm{mM})$ exceeds the concentration of $p$-coumaric acid $(20$ $\mathrm{mM}$ ) by far. In such a relatively low concentration, this antioxidant could not compete effectively with glucose for the hydroxyl radical, since glucose was at a high concentration and readily reacted with hydroxyl radical. The inability of antioxidants to compete with glucose in our test system is comparable with the in vivo situation in poorly regulated diabetes where the concentration of glucose is also much higher than the maximally achievable antioxidant concentration.

\section{Discussion}

Oxidative stress is caused by an imbalance between antioxidants and reactive oxygen species (ROS). Of these ROS, the hydroxyl radical is the most reactive. It is not generally appreciated that glucose is an excellent scavenger of hydroxyl radicals. At $30 \mathrm{mM}$ glucose (the $\mathrm{EC}_{50}$ ), the DMPO$\mathrm{OH}$ signal was reduced to $50 \%$ of that of the incubation in the absence of glucose. At a concentration of $250 \mathrm{mM}$, no DMPO-OH signal at all was detected. The composition of the incubation mixture used in the present study was effectively designed to obtain clear-cut responses. The glucose concentration in this in vitro assay appears high compared to the physiological range, which may exceed $15 \mathrm{mM}$ in poorly regulated diabetes. However, it should be noted that in the described experiments the reaction rate of glucose with the hydroxyl radical is relative to that of DMPO with the hydroxyl radical. DMPO reacts reasonably quickly with hydroxyl radicals and is used at a relatively high concentration of $50 \mathrm{mM}$. The ostensible activity of glucose in the assay could be easily boosted by lowering the concentration of DMPO or by using a spin trap that reacts slowly with hydroxyl radicals. The $\mathrm{EC}_{50}$ values obtained in in vitro experiments are not equal to the $\mathrm{EC}_{50}$ values in the in vivo situation [3]. Extrapolation from in vitro to in vivo should be based on the reaction rate 
constants, which are identical in vitro and in vivo, and on the concentrations.

The rate of the reaction of glucose with hydroxyl radicals $\left(1.5 * 10^{9}[4]\right)$ is relatively high. The concentration of glucose is also relatively high, especially in poorly regulated DM. This indicates that the reaction with glucose is a major pathway for hydroxyl radicals formed in diabetics, despite the relatively high $\mathrm{EC}_{50}$ value of glucose to reduce the DMPO-OH signal in the in vitro experiment.

The scavenging of hydroxyl radicals by this sugar leads to the formation of reactive glucose-derived species (fig. 2). These RGS have, comparable with hydroxyl radicals, a reactivity that is high enough to damage cells by reacting with important cellular components, such as proteins, lipids and DNA. Advanced glycosylation end products (AGEs) can be formed from RGS after reaction with proteins. Formation of the AGEs will consequently impair protein and cellular function. Binding of AGEs to AGE receptors can lead to adverse modification of cell signaling and enhance production of ROS $[5,6]$. In diabetes, these harmful processes, summarized in figure 5 , are involved in the development of complications such as cardiovascular disease, nephropathy, retinopathy and neuropathy $[1,5,6]$. Since non-enzymatic glycation is due to an oxidation process, intervention with antioxidants appears to be a logical strategy.

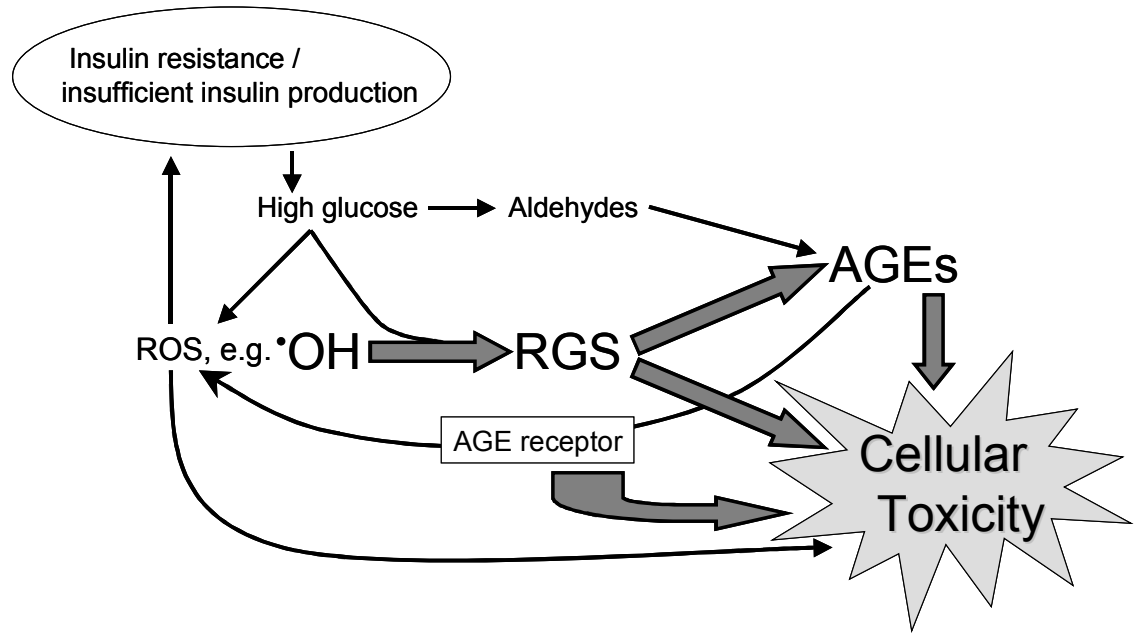

Fig. 5. The involvement of RGS in Diabetes Mellitus mediated toxicity. High glucose levels result both directly and indirectly in the formation of AGEs and cellular toxicity. In this process RGS plays a pivotal role. 
Generally speaking, catechol and catechol containing antioxidants, including numerous flavonoids and other polyphenols, qualify as good antioxidants. That catechol and the catechol containing compounds caffeic acid and monoHER protect against hydroxyl radicals, while under the same conditions they enhance RGS formation, was a somewhat surprising observation. This indicates that the underlying mechanism for increasing DMPO-RGS formation by these compounds is not increased hydroxyl radical production and requires further investigation. The differing nature of RGS, which is a carbon-centered-radical, compared to the hydroxyl radical, which is an oxygen-centered-radical, is probably involved.

In vivo, a prooxidant effect of catechol, caffeic acid and monoHER on RGS formation is unwanted and the use of these "antioxidants" might therefore be contra-indicated in diabetes. Lipoic acid and p-coumaric acid could be of value as they protect against both the hydroxyl radical and RGS. The findings concerning lipoic acid are consistent with previously published observations in which lipoic acid was shown to be protective in diabetes in vivo [7-10]. Interestingly, the possible involvement of RGS scavenging by lipoic acid has been shown in this report to be a plausible process which may occur in vivo and it has not been previously addressed.

In summary, it should be noted that glucose itself is an efficient hydroxyl radical scavenger and that, especially at high glucose concentration, RGS appear to be more relevant to eventual reactive species formation than the hydroxyl radical itself. Antioxidant strategies in DM should therefore be more specifically aimed at the protection against RGS, as this report shows that protection offered by antioxidants against RGS markedly differs from their protection against hydroxyl radicals. The reported beneficial effects of some antioxidants in DM, such as lipoic acid, might involve the scavenging of RGS. 


\section{References}

1. Halliwell, B. and J.M.C. Gutteridge (1999) Free radicals in biology and medicine, ed. e. edition. Oxford: Clarendon Press.

2. Bast, A. and G.R.M.M. Haenen (2002) The toxicity of antioxidants and their metabolites, Environm. Toxicol. Pharmacol. 11, 251-258.

3.Haenen, G.R.M.M., M.J.T.J. Arts, A. Bast and M.D. Coleman (2006) Structure and activity in assessing antioxidant activity in vitro and in vivo. A critical appraisal illustrated with the flavonoids, Environmental Toxicology and Pharmacology 21, 191-198.

4. Buxton, G.V., C.L. Greenstock, W.P. Helman, A.B. Ross (1988) Critical review of rate constants for reactions of hydrated electrons, hydrogen atoms and hydroxyl radicals in aqueous solution, J. Phys. Chem. Ref. Data 17, 513-882.

5. Rahimi, R., S. Nikfar, B. Larijani and M. Abdollahi (2005) A review on the role of antioxidants in the management of diabetes and its complications, Biomed. Pharmacother. 59, 365-373.

6. Ahmed, N., Advanced glycation endproducts -role in pathology of diabetic complications, Diab. Res. Clin. Pract. 67, 3-21.

7. Biewenga, G., G.R. Haenen and A. Bast (1997) The role of lipoic acid in the treatment of diabetic polyneuropathy, Drug Metab. Rev. 29, 1025-1054.

8. Cameron, N.E. and M.A. Cotter (1999) Effects of antioxidants on nerve and vascular dysfunction in experimental diabetes, Diab. Res. Clin. Pract. 45, 137-146.

9. Hofmann, M.A., S. Schiekofer, B. Isermann, M. Kanitz, M. Henkels, M. Joswig, A. Treusch et al. (1999) Peripheral blood mononuclear cells isolated from patients with diabetic nephropathy show increased activation of the oxidative-stress sensitive transcription factor NF-kappa B, Diabetol. 42, 222-232.

10. Coleman, M.D., S. Fernandez, L.A. Khanderia (2003) Novel clinical monitoring method to evaluate a triple antioxidant combination (vitamins $\mathrm{E}, \mathrm{C}$ and a-lipoic acid) in diabetic volunteers using in vitro methaemoglobin formation, Environm. Toxicol. Pharmacol. 14, 3342 



\title{
Chapter 9
}

\section{Oxidative degradation of lipids during mashing}

\author{
Mariken J.T.J. Arts \\ Christoph Grun \\ Ruud L. de Jong \\ Hans-Peter Voss \\ Aalt Bast \\ Martin J. Müller \\ Guido R.M.M. Haenen
}

Submitted for publication 


\begin{abstract}
The ingredients of beer contain a high concentration of poly unsaturated fatty acids (PUFAs), such as linolic and linolenic acid. These compounds are readily oxidized, resulting in the formation of lipid-derived products that reduce the taste and quality of beer enormously. During mashing relatively high amounts of PUFAs are exposed to atmospheric oxygen at a relatively high temperature. This makes mashing a critical step in the brewing process with regard to the formation of lipid-derived off taste products. $\mathrm{F}_{1}$ phytoprostanes $\left(\mathrm{PPF}_{1} \mathrm{~s}\right)$, changes in antioxidant capacity and mono-hydroxy-fatty acids (OH-FAs) were used as markers for the detection of oxidative damage to fatty acids during the mashing. The observed pattern of OH-FA formation indicates that enzymatic oxidation of PUFAs is more important than non-enzymatic oxidation during the mashing process. Nevertheless, substantial non-enzymatic radical formation is evident from the increase of specific OH-FAs and $\mathrm{PPF}_{1} \mathrm{~s}$.

It was found that a low oxygen tension reduces oxidative damage and gives a higher antioxidant capacity of the mashing mixture. This indicates that mashing should be done under low oxygen pressure.
\end{abstract}




\section{Introduction}

Beer is a complex mixture of various compounds, introduced to it by the ingredients hop, malt, i.e. germinating barley, water and yeast. In the ingredients of beer, as well as in the intermediate products of the first steps of the brewing process, a high concentration of poly unsaturated fatty acids (PUFAs) is present [1].

The quality of beer is negatively influenced by oxidation. For example, off taste products are formed by oxidation of lipids and other beer components. The most vulnerable step, with regard to lipid oxidation, in the production of beer is the mashing. This process involves increasing the temperature of the mash, i.e. a mixture of malt and water, to the optimum temperature for the desired enzymes, and maintaining a rest (i.e. holding for a period of time) at that temperature. Besides the elevated temperatures during the mashing, the mixture is also exposed to atmospheric oxygen which promotes oxidative damage. These conditions in combination with the presence of a high concentration of easily oxidized products such as poly-unsaturated fatty acids (PUFAs) [2], makes the mashing a critical step in the brewing process.

The most abundant PUFAs in the ingredients of mash are linoleic acid (C18:2) and linolenic acid (C18:3) [1]. The latter PUFA is the most sensitive to oxidation due to its three double bonds. Oxidation of these PUFAs will result in the formation of hydroperoxides. These hydroperoxides are reactive and degrade easily, forming mono-hydroxy fatty acids (OH-FAs), phytoprostanes and other products, such as carbonyls, aldehydes and ketons (figure 1).

Apart from autoxidation, OH-FAs can also be formed by photooxidation [3] and enzymatic oxidation. It is possible to differentiate between these routes of formation since enzymatically conversions solely give 9(S)products [4] and 13(S)-products, due to the specificity of the lipoxygenases (LOX) [5-7]. Barley is reported to contain two LOX enzymes. LOX-1, mainly present in ungerminated barley [8], is responsible for the production of 9-products, whereas the 13-product is mainly formed by the other iso-enzyme LOX-2 [9], that appears during germination [8].

The non-enzymatic processes produce racemic compounds, giving all isomers (9-, 12-, 13- and 16- OH-FAs) in almost the same yield [4]. This makes 12- and 16- OH-FAs formation specific for non-enzymatic oxidation [10]. Ten- and 15- OH-FAs are selectively used as markers of photooxidation (unpublished data). 
$\mathrm{F}_{1}$-phytoprostanes $\left(\mathrm{PPF}_{1} \mathrm{~s}\right)$ are cyclic oxylipins that are chemically stable end products of autoxidation of linolenic acid [11]. These plant-derived compounds are equivalent to the mammalian isoprostanes, but differ in the length of the carbon chain (18 carbons versus 20 carbons), and in the amount of double bonds ( $\mathrm{PPF}_{1} \mathrm{~s}$ contain one double bond less) [12].

Hydroperoxides can also directly degrade into low molecular weight compounds, such as carbonyls, ketones and acids [13]. These products can cause a stale, cardboard $((E)$-2-nonenal) or papery off-flavour $[1,2,13,14]$.

It is known that during mashing antioxidants, such as tannins and anthocyanogens, are released from the barley and are dissolved into the extract solution [1]. The total antioxidant capacity of these compounds, that protects the mash against non-enzymatic oxidation, can be measured with the Trolox Equivalent Antioxidant Capacity (TEAC) assay.

The aim of this study is to evaluate the role of oxidative lipid degradation during the most critical step in the brewing process, i.e. the mashing. In order to achieve this, several parameters, such as the OH-FAs, $\mathrm{PPF}_{1} \mathrm{~s}$ and changes in the TEAC, were measured during the mashing process. It has been reported that $\mathrm{OH}-\mathrm{FAs}$ are mainly formed during mashing [15]. To evaluate the role of oxygen on oxidative stress during the mashing process, the measurements will be done in an oxygen-rich and an oxygen-poor environment. 


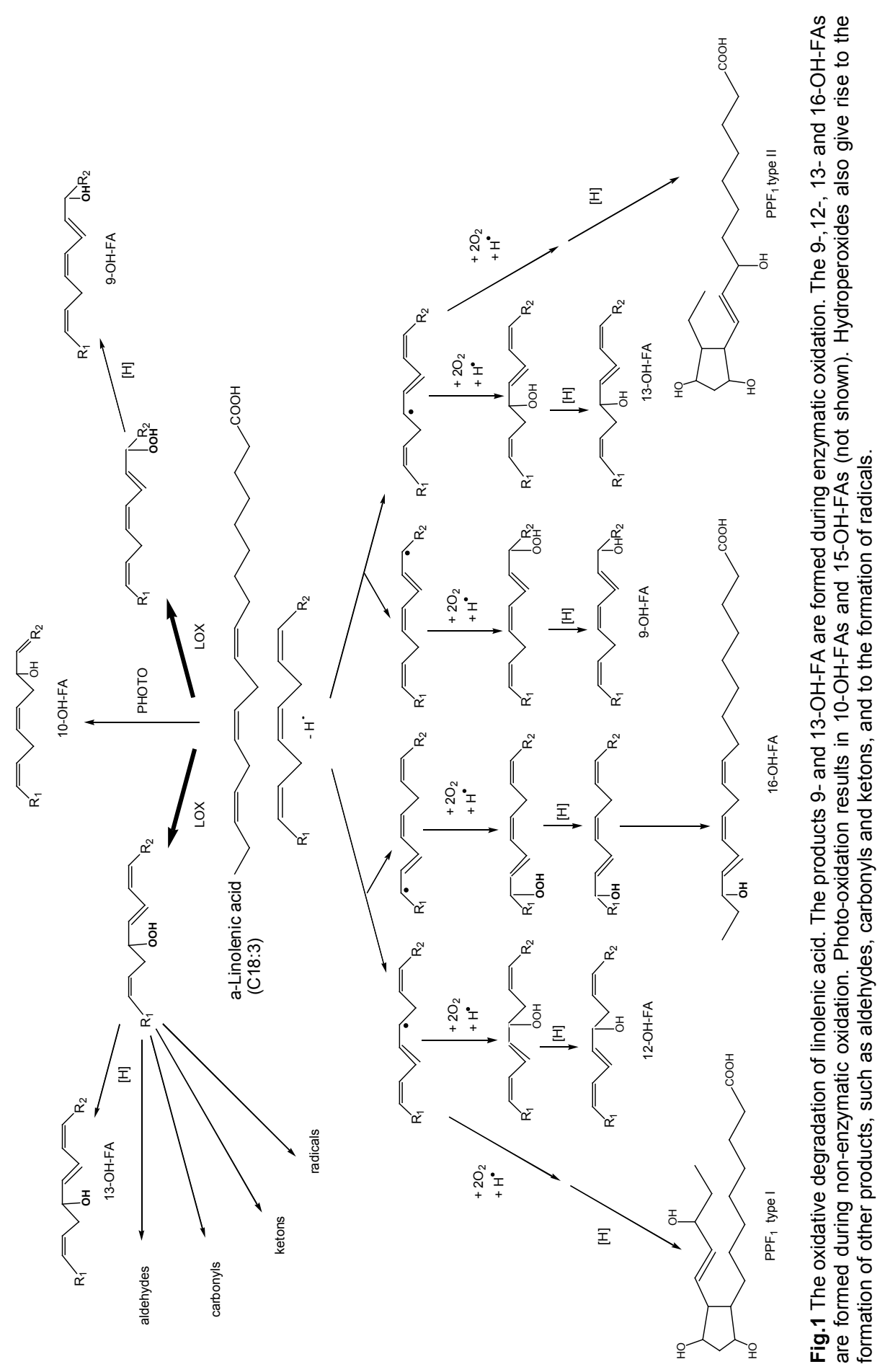




\section{Material \& Methods}

\section{Chemicals}

Butylated hydroxytoluene (BHT), triphenylphosphine (TPP), (trimethylsilyl)diazomethane and 2,2'-azinobis-(3-ethylbenzothiazoline-6sulfonic acid) (ABTS) were obtained from Aldrich Chemical Compagny. $\mathrm{N}, \mathrm{O}$ bis(trimethylsilyl)-trifluoroacetamide (BSTFA was purchased from Pierce, Rockford, IL, USA. Potassium persulfate (di-potassium peroxydisulfate) and trichloroacetid acid (TCA) were obtained from Merck and 15-hydroxyeicosatetraenoic acid from Cayman Chemicals, Ann Arbor, USA. All other chemicals were of analytical grade purity.

\section{Preparation of the mashing samples}

To assess the influence of oxygen, part of a batch of malt was milled under oxygen and another part was milled under argon. After millning, both malt parts were incubated with pre-heated water of $58^{\circ} \mathrm{C}(\mathrm{t}=0 \mathrm{~min})$ in a laboratory mash bath with a malt:water ratio of 1:3.5 (w/v). The oxygen-rich milled malt was mixed with aerated water and the mixture was continuously exposed to oxygen ( $100 \%$ oxygen, $1 \mathrm{~atm}$.) while the oxygen-poor milled malt was mixed with twice de-aerated water and was kept under argon (1 atm.). A temperature-program was started, raising the temperature in several steps and rests to $76^{\circ} \mathrm{C}$ at $120 \mathrm{~min}$.

At the time-points $\mathrm{t}=0,5,30,60$ and $120 \mathrm{~min}$ three $25 \mathrm{ml}$ aliquots of each mixture were taken for measuring $\mathrm{PPF}_{1} \mathrm{~s}$ and $\mathrm{OH}-\mathrm{FAs}$. To two aliquots $125 \mu \mathrm{l}$ of a $30 \mathrm{mg} \mathrm{BHT} / \mathrm{ml}$-solution and $10 \mathrm{mg}$ of triphenylphosphine was added. Subsequently these samples were centrifuged (5 min, 2000xg, $4^{\circ} \mathrm{C}$ ) and the supernatant was frozen under liquid nitrogen. The third aliquot was directly frozen under liquid nitrogen without any additions. In this aliquot the TEAC was assessed. All samples were stored at $-80^{\circ} \mathrm{C}$ until analysis.

\section{Mono-hydroxy fatty acid and phytoprostanes}

Hydroxy fatty acid and phytoprostane extraction, purification and hydrogenation [16]

Mash supernatant $(5 \mathrm{~mL})$ was transferred into a $50 \mathrm{~mL}$ Falcon tube. 15hydroxyeicosatetraenoic acid (15-HETE) and ${ }^{18} \mathrm{O}$-labeled $\mathrm{F}_{1^{-}}$ phytoprostanes were added as internal standards (100 $\mathrm{ng}$ of both for the analysis of free hydroxy fatty acids and free $F_{1}$-phytoprostanes). Saturated $\mathrm{NaCl}$ solution $(10 \mathrm{ml}), 1 \mathrm{M}$ citric acid $(0.5 \mathrm{ml})$, ethyl acetate $(25$ $\mathrm{ml}$ containing $0.005 \%(\mathrm{w} / \mathrm{v})$ butylated hydroxytoluene as antioxidant) and 
triphenylphosphine $(50 \mathrm{mg})$ was added to the frozen sample. The mixture was homogenized for 3 min with a high performance disperser (UltraTurrax T 25 at 24,000 rpm, IKA-Werk, Germany). After centrifugation (10 min, 2000g), the ethyl acetate phase was removed and applied directly to an aminopropyl solid-phase extraction column $(500 \mathrm{mg})$. The column was washed with $3 \mathrm{ml}$ of chloroform/isopropanol, 2/1 (v/v) and OH-FAs were eluted with $6 \mathrm{ml}$ of diethyl ether/acetic acid, 98/2 (v/v). Subsequently $\mathrm{PPF}_{1} \mathrm{~s}$ were eluted with $6 \mathrm{ml}$ of diethyl ether/ methanol/ acetic acid, $90 / 20 / 2(\mathrm{v} / \mathrm{v} / \mathrm{v})$. Both samples were taken to dryness at $40^{\circ} \mathrm{C}$ under a stream of nitrogen.

\section{Fat hydrogenation}

Two to $5 \mathrm{mg}$ of $\mathrm{PtO}_{2}$ hydrate catalyst was added to each sample. Samples were then suspended in $1 \mathrm{ml}$ of methanol and stirred vigorously for 20 min under an atmosphere of hydrogen. The catalyst was filtered off by passing the suspensions through a pipette tip packed with glass fiber filter. The methanol solutions were taken to dryness and derivatized for GC-MS analysis.

\section{Derivatization of hydroxy fatty acids}

The sample was methylated by adding $50 \mu \mathrm{l}$ of methanol, $200 \mu \mathrm{l}$ of diethyl ether and $5 \mu \mathrm{l}$ of (trimethylsilyl)diazomethane (2 M solution in hexane). After $5 \mathrm{~min}$ of incubation at room temperature, the sample was taken to dryness under a stream of nitrogen and suspended in $100 \mu \mathrm{l}$ of chloroform. After addition of $50 \mu \mathrm{l}$ of N,O-Bis-(trimethylsilyl)trifluoracetamid (BSTFA) the sample was heated at $40^{\circ} \mathrm{C}$ for 1 hour, taken to dryness and reconstituted in $20 \mu \mathrm{l}$ of hexane. An aliquot, $2 \mu \mathrm{l}$, were analyzed by GC-MS.

\section{Derivatisation of $\mathrm{F}_{1}$-phytoprostanes}

The hydrogenated sample was reconstituted in $200 \mu \mathrm{l}$ of chloroform and treated with $10 \mu \mathrm{l}$ of PFB bromide and $10 \mu \mathrm{l}$ of $\mathrm{N}, \mathrm{N}$-diethylisopropylamin at $40^{\circ} \mathrm{C}$ for 1 hour. The mixture was taken to dryness, reconstituted in 2 $\mathrm{ml}$ of chloroform and applied to a silica solid phase extraction column. The column was washed with $3 \mathrm{ml}$ of diethyl ether. $F_{1}$-phytoprostane PFB esters were eluted with $6 \mathrm{ml}$ of diethyl ether/ methanol, 90/10 (v/v). The sample was taken to dryness and TMS ether derivatives were prepared by addition of $50 \mu \mathrm{l} \mathrm{BSTFA}$. After incubation at $40^{\circ} \mathrm{C}$ for 1 hour, the sample was dried under a stream of nitrogen and reconstituted in $20 \mu \mathrm{l}$ of hexane. 


\section{GC-MS}

Hydroxy fatty acids and phytoprostane derivatives were analyzed on a HP-5 column $(30 \mathrm{~m} \times 0.25 \mathrm{~mm}$ ), linear He flow at $23 \mathrm{~cm} / \mathrm{s}$. For OH-FA analysis a column temperature step gradient $225^{\circ} \mathrm{C}$ at $20^{\circ} \mathrm{C} / \mathrm{min}, 225-$ $275^{\circ} \mathrm{C}$ at $5^{\circ} \mathrm{C} / \mathrm{min}, 275-300^{\circ} \mathrm{C}$ at $20^{\circ} \mathrm{C} / \mathrm{min}, 300^{\circ} \mathrm{C}$ for $5 \mathrm{~min}$ was applied. The injector of the splitless mode was set at $280^{\circ} \mathrm{C}$. Data were collected in the $\mathrm{El}$ mode. For analysis of $\mathrm{F}_{1}$-phytoprostanes the column temperature was programmed from $175^{\circ} \mathrm{C}$ to $285^{\circ} \mathrm{C}$ at $30^{\circ} \mathrm{C} / \mathrm{min}$ and $285^{\circ} \mathrm{C}$ to $300^{\circ} \mathrm{C}$ at $2.5^{\circ} \mathrm{C} / \mathrm{min}$., data were collected in the $\mathrm{NICl}$ mode. Results are presented as the mean of at least two independent experiments. The error bars represent half of the range.

\section{Trolox Equivalent Antioxidant Capacity (TEAC) assay}

Preparation of the $\mathrm{ABTS}^{\circ}$ solution.

A $7 \mathrm{mM}$ solution of ABTS in milli-Q was prepared and $A B T S^{\bullet}$ was formed after addition of potassium persulfate to the mixture in a final concentration of $2.45 \mathrm{mM}$. After a 12-16 hour incubation at room temperature, the stock solution was diluted with PBS till the desired concentration was reached [17].

\section{TEAC asssay}

The mashing samples were thawed at room temperature and centrifuged for $5 \mathrm{~min}$ at $3400 \mathrm{rpm}\left(\right.$ at $\left.4^{\circ} \mathrm{C}\right)$. The supernatant was used for the TEAC assay. To exclude the influence of light, the handling was done in reduced light.

To a fixed volume of $50 \mu$ supernatant, $\mathrm{ABTS}^{\bullet}$ in a variable concentration was added. The concentration of $A^{A B T S}$ was varied from 0 to approximately $45 \mu \mathrm{M}$ in several different incubations. After a $6 \mathrm{~min}$ incubation at $37^{\circ} \mathrm{C}$, the absorbance at $734 \mathrm{~nm}$ was spectrophotometrically determined. The concentration of ABTS ${ }^{\circ}$ was calculated using a molar extinction coefficient of $1.5 * 10^{4} \mathrm{M}^{-1}$ [17]. The reduction in $\mathrm{ABTS}^{\circ}$ concentration is derived from the absorbance at 734 $\mathrm{nm}$ of the reference (only containing $\mathrm{ABTS}^{\circ}$ ) and the incubation containing the fixed volume of supernatant plus the same concentration of ABTS:

The reduction in $\mathrm{ABTS}^{\circ}$ concentration is plotted against the initial concentration of $\mathrm{ABTS}^{\circ}$. The curve is fitted according to the exponential function $y=C\left(1-e^{\left(-b^{*}\right)}\right)$ using Sigma Plot (version 4.01) on a standard personal computer. In this formula $y$ is the reduction in ABTS $^{\circ}$ concentration, $x$ is the initial $A B T S^{\circ}$ concentration and $C$ is the maximal amount of $A B T S^{\circ}$ scavenged by the supernatant in the volume tested 
[18]. Results are presented as the mean of at least two independent experiments. The error bars represent half of the range.

\section{Results}

In a mash mixture, consisting of malt and water (1:3.5, w/w), exposed to atmospheric oxygen, OH-FAs were measured at $t=5$ and $t=120 \mathrm{~min}$. Figure 2 shows that enzymatic OH-FA formation (reflected by 9- and 13$\mathrm{OH}-\mathrm{FA}$ formation) plays a more dominant role compared to the nonenzymatic autoxidation (reflected by $10-, 12-$ and 16-OH-FA formation) through photo-oxidation and free radical catalyzed oxidation.

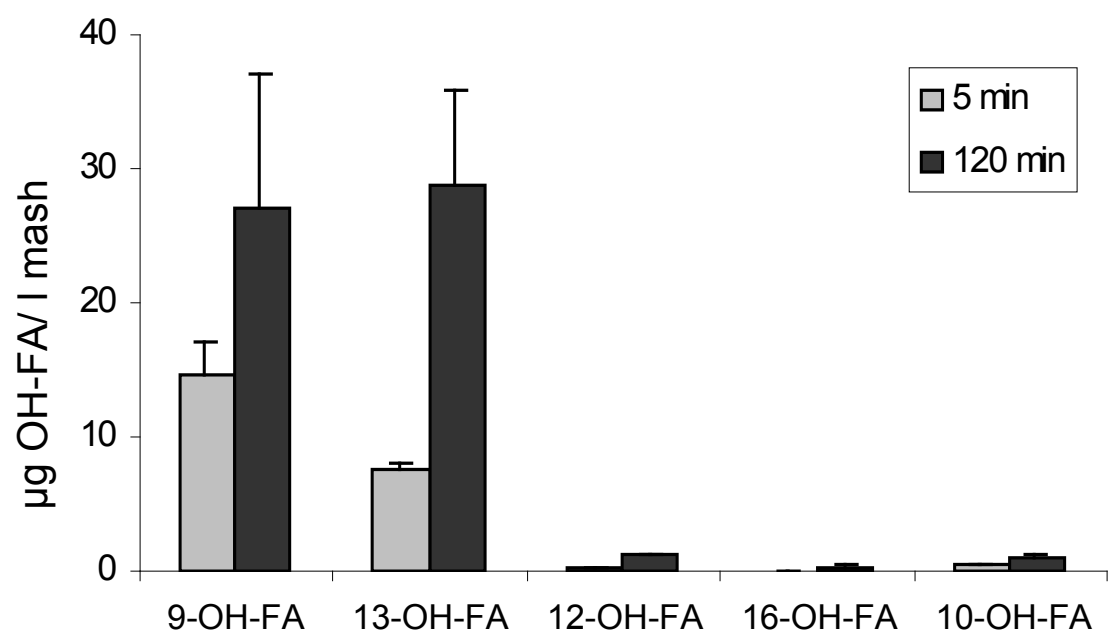

Fig. 2. OH-FA concentrations in supernatants of mash, produced under high oxygen pressure, at 5 and $120 \mathrm{~min}$. The non-enzymatically produced OH-FAs are represented by 12- and 16-OH-FAs, photo-oxidation yields 10-OH-FA. Enzymatic oxidation results solely in 9- and 13-OH-FAs.

$\mathrm{F}_{1}$-phytoprostanes $\left(\mathrm{PPF}_{1} \mathrm{~s}\right)$ are chemically stable end products of nonenzymatic oxidation of linolenic acid [12]. The presence of these compounds before the actual mashing (figure 3 ) indicates that $\mathrm{PPF}_{1} \mathrm{~s}$ are already present in the malt. $\mathrm{PPF}_{1}$ concentration increases in time. This indicates that non-enzymatic oxidation also occurs in the mashing process. Maximum $\mathrm{PPF}_{1}$ formation takes place during the first five minutes of the mashing process. After this rapid increase in $\mathrm{PPF}_{1}$ concentration, a plateau is reached. Oxygen pressure affects $\mathrm{PPF}_{1}$ 
formation. At 120 minutes the plateau with high oxygen $\left(100 \% \mathrm{O}_{2}, 1\right.$ atm.) is twice as high as that with low oxygen pressure (100\% $\mathrm{Ar}, 1 \mathrm{~atm}$.$) .$

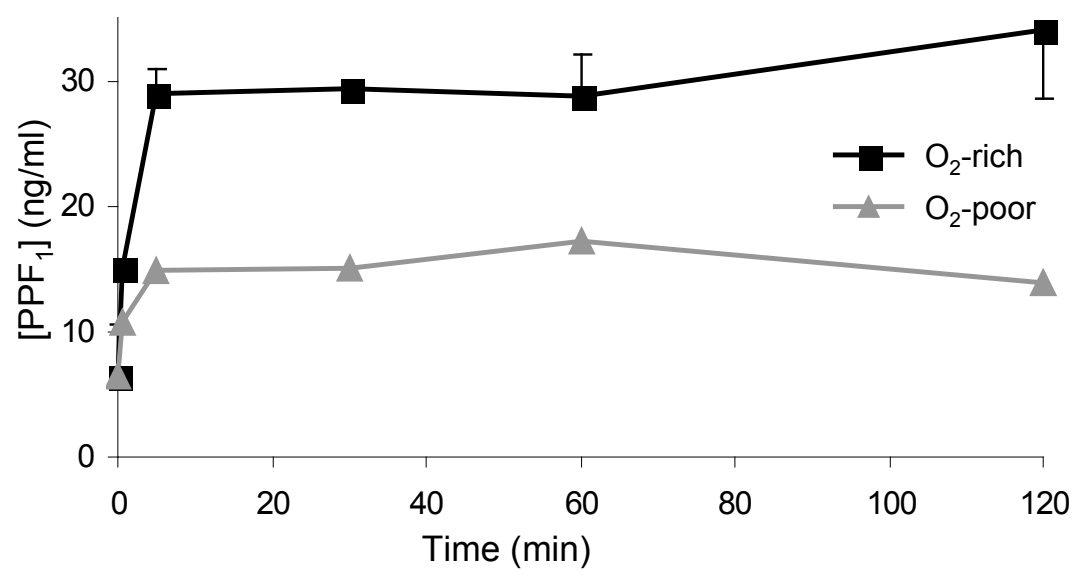

Fig. 3. $\mathrm{PPF}_{1}$-concentration of both oxygen poor and oxygen rich mash in the course of time.

During mashing, the TEAC in both oxygen-rich and oxygen-poor mixture raises (Fig. 4a en b). A faster increase in TEAC is observed in the oxygen-rich mash. Nevertheless, the TEAC in the oxygen-poor mash is higher at the end of the mashing period (Fig. 4b), indicating that oxygenpoor mash has finally a higher antioxidant capacity than the oxygen-rich mash.

\section{Discussion}

During mashing the easily oxidizable PUFAs in malt are subjected to high temperatures and excess of oxygen. This makes mashing a critical step in the brewing process.

The results obtained from $\mathrm{OH}-\mathrm{FA}$ and $\mathrm{PPF}_{1}$ formation indicate that oxidative damage of lipids indeed takes place. The OH-FAs (Figure 1) are mainly formed by LOX-catalyzed oxidation, indicated by formation of mainly 9- and 13- OH-FAs. 

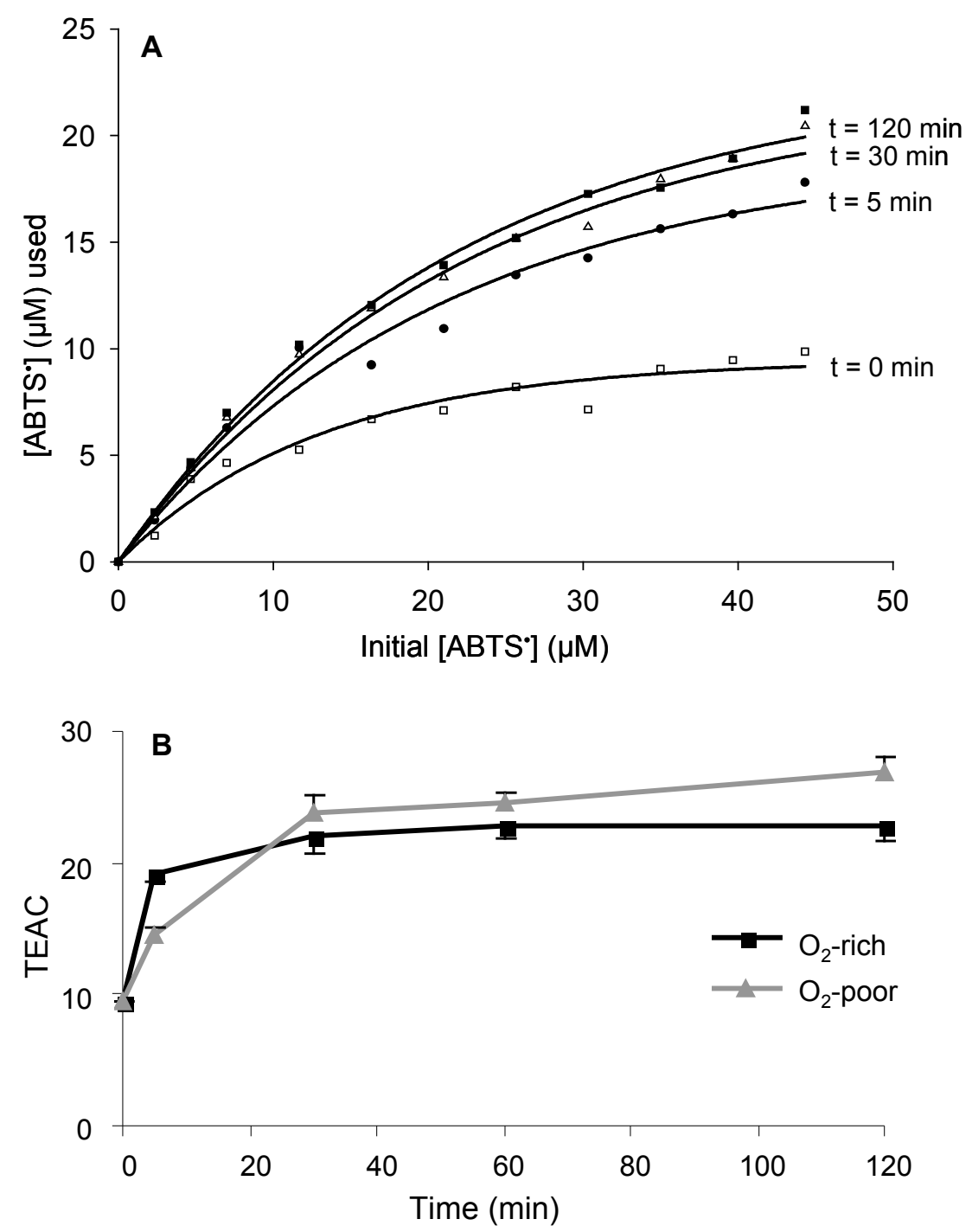

Fig. 4A. Consumption of ABTS by $50 \mu$ supernatant of mash at four different time-points, produced under low oxygen tension, with a variable initial concentration of ABTS*. The data of the ABTS consumption were fitted with an exponential function as described in the material and method section. A typical example out of three independent experiments is shown. This approach gives the actual TEAC value [23].

4B: The TEAC values of low and high oxygen tension mash in time. 
The intermediate products in OH-FA formation are hydroperoxides, which easily generate radicals. These radicals might inflict damage to several targets such as proteins. This indicates that the enzymatic oxidation of PUFAs to hydroperoxides will also give rise to non-enzymatic radical formation. Radical formation is also evident from the increase of OH-FAs and $\mathrm{PPF}_{1} \mathrm{~s}$, markers of non-enzymatic hydroperoxide formation, in time during the mashing process.

It is expected that during an oxidative process, such as mashing, antioxidants are being consumed. Surprisingly, the total antioxidant capacity, reflected by the TEAC, increases in time during this process. Possible explanations for this rise in TEAC are:

1. The formation of reaction products that might have a higher TEAC value [18].

2. The release of phenolic $-\mathrm{OH}$ groups, that had been bound to a sugar due to enzymes that are capable of splitting off sugars. In general, the aglycon is a better antioxidant than the sugar containing compound, which leads to a higher TEAC value [19].

3. A higher solubility of compounds by the elevated temperature. During mashing antioxidants, such as tannins and anthocyanogens, are released from the barley and are dissolved into the extract solution [1], which will lead to a higher TEAC.

4. The denaturation of proteins leading to protein unfolding, which allows previously inaccessible antioxidant aminoacids to participate in the scavenging process (unpublished data).

5 . The reduced binding of antioxidants by protein denaturation, resulting in less masking and a subsequently higher TEAC [20].

All above mentioned processes might have a contribution to an increase of the TEAC during the mashing, but it is unknown to what extent. The faster increase in TEAC in the oxygen-rich mash, compared to the oxygen-poor mash, can be explained by (i) the faster formation at high oxygen pressure of reaction products that have paradoxally a higher TEAC [18] and (ii) by faster protein denaturation leading to less antioxidant protein binding and unfolding of proteins. The paradoxal rise in antioxidant capacity at this stage of the brewing process is advantageous since antioxidants prevent excessive oxidative damage during the mashing process.

The higher TEAC of the oxygen-poor mash at the end of the mashing period can be explained by a lower oxidative consumption of antioxidants compared to the oxygen-rich mixture. As expected, at high oxygen 
pressure the $\mathrm{PPF}_{1}$-formation is higher than at low oxygen pressure. This indicates that lipid oxidation is indeed higher at a higher oxygen tension, which is in line with the lower TEAC at the end of the mashing under high oxygen pressure. Thus, at low oxygen pressure, oxidative damage during mashing is relatively low and the final antioxidant capacity is relatively high.

\section{Conclusion}

Enzymatic oxidation appears to be the main route of oxidation of the PUFAs during the mashing. Hydroperoxides formed by lipoxygenases might give rise to the formation of free radicals, that in turn are responsible for the observed non-enzymatic lipid oxidation yielding, among other products, $\mathrm{PPF}_{1} \mathrm{~s}$ and a series of OH-FA.

Based on these conclusions, it can be hypothesized that $\mathrm{PPF}_{1} \mathrm{~s}$ might be used as quality markers of mashing mixture. Possibly, these compounds can also be used as markers for oxidative damage during the production of beer, especially during the mashing, since they are not degraded. No changes in $\mathrm{PPF}_{1}$ concentration were detected during storage of beer (unpublished results), indicating that during the oxidative processes that take place during storage of beer no $\mathrm{PPF}_{1} s$ are being formed. This could have been anticipated since there are practically no PUFAs, i.e. the precursors of $\mathrm{PPF}_{1} \mathrm{~s}$, present in the beer $[21,22]$.

Mashing under low oxygen tension results in less oxidative damage and a higher antioxidant capacity than mashing under high oxygen tension, as shown by the $\mathrm{PPF}_{1}$ reduction. This indicates that mashing should be done under low oxygen pressure to minimize oxidative damage and preserve antioxidants. 


\section{References}

1. Kunze, W., Technology brewing and malting. 7th ed., Berlin, 1996, 727.

2. Vanderhaegen, B., H. Neven, H. Verachtert and G. Derdelinckx (2006) The chemistry of beer aging - a critical review, Food Chem. 95, 357-381.

3. Op den Camp, R.G.L., D. Przybyla, C. Ochsenbein, C. Laloi, C. Kim, A. Danon, D. Wagner, E. Hideg et al. (2003) Rapid Induction of Distinct Stress Responses after the Release of Singlet Oxygen in Arabidopsis, Plant Cell 15, 2320-2332.

4. Montillet, J.L., J.L. Cacas, L. Garnier, M.H. Montane, T. Douki, J.J. Bessoule, L. Polkowska-Kowalczyk, U. Maciejewska, J.P. Agnel and A. Vial, C. Triantaphylides (2004) The upstream oxylipin profile of Arabidopsis thaliana: a tool to scan for oxidative stresses, Plant J. 40, 439-451.

5. Blee, E. (1998) Phytooxylipins and plant defense reactions, Prog. Lipid Res. 37, 33-72.

6. Holtman, W.L., J.C. Vredenbregt-Heistek, N.F. Schmitt, I. Feussner et al. (1997) Lipoxygenase-2 oxygenates storage lipids in embryos of germinating barley, Eur. J. Biochem. 248, 452-458.

7. Van Aarle, P.G.M., M.M.J. de Barse, G.A. Veldink and J.F.G. Vliegenthart (1991) Purification of a lipoxygenase from ungerminated barley Characterization and product formation, FEBS letters 280, 159-162.

8. Yang, G. and P.B. Schwarz (1995) Activity of lipoxygenase isoenzymes during malting and mashing, J. Am. Soc. Brew. Chem. 53, 45-49.

9. Doderer, A., I. Kokkelink, S. van de Veen, B. Valk, A. Schram and A. Douma Purification and characterization of two lipoxygenase isoenzymes from germinating barley, BBA 1120, 97-104.

10. Berger, S., H. Weichert, A. Porzel, C. Wasternack, H. Kuhn and I. Feussner (2001) Enzymatic and non-enzymatic lipid peroxidation in leaf development, $B B A$ 1533, 266-276.

11. Imbusch, R. and M.J. Mueller (2000) Formation of isoprostane F2-like compounds (phytoprostanes F1) from [alpha]-linolenic acid in plants, Free Rad. Biol. Med. 28, 720-726. 12. Müller, M. (1998) Radically novel prostaglandins in animals and plants: the isoprostanes, Chem. Biol. 5, R323-333.

13. Kobayashi, N., H. Kaneda, Y. Kano and S. Koshino (1992) Determination of fatty acid hydroperoxides produced during the production of wort, J. Inst. Brew. 99, 143-146.

14. Drost, B.W., R. van den Berg, F.J.M. Frijee, E.G. van der Velde and M. Hollemans (1990) Flavor Stability, J. Am. Soc. Brew. Chem. 48, 124-131.

15. Kobayashi, N., H. Kaneda, H. Kuroda, J. Watari, T. Kurihara and K. Shinotsuka (2000) Behavior of Mono-, Di-, and trihydroxyoctadecenoic acids during mashing and methods of controlling their production, J. Biosci. Bioeng. 90, 69-73.

16. Müller, M.J., L. Mene-Saffrane, C. Grun, K. Karg and E.E. Farmer (2006) Oxylipin analysis methods, Plant J. 45, 472-489.

17. Re, R., N. Pellegrini, A. Proteggente, A. Pannala, M. Yang and C. Rice-Evans (1998) Antioxidant activity applying an improved ABTS radical cation decolorization assay, Free Radical Biol. Med. 26, 1231-1237.

18. Arts, M.J.T.J., G.R.M.M. Haenen, H.-P. Voss and A. Bast (2004) Antioxidant capacity of reaction products limits the applicability of the trolox equivalent antioxidant capacity (TEAC) assay, Food Chem. Toxicol. 42, 45-49.

19. Van den Berg, R., G.R.M.M. Haenen, H. van den Berg, W. van der Vijgh and A. Bast (2000) The predictive value of the antioxidant capacity of structurally related flavonoids using the trolox equivalent antioxidant capacity (TEAC) assay, Food Chem. 70, 391-395.

20. Arts, M.J.T.J., G.R.M.M. Haenen, H.-P. Voss and A. Bast (2001) Masking of antioxidant capacity by the interaction of flavonoids with protein, Food Chem. Toxicol. 39, 787-791.

21. De Vries, K. (1990) Determination of free fatty acids in wort and beer, J. Am. Soc. Brew. Chem. 48, 13-17.

22. Chen, E.-H. (1980) Utilization of wort fatty acids by yeast during fermentation, J. Am. Soc. Brew. Chem. 38, 148-153. 


\section{Chapter 10}

Summary and perspective 



\section{Summary and Perspective}

The aim of the thesis is to examine several factors that describe and determine the efficacy of antioxidants. In chapter 3-5, the contribution of reaction products is determined, in chapter 6-7 the influence of the matrix is studied and in chapter 8 the dependency on the type of radical is examined. In chapter 9 the oxidative processes during mashing in the brewing process are discussed.

In chapter 3 the Trolox Equivalent Antioxidant Capacity (TEAC) assay, a frequently applied assay for assessing antioxidants, has critically been evaluated on its applicability to characterize the antioxidant capacity of antioxidants. In this assay the antioxidant reacts with a relatively stable radical, the $A B T S^{*}$. In this reaction the blue/green $A B T S^{\bullet}$ is converted into the colorless $A B T S$ and the antioxidant is oxidized. The amount of ABTS ${ }^{\circ}$ scavenged by a certain amount of antioxidant gives the TEAC.

The applicability of the TEAC assay was tested by comparing the results of the assay to those of other in vitro screening assays. Catechol, resorcinol and hydroquinone, compounds that are structurally closely related, were used for this comparison. Resorcinol had the lowest activity in the inhibition of lipid peroxidation as well as in the scavenging of superoxide radicals or peroxynitrite. On the contrary, resorcinol had the highest TEAC. A comparable discrepancy between the screening assays is found with flavonoids, compounds with a relatively complex chemical structure. A relatively high TEAC might be explained by the formation of products from the antioxidant during the TEAC assay. Some of these products might be able to react with the ABTS $S^{*}$. This is illustrated by the antioxidant activity of the product of resorcinol which has a substantial antioxidant capacity. The TEAC of resorcinol is in fact the TEAC of resorcinol plus the TEAC of the reaction product(s) of resorcinol. The TEAC reported in literature is therefore an overestimate of the actual TEAC of resorcinol itself. The reaction products of several other antioxidants (such as catechol and hydroquinone) do not react with the $\mathrm{ABTS}^{\circ}$ and therefore do not contribute to the TEAC of these compounds.

The fact that the TEAC doesn't necessarily reflect the antioxidant capacity of only one structure is also demonstrated in chapter 4 . In this chapter the behaviour of the antioxidants trolox and chrysin in the TEAC was studied in detail, including the formation and contribution of reaction products formed during the TEAC. HPLC analysis of the reaction mixture 
obtained after scavenging of ABTS ${ }^{\bullet}$ by the flavonoid chrysin, showed the formation of a reaction product that was also able to react with ABTS ${ }^{\circ}$. The product appeared to react relatively fast, also having a higher TEAC than the parent compound, chrysin. In contrast, the reaction product of trolox, i.e. the trolox quinone, didn't react at all with ABTS'.

The experiments described in chapter 3 and 4 show that the TEAC is the antioxidant capacity of the parent compound plus the potential antioxidant capacity of the reaction product. The possible contribution of more than one compound to the TEAC hampers the applicability of this assay for ranking antioxidants and for the construction of SARs. The fundament of a SAR is that the activity has to be attributed to a single and well defined molecular structure. Nevertheless, TEAC-based SARs have frequently been constructed. Examination of these (Q)SARs in detail, as has been done in chapter 3, reveals, as expected, various inconsistencies.

Under the conditions used in the assay, the reaction of most antioxidants (or their products) with $\mathrm{ABTS}^{\bullet}$ doesn't reach completion within the time span of the assay. This leads to an underestimation of the TEAC of these compounds. Moreover, the time span and conditions that have been used, are variable. These flaws partly explain the inaccurate and imprecise TEAC values reported in literature.

In chapter $\mathbf{5}$ a modified TEAC is proposed. Incubations with different concentrations of $A B T S^{\circ}$ and a fixed concentration of antioxidant were performed. The decrease in ABTS after 6 minutes was plotted against the initial concentration of $\mathrm{ABTS}^{\circ}$ and fitted by an exponential function. Extrapolation of the fit to an infinite excess of $A B T S^{\bullet}$ resulted in the maximal concentration of $\mathrm{ABTS}^{\circ}$ that can be scavenged by the antioxidant at the concentration employed. This can be used to determine the actual TEAC of antioxidants, i.e. the total antioxidant capacity, representing the sum of the antioxidant capacity of the parent compound and that of the oxidation product(s) of the parent compound.

The impact of the matrix on the antioxidant effect is examined in chapters 6 and 7 . In chapter 6 the interaction between different ingredients in complex mixtures was studied by adding antioxidants to blood plasma and assessing the antioxidant capacity of the mixture. The results show that the antioxidant capacity of several flavonoids and bloodplasma is not additive, but that it is less than the sum of the antioxidant capacity of flavonoid and plasma separately. In chapter 7 , it was shown that the antioxidant capacity of several components of green and black tea with $\alpha-, \beta$-, and $\mathrm{k}$-casein also showed lower total 
antioxidant capacity than expected. This masking of antioxidant capacity appeared to depend both on the protein and the flavonoid used and was partly due to interactions between the antioxidant and proteins. However, the antioxidant capacity of some hydrophobic compounds, e.g. $\alpha$ tocopherol, is not affected by the interaction.

As depicted in chapter 8, it was observed that in a glucose-rich environment, such as in poorly regulated Diabetes Mellitus (DM), hydroxyl radicals immediately are converted into reactive glucose-derived species (RGS). The protection against these RGS appeared to differ markedly from the protection against hydroxyl radicals. Some "antioxidants" that efficiently protected against hydroxyl radicals, even enhanced the RGS production, indicating that these antioxidants may be contra-indicated in the protection against oxidative stress in DM. The results demonstrate that the efficacy of an antioxidant strongly depends on the type of radical.

In chapter 9, $\mathrm{F}_{1}$-phytoprostanes $\left(\mathrm{PPF}_{1} \mathrm{~s}\right)$, changes in antioxidant capacity and mono-hydroxy-fatty acids, markers for the detection of oxidative damage to fatty acids during the mashing in the brewing process were studied. Based on the formation of specific markers, it was found that enzymatic oxidation is the main route of oxidation during mashing. Nevertheless, substantial non-enzymatic oxidation of PUFAs also takes place. It was observed that mashing preferably should be done under low oxygen tension to minimize oxidative damage and preserve antioxidants.

\section{Perspective}

Besides the relatively well known aspects that influence an effective antioxidant protection, such as the reactivity of the antioxidant with the oxidative species and the amount of antioxidant added, other aspects that are important for antioxidant activity are:

Reaction products. As shown in chapter 3-5, reaction products may display antioxidative activities, enhancing the antioxidant capacity and the protection offered by the parent compound itself. However, reaction products sometimes have prooxidant effects or appear to be toxic, as described in chapter 2.

The matrix. Masking, caused by the environment of the antioxidant(s), might result in less total antioxidant capacity than is expected based on 
the sum of the separate capacities (chapter 6-7). This reduces the protection against free radicals.

Another potential problem is the lipophilicity of antioxidants. The local concentration of antioxidants in e.g. lipid membranes largely depends on the lipophilicity of the compound. In lipid peroxidation, not only lipophilicity but also the amphiphilic character of compounds seems to play a role. The concentration of an antioxidant at the precise site of action in twophase systems usually is not well evaluated or understood. This hampers a straightforward comparison of compounds, since activity is directly related to the concentration at the site of action. It is often incorrectly assumed that the concentration in the aqueous solution is identical to the concentration at the site of action (chapter 2).

The type of radical. Some efficient scavengers of hydroxyl radicals, show no or low protection against reactive glucose-derived species (chapter 8), indicating that different types of radicals require different types of antioxidants. Depending on the type of radicals formed, site specific scavenging can take place (chapter 2).

Future studies on antioxidants should also address the formation and properties of the antioxidant reaction products, compartmentalization, the influence of the matrix and other types of reactive species. A better understanding of these aspects will lead to a more accurate characterization of antioxidant activity and a more complete understanding of the activity of antioxidants. In this way the health effects and the actual mode of action of different antioxidants can be elucidated. Ultimately, this offers the opportunity to rationalize and optimize antioxidant intervention. 
Samenvatting 



\section{Samenvatting}

Antioxidanten spelen een belangrijke rol in tal van biochemische processen, variërend van het ontstaan van ziekten tot het verouderen van voedingsmiddelen. Om deze rol accuraat te kunnen evalueren, dient de activiteit van de antioxidant op de juiste manier gekarakteriseerd te worden. In dit proefschrift wordt onderzoek naar enkele factoren die de effectiviteit van antioxidanten bepalen, beschreven.

In de hoofdstukken 3-5 wordt de bijdrage van de reactieproducten behandeld, in de hoofdstukken 6 en 7 wordt de invloed van de matrix op de antioxidant capaciteit beschreven en in hoofdstuk 8 wordt nagegaan of effectiviteit van antioxidanten ook afhankelijk is van het type radiaal.

In hoofdstuk 3 is het Trolox Equivalent Antioxidant Capacity (TEAC) assay, een veelvuldig toegepaste methode om de capaciteit van antioxidanten te bepalen, kritisch bekeken. De focus ligt op de toepasbaarheid van het assay in het karakteriseren van de antioxidant effectiviteit. In dit assay reageert een antioxidant met een relatief stabiel radicaal, het $A B T S^{\circ}$. Gedurende deze reactie wordt het groen/blauwe $\mathrm{ABTS}^{\circ}$ in het kleurloze ABTS omgezet door de antioxidant, welke zelf hierbij geoxideerd wordt. De hoeveelheid ABTS ${ }^{\bullet}$ die door een bepaalde hoeveelheid antioxidant wordt weggevangen, geeft de TEAC.

De bruikbaarheid van het TEAC assay wordt getest door de resultaten van dit assay te vergelijken met die van andere in vitro screeningsassays. Hiervoor worden de verbindingen catechol, resorcinol en hydroquinon, die qua structuur op elkaar lijken, gebruikt. Resorcinol heeft van de geteste verbindingen de laagste activiteit in zowel het inhiberen van lipide peroxidatie als in het wegvangen van superoxide radicalen en peroxinitriet. Daarentegen blijkt resorcinol de hoogste TEAC te hebben. Een vergelijkbare discrepantie tussen de resultaten van deze assays met het TEAC assay wordt ook gezien bij qua structuur meer complexe antioxidanten, zoals bij de flavonoïden. Een relatief hoge TEAC zou verklaard kunnen worden door het vermogen van producten, gevormd tijdens het TEAC assay uit deze antioxidanten, om ook ABTS ${ }^{\circ}$ weg te vangen. Een voorbeeld hiervan is het reactieproduct van resorcinol dat ook een antioxidant capaciteit bezit. De TEAC van resorcinol is dus in feite de TEAC van resorcinol plus de TEAC van resorcinol's reactieproduct(en). De gerapporteerde TEAC van resorcinol is derhalve een overschatting van de eigenlijke TEAC van resorcinol zelf. De reactieproducten van andere antioxidanten (zoals catechol en 
hydroquinon) reageren niet met het $\mathrm{ABTS}^{\bullet}$ en dragen derhalve niet bij aan de gevonden TEAC.

Dat de TEAC niet altijd toe te schrijven is aan de antioxidant capaciteit van één enkele structuur, wordt ook aangetoond in hoofdstuk 4. In dit hoofdstuk wordt de vorming en bijdrage van reactieproducten van de antioxidanten trolox en chrysine in het TEAC assay gekwantificeerd. HPLC analyse laat bij chrysine de vorming van een reactieproduct zien dat in staat is om met ABTS ${ }^{\bullet}$ te reageren. Uit nadere analyse blijkt dat het product relatief snel reageert en dat het een hogere TEAC heeft dan de moederverbinding chrysine. Daarentegen reageert het reactieproduct van trolox, het trolox quinon, niet met het ABTS'.

De experimenten beschreven in hoofdstuk 3 en 4 tonen aan dat de TEAC de antioxidant capaciteit van de moederverbinding plus de mogelijke antioxidant capaciteit van de reactieproducten vertegenwoordigt. De mogelijke bijdrage van meer dan één verbinding aan de TEAC belemmert de toepassing van dit assay voor het vergelijken van antioxidanten en voor het maken van structuur activiteits relaties (SARs). Het fundament van een SAR is dat de activiteit gekoppeld kan worden aan één enkele en goed gedefinieerde moleculaire structuur. Niettemin zijn talloze op TEAC gebaseerde SARs opgesteld. Nauwgezette analyse van deze SARs, zoals heeft plaatsgevonden in hoofdstuk 3, laat inderdaad diverse tegenstrijdigheden zien tussen de in deze SAR voorspelde waarde en de daadwerkelijke gevonden activiteit van antioxidanten.

Naast de bijdrage van reactieproducten is een andere belangrijke tekortkoming van het TEAC assay de tijdsduur waarbinnen de antioxidant met het ABTS ${ }^{\bullet}$ kan reageren. Deze is relatief kort waardoor de reactie tussen antioxidanten en ABTS ${ }^{*}$ niet volledig is voltooid binnen de tijdsduur van de meting. Dit leidt tot een onderschatting van de TEAC van deze verbindingen. Bovendien zijn de condities waaronder de TEAC bepaling in diverse protocollen plaats vindt variabel. Deze zwakke plekken verklaren grotendeels de verschillen in TEAC waarden, die in de literatuur gerapporteerd worden.

In hoofdstuk $\mathbf{5}$ wordt een wijziging in het TEAC assay voorgesteld. In de nieuwe procedure dienen incubaties met verschillende concentraties $\mathrm{ABTS}^{\circ}$ en een vaste concentratie antioxidant te worden uitgevoerd. De afname in ABTS na 6 minuten wordt vervolgens uitgezet tegen de begin concentratie van $\mathrm{ABTS}^{\circ}$ en gefit met behulp van een exponentiële functie. Extrapolatie van de fit naar een oneindige overmaat aan $\mathrm{ABTS}^{*}$ resulteert 
in de maximale concentratie $\mathrm{ABTS}^{\bullet}$ die weggevangen kan worden door de antioxidant in de gebruikte concentratie. Deze strategie kan gebruikt worden voor het bepalen van de werkelijke TEAC van antioxidanten, namelijk de totale antioxidant capaciteit. Dit is de som van de antioxidant capaciteit van de moederverbinding en de hieruit gevormde product(en).

De invloed van de matrix op het antioxidant effect wordt onderzocht in de experimenten beschreven in hoofdstukken 6 en 7 . In hoofdstuk 6 werden antioxidanten aan bloed plasma toegevoegd. De toename in TEAC van het bloed werd vergeleken met de TEAC van de antioxidant.

De resultaten leerden dat de TEAC van verscheidene flavonoïden en bloedplasma niet additief is, maar minder is dat de som van de afzonderlijke TEAC waarden (van het flavonoïd en het plasma). Hoofdstuk 7 liet zien dat de TEAC van diverse componenten van groene en zwarte thee met $\alpha-, \beta$-, en $\mathrm{k}$-caseïne lager was dan op basis van de afzonderlijke componenten verwacht zou worden. Deze maskering van antioxidant capaciteit bleek zowel afhankelijk van het gebruikte eiwit als van het flavonoïd en was deels te wijten aan interacties tussen de antioxidant en plasma eiwitten. De antioxidant capaciteit van sommige hydrofobe verbindingen, zoals bijvoorbeeld $\alpha$-tocoferol bleek echter niet beïnvloed te worden door de interactie.

Met behulp van de experimenten weergegeven in hoofdstuk 8 werd aangetoond dat in een glucoserijke omgeving, zoals het geval is in slecht gereguleerde Diabetes Mellitus (DM), hydroxyl radicalen snel worden omgezet in reactieve, van glucose-afgeleide, deeltjes (RGS). De bescherming tegen deze RGS blijkt duidelijk te verschillen van de bescherming tegen hydroxyl radicalen. Sommige "antioxidanten" die efficiënt beschermen tegen hydroxyl radicalen, vergroten de RGS productie zelfs, wat aangeeft dat deze antioxidanten gecontraïndiceerd zijn in de bescherming tegen oxidatieve stress in DM. De resultaten laten zien dat het effect van een antioxidant zeer sterk afhangt van het type radicaal.

In hoofdstuk 9 werden markers zoals $\mathrm{F}_{1}$-fytoprostanen ( $\left.\mathrm{PPF}_{1} \mathrm{~s}\right)$, monohydroxy-vetzuren en veranderingen in antioxidant capaciteit tijdens het maischen bestudeerd voor het detecteren van oxidatieve schade aan vetzuren gedurende het brouwproces van bier. $\mathrm{PPF}_{1} \mathrm{~s}$ blijken toepasbaar te zijn om de mate van oxidatieve schade in het maische mengsel te monitoren. Ze zouden kunnen worden gebruikt als kwaliteits marker van het maische mengsel. Gevonden werd dat bij maischen verlagen van de 
zuurstofspanning de oxidatieve schade vermindert en antioxidant capaciteit verhoogt. Dit betekent dat maischen bij voorkeur onder lage zuurstofspanning uitgevoerd dient te worden.

\section{Perspectief}

Een aantal factoren bepalen de activiteit van antioxidanten. Factoren die algemeen onderkend worden zijn de reactiesnelheid van de antioxidant met reactieve deeltjes en de toegevoegde hoeveelheid. Factoren waar geen of te weinig aandacht naar uitgaat zijn:

Reactieproducten. Zoals aangetoond in hoofdstuk 3-5 kunnen reactieproducten ook antioxidant activiteit vertonen. Deze producten kunnen in grote mate bijdragen aan de totale antioxidant capaciteit en de bescherming. Daarentegen kunnen reactieproducten ook prooxidante of toxische effecten hebben, zoals beschreven in hoofdstuk 2.

De matrix. Maskering, veroorzaakt door de interactie van antioxidanten met andere bestanddelen van de matrix, kan resulteren in een lagere totale antioxidant capaciteit (hoofdstuk 6-7). Dit vermindert de effectiviteit van de antioxidanten. Een ander aspect is de lipofiliteit van antioxidanten. De lokale concentratie van antioxidanten in bijv. lipide membranen hangt primair af van de lipofiliteit van de verbinding. In lipide peroxidatie lijkt niet alleen de lipofiliteit maar ook het amfifiele karakter van de verbindingen een rol te spelen. De concentratie van een antioxidant precies op de plaats waar de antioxidant haar werking uitvoert in twee-fase systemen wordt over het algemeen slecht onderkend en begrepen. Dit bemoeilijkt een juiste vergelijking van verbindingen, omdat de activiteit direct gerelateerd is aan de concentratie op de plaats van werking (hoofdstuk 2).

Het type radicaal. Sommige efficiënte scavengers van hydroxyl radicalen laten slechts geringe protectie zien tegen reactieve, van glucoseafgeleide, deeltjes (RGS) (hoofdstuk 8). Dit geeft aan dat verschillende typen radicalen andere eisen stellen aan een antioxidant.

In toekomstig antioxidant-onderzoek zou meer aandacht geschonken moeten worden aan producten die uit de antioxidant worden gevormd, compartimentalisatie, de invloed van de matrix en aan het specifieke karakter van reactieve deeltjes waartegen beschermd moet worden. 
Meer kennis omtrent deze aspecten zal tot een meer accurate karakterisering van de activiteit van antioxidanten leiden. Dit draagt er tevens toe bij dat het werkingsmechanisme van antioxidanten opgehelderd wordt. Dit vormt het fundament om tot een wetenschappelijk onderbouwde toepassing van antioxidanten te komen. 

Dankwoord 

Bij de totstandkoming van dit proefschrift hebben velen een belangrijke rol gespeeld en het is mede dankzij hen dat dit boekje zijn huidige vorm heeft gekregen. Een woord van dank is dan ook zeker op z'n plaats.

Allereerst dank aan het promotieteam, bestaande uit promotor Prof. dr. A. Bast en copromotores Dr. G.R.M.M. Haenen en Dr. H.-P. Voss.

Beste Aalt, bedankt dat je me de mogelijkheid hebt geboden om dit promotie-onderzoek uit te voeren. Ik denk met veel plezier en waardering terug aan onze (nu en dan hoog oplopende) gesprekken en de werkbesprekingen met jou en Guido. Deze waren doorgaans zeer verhelderend, gaven regelmatig aanleiding tot de nodige (niet altijd even relevante) discussies en waren altijd alles behalve saai! Je humor en enthousiasme zijn voor mij absoluut een bron van energie en motivatie geweest. Dank voor je kundige begeleiding, waar ik "iets" langer gebruik van heb mogen maken dan vooraf in de planning lag. In je rol als voorzitter van de examencommissie moet het je echter toch deugd doen dat je geneeskundestudenten hun studievoortgang zo goed bewaken...

Beste Guido, elke uitspraak zou te kort doen aan jouw bijdrage tijdens mijn AIO-periode. Je bent door je deskundigheid, creativiteit, toewijding en enorme betrokkenheid voor mij een grote hulp geweest. Ondanks je chronisch overvolle agenda was je altijd bereid tijd vrij te maken om me verder te helpen, me een peptalk te geven of om mijn schrijfsels te voorzien van je (vaak onleesbaar) kritisch commentaar. Je hebt tijdens mijn promotie-onderzoek een meer dan onmisbare rol vervuld, waarvoor ik je hartelijk wil bedanken.

Beste Hans-Peter, als copromotor "op afstand" zagen we elkaar niet heel frequent. De momenten dat we afspraken waren daarentegen uitermate productief en altijd gezellig. Dank voor de plezierige samenwerking.

Vervolgens wil ik graag mijn collega's van Humane Toxicologie bedanken voor de goede werksfeer en de gezelligheid zowel tijdens als buiten werktijd.

Chris, door mijn eindstage met jou als stagebegeleider ben ik bij Humane Toxicologie terechtgekomen. Dit resulteerde vervolgens in de mogelijkheid tot het uitvoeren van dit promotie-onderzoek. Hoewel je al lang niet meer bij Humane Toxicologie werkzaam bent, hebben we altijd leuk contact gehouden. Ik wil je graag bedanken voor de samenwerking, en voor de belangstelling die je altijd toont in hetgeen me bezig houdt. Gertjan, tegelijkertijd zijn we vanuit Amsterdam naar Maastricht gekomen en we hadden meteen een klik. Ik heb je ervaren als een zeer flexibele, sociale en kundige collega, die altijd bereid was om even mee te denken. 
Ook buiten de werksfeer bewaar ik vele goede herinneringen met het congres in Rome als hoogtepunt. Tevens wil ik jou en Suzanne hartelijk danken voor jullie gastvrijheid die ik de afgelopen jaren met enige regelmaat heb mogen ervaren. Rachelle, als kamergenootjes hebben we samen heel wat "AlO-lief en leed" gedeeld. Dank voor deze mooie tijd (en voor het feit dat je mijn begrip van de Limburgse taal naar een wat hoger niveau hebt weten te tillen; ik heb er tijdens mijn huidige co-schap in Limburg nog dagelijks profijt van..)! Agnes, oud-kamergenootje, spontane, vrolijke noot en meer dan grote hulp in de laatste fase van mijn AlO-periode. Helaas kun je, door je huidige onderzoek aan de Universiteit van Vermont, de verdediging niet bijwonen en ga je ook het feest missen... (deze schade halen we tzt ruimschoots in, deal?). Dank voor je betrokkendheid, hulp en gezelligheid in de afgelopen jaren en voor de kritische blik op mijn laatste artikelen. Tot Skype! Marc, Leo en Marie-José, bedankt voor jullie hulp en ondersteuning zowel binnen als buiten het lab. Els, als kersverse doctor loop je een dikke maand op me voor. Ik heb genoten van onze wederzijdse peptalks in de afsluitende fase van onze AlO-periode en je betrokkenheid als zeer plezierig en motiverend ervaren. Dank hiervoor en succes met alle voorbereidingen voor je volgende mijlpaal! Roger, hartelijk dank voor je creatieve bijdrage aan dit boekje, je optimisme en voor de prettige en positieve sfeer die je altijd weer weet te creëren. Verder wil ik Chantal, Bashir, Gudrun, Evi, Liesbeth, Saskia, Shufan en Eric danken voor de plezierige samenwerking en wil ik laatstgenoemden daarnaast nog veel succes wensen met het voltooien van hun eigen promotie-avontuur.

Leden van de beoordelingscommissie, Prof. dr. R.P. Mensink, Dr. J. Dallinga, Prof. dr. M.P. van Dieijen-Visser, Dr. C.G. Schalkwijk, Prof. dr. W.J.F. van der Vijgh, hartelijk dank voor de beoordeling van het manuscript.

De stagiaires Bas, Stan, Lonneke en Sasja, wil ik bedanken voor de plezierige en leerzame samenwerking en voor alle experimenten die ze uitgevoerd hebben. Een aantal ervan heeft geresulteerd in een paar mooie artikelen. Dank voor jullie inzet!

Verder wil ik de collega's van Farmacologie \& Toxicologie bedanken voor het aangename contact dat ik de afgelopen jaren mocht ervaren. Een speciaal woord van dank gaat daarbij uit naar Els, Mariëlle en Mia voor alle administratieve hulp en voor het feit dat hun deur altijd open stond. 
De collega's van GRAT bedankt ik ook voor het leuke contact en voor de assistentie en adviezen die ik mocht ontvangen bij mijn experimenten op de GC (Edwin) en de ESR (Jacco).

Suus, gelukkig recent weer contact hersteld na elkaar wat uit het oog te zijn verloren. Dank voor je aanbod om enkele hoofdstukken uit dit boekje nog eens kritisch te bekijken. Dat heeft me zeker een stukje meer rust gegeven.

Vervolgens een woord van dank voor Johan Lasaroms (RIKILT) voor zijn verwoede pogingen om met behulp van de LC-MS het reactieproduct, beschreven in hoofdstuk 4, in kaart te brengen. Helaas gooide de instabiliteit van het product roet in het eten. Ruud en Ariëtte wil ik danken voor de zeer aangename samenwerking en het leuke contact in de afgelopen jaren. Ruud, geniet van alle mooie wandelingen waar je door je pensioen nu ongetwijfeld meer tijd voor zult hebben!

Furthermore, I would like to thank Prof. dr. Martin Müller and Christoph Grun of the "Julius-von-Sachs-Institut of Biosciences" in Würzburg for their hospitality and co-operation. Christoph, thank's a lot for all your work on the phytoprostanes and mono-hydroxy-fatty acids in mash, for your patience and, of course, for teaching me "the rule"....

Zonder sociale contacten en sport zouden de afgelopen jaren ongetwijfeld minder plezierig en meer stressvol zijn geweest. Daarom een woord van dank aan m'n vrienden en teamgenoten voor de gezelligheid, interesse en welkome afleiding.

Familie Arts, familie Bardoel en familie Sleegers, dank voor de interesse en het begrip als ik weer eens ergens schitterde door afwezigheid. Om dit boekje ging het nou allemaal! Bart, nog een paar jaar en dan is de beurt aan jou!

Sabine, wat een tiental jaar geleden begon als een bezoekje aan het Vrolikmuseum met een anonieme collega-studente is in de loop van de jaren uitgegroeid tot een mooie en hechte vriendschap. Ik ben er trots op dat je m'n paranimf wilt zijn. De wetenschap dat jij en Arno zo'n moeilijke periode doormaken, doet me veel. Weet dat ik aan jullie denk!

Dank aan mijn broers Han en Sjef. Ook al wonen we niet meer bij elkaar in de buurt, toch zien we elkaar gelukkig regelmatig en geniet ik van jullie beider humor en verhalen. De wetenschap dat we altijd bij elkaar kunnen 
aankloppen is prettig en rustgevend. Han, je oprechtheid en belangstelling waardeer ik enorm en ik bewonder de manier waarop je in het leven staat. Sjef, de wijze waarop je je zaken aanpakt en met mensen weet om te gaan, vind ik grote klasse. Jouw interesse, steun en betrokkenheid doen me altijd uitermate goed. Het is daarom een geruststellend gevoel dat je naast me staat tijdens m'n verdediging. Heren, met jullie heb ik het echt getroffen!

Lieve pa en ma, bedankt voor alle mogelijkheden die jullie me hebben geboden, de vanzelfsprekendheid waarmee jullie telkens weer voor me klaarstaan en voor de belangstelling en steun bij alles wat ik doe. Ook in perioden waarin mijn prioriteiten duidelijk anders lagen dan jullie ze graag hadden gezien, kon ik altijd terugvallen op het thuisfront. Bedankt dat jullie er altijd onvoorwaardelijk voor me zijn. Dit boekje is voor jullie!

En tot slot Gerard, mijn rustpunt en rots in de branding. De combinatie van onderzoek en studie hebben ook impact gehad op jou. Ik besef me ten volle dat ik op bepaalde momenten niet de makkelijkste en gezelligste persoon ben geweest om mee samen te leven. De aandacht ging, ook in vakanties, weekenden en avonduren, vaak uit naar proefschrift en studieboeken. Toch heb je me altijd gesteund in m'n keuzes, hielp me met je nuchtere kijk de dingen weer op een rijtje te zetten en sprak me moed en vertrouwen in als ik het weer eens even niet zag zitten. Nu het boekje af is, is er gelukkig meer tijd voor ons samen. Bedankt voor je geduld, begrip en steun. Zonder jou was dit allemaal niet gelukt. Dikke kus! 
Curriculum Vitae 



\section{Curriculum Vitae}

Mariken Jeanette Truike Jacobine Arts werd geboren op 18 juli 1973 te Deurne. In 1993 behaalde ze het VWO diploma aan het Elckerlyc College te Helmond. Een jaar later startte ze met de opleiding Medische Biologie aan de Universiteit van Amsterdam. Haar afstudeerstage vond plaats aan de Universiteit Maastricht binnen de capaciteitsgroep Farmacologie en Toxicologie, sectie Humane Toxicologie, onder leiding van Dr. Ir. C.T.A. Evelo. Direct na het behalen van haar doctoraaldiploma (2000) begon ze bij dezelfde capaciteitsgroep op 1 maart als assistent in opleiding. Het onderzoek werd uitgevoerd onder begeleiding van Dr. G.R.M.M. Haenen en Prof. dr. A. Bast en staat beschreven in dit proefschrift.

Tijdens deze periode werd tevens het certificaat "Stralingshygiëne, deskundigheidsniveau $5 \mathrm{~b}$ " behaald en volgde ze verscheidene modules van de Postdoctorale Opleiding Toxicologie. In 2007 hoopt ze zich als toxicoloog te kunnen registreren.

Vanaf september 2005 is Mariken, in het kader van de geneeskundeopleiding waarmee ze in 2002 startte, werkzaam als co-assistent in het Catharina Ziekenhuis te Eindhoven. Het doctoraaldiploma werd in 2006 behaald. In januari 2008 verwacht ze haar geneeskundeopleiding aan de Universiteit Maastricht te voltooien. 

List of Publications 



\section{Full papers}

M.J.T.J. Arts, G.R.M.M. Haenen, H.-P. Voss, A. Bast. Masking of antioxidant capacity by the interaction of flavonoids with protein. Food and Chemical Toxicology 39: 787-791, 2001.

M.J.T.J. Arts, G.R.M.M. Haenen, L.C. Wilms, S.A.J.N. Beetstra, C.G.M. Heijnen, H.-P. Voss, A. Bast. Interactions between flavonoids and proteins: Effect on the total antioxidant capacity. Journal of Agricultural and Food Chemistry 50: 1184-1187, 2002.

M.J.T.J. Arts, J.S. Dallinga, H.-P. Voss, G.R.M.M. Haenen, A. Bast. A critical appraisal of the use of the antioxidant capacity (TEAC) assay in defining optimal antioxidant structures. Food Chemistry 80: 409-414, 2003.

M.J.T.J. Arts, G.R.M.M. Haenen, H.-P. Voss, A. Bast. Antioxidant capacity of reaction products limits the applicability of the Trolox Equivalent Antioxidant Capacity (TEAC) assay. Food and Chemical Toxicology 42: 45-49, 2004.

M.J.T.J. Arts, J.S. Dallinga, H.-P. Voss, G.R.M.M. Haenen, A. Bast. A new approach to assess the total antioxidant capacity using the TEAC assay. Food Chemistry 88: 567-570, 2004.

G.R.M.M. Haenen, M.J.T.J. Arts, A. Bast, M.D. Coleman. Structure and activity in assessing antioxidant activity in vitro and in vivo. A critical appraisal illustrated with the flavonoids. Environmental Toxicology and Pharmacology 21: 191-198, 2006.

M.J.T.J. Arts, M.D. Coleman, A. Bast, G.R.M.M. Haenen. The involvement of reactive glucose-derived species (RGS) in diabetes. Implication for antioxidant treatment. Submitted for publication.

M.J.T.J. Arts, C. Grun, R.L. de Jong, H.-P. Voss, A. Bast, M. Mueller, G.R.M.M. Haenen. Oxidative degradation of lipids during mashing. Submitted for publication. 


\section{Abstracts}

M.J.T.J. Arts, G.R.M.M. Haenen, A. Bast. The influence of the matrix on the total antioxidant capacity. In: Proceedings of the scientific meeting of the Netherlands Society of Toxicology. Kerkrade, 2000.

M.J.T.J. Arts, G.R.M.M. Haenen, A. Bast. Trolox Equivalent Antioxidant Capacity (TEAC) assay, a useful assay for the construction of structure activity relationships (SARs)? In: Proceedings of the scientific meeting of the Netherlands Society of Toxicology, Nijmegen, 2001.

M.J.T.J. Arts, G.R.M.M. Haenen, H.-P. Voss, A. Bast. The influence of the matrix on the total antioxidant capacity. In abstract book of: The meeting of the Society for Free Radical Research Europe. Rome, 2001.

M.J.T.J. Arts, G.R.M.M. Haenen, A. Bast. Interactions between flavonoids and proteins. Seminar of the European Graduate School. Maastricht, 2002.

M.J.T.J. Arts, G.R.M.M. Haenen, A. Bast. The TEAC-assay cannot be used for the construction of structure activity relationships (SARs). In: Proceedings of the scientific meeting of the Netherlands Society of Toxicology. De Bilt, 2003. 